\title{
Investment-Timing and the Threat of Disruption
}

\author{
By \\ RYAN JOHN CAMPBELL
}

A thesis

submitted to Victoria University of Wellington in fulfilment of the requirements for the degree of Master of Commerce in Finance

Victoria University of Wellington 2019 



\begin{abstract}
An incumbent firm needs to determine how to best manage the risk of the arrival of a disruptive technology. The numerous actions available to the incumbent firm indicates a complex real-options model of investment is required. This thesis investigates the behaviour of an incumbent firm, with assets-in-place, when they have access to an investment opportunity. The incumbent must not only choose when to invest in the opportunity, but also the optimal structure with which to compete against a new entrant who also has this investment opportunity.

In order to delay competition in the market the incumbent can elect to permanently abandon the innovative option rather than seek to compete with the new entrant. The assets-in-place contributes significant value to the incumbent and by delaying the competition effect, the incumbent can reduce the cannibalization of assets-in-place. This is despite the fact that the incumbent can attempt to profitably invest in the innovation before the entrant. Clearly the assets-in-place provide a benefit to firm value for the incumbent, but act as a burden for the growth option's development. Should consumer preferences begin to favour the innovation, then the decision to abandon the growth option loses its value. The incumbent in this instance does not care that they may accelerate the entrant's investment as they can still profitably preempt the entrant.

In a competitive market, when the incumbent efficiently produces the innovation at no extra cost compared to an independent firm, the incumbent will elect to internalise, rather than spin off, the growth option. When the incumbent produces the innovation at a higher cost, than other market participants, they will spin off the growth option instead of internalising. When consumers favour the innovation, the incumbent becomes indifferent between spinning off and internalising the growth option as the objective functions in both cases converge to maximising the value of the growth option.
\end{abstract}




\section{Acknowledgements}

I would first like to acknowledge my supervisor Prof. Graeme Guthrie. Without your help this thesis would not have been possible. I will always appreciate the fact you were readily available when I needed guidance, and have helped me not only for this thesis, but also during my Honours year as well.

I would also like to thank my family and friends who supported me throughout my time at university. To my parents especially, you motivated me to always try my best and I could not ask for better support. To my best friends Garima, Scott and Derik I can never thank you enough for the chats, drinks and being great all-round people.

To my colleagues at Garnham Law, thank you for the advice and encouragement you provided for both my studies and in the workplace. You have all taught me so much and I will always be grateful for that.

Finally, I would like to thank Victoria University of Wellington, in particular the School of Economics and Finance, for providing me with the skills and knowledge to excel in the real world. 


\section{Contents}

1 Introduction $\quad 1$

1.1 Threat of disruption in the market .................. 1

1.2 Responses to the threat of disruption . . . . . . . . . . . . . . 3

1.2.1 Internalise the growth option . . . . . . . . . . . 4

1.2.2 Spin off the growth option . . . . . . . . . . . . 5

1.2.3 Abandon the growth option . . . . . . . . . . . 6

1.3 Real options literature and disruption . . . . . . . . . . . . . . . . 7

1.4 Management literature and disruption . . . . . . . . . . . . . . . 10

1.5 Contributions to the existing literature . . . . . . . . . . . . 12

1.5.1 Extension of real options papers . . . . . . . . . . . . . . . . . 12

1.5.2 Firm structure, collusion and best response . . . . . . . . . . . . 13

1.5.3 Output Market . . . . . . . . . . . . . . . 15

$\begin{array}{lll}2 & \text { Model Framework } & 17\end{array}$

2.1 Model Overview and Assumptions . . . . . . . . . . . . . . . 17

2.2 Market Structure . . . . . . . . . . . . . . . . . . . . . . . 19

2.3 "Output Market" Equilibrium . . . . . . . . . . . . . . . . 20

2.3.1 Demand Function . . . . . . . . . . . . . . . . 20

2.3 .2 Output Price Determination . . . . . . . . . . . . . . . 22

2.4 The Underlying Valuation Equation . . . . . . . . . . . . . . . . . . 24

2.5 Backward Induction $\ldots \ldots \ldots \ldots \ldots$

2.5.1 After Investment . . . . . . . . . . . . . . . . . . . 25

2.5.1.1 After the Incumbent Invests . . . . . . . . . . . . . . 26

2.5.1.2 After the Entrant Invests _. . . . . . . . . . . . . . . 26 
2.5.1.3 After the Spin-Off Invests . . . . . . . . . . . . . . . 27

2.5.2 Before Any Investment . . . . . . . . . . . . . . . 27

2.5.2.1 Best Response with no Strategic Interaction . . . . . . . . . . 29

2.5.2.2 Incumbent's Best Response with Strategic Interaction . . . . . 30

2.5.2.3 Entrant's Best Response with Strategic Interaction . . . . . . . 31

2.5.2.4 Spin-Off's Best Response with Strategic Interaction . . . . . . . 31

2.6 Markov Perfect Equilibria . . . . . . . . . . . . . . . . 32

2.7 Expected Rate of Return . . . . . . . . . . . . . . . . . 33

3 Firm Behaviour with Disruption $\quad 34$

3.1 Investment Problem . . . . . . . . . . . . . . . . . . 35

3.1 .1 Preemption payoffs $\ldots \ldots \ldots \ldots$. . . . . . . . . . . . . . .

3.1.2 Market values . . . . . . . . . . . . . . . . . . . . . . . 40

3.1.3 Real options analysis compared to static models . . . . . . . . . . . . . 43

3.2 Decomposed Value Comparison _. . . . . . . . . . . . . . . . . . 45

3.2.1 Cannibalization of Assets-in-Place . . . . . . . . . . . . 45

3.2 .2 Incumbent Design . . . . . . . . . . . . . . . . . . . . . . . . . 48

3.3 Firm-level expected rate of return . . . . . . . . . . . . . . . . 52

4 Characteristics of Disruption $\quad 56$

4.1 Inefficiences of architectural innovation . . . . . . . . . . . . 56

4.2 Vulnerability of assets-in-place . . . . . . . . . . . . . . . 65

4.3 Importance of assets-in-place . . . . . . . . . . . . . . . . . 77

5 Concluding Remarks $\quad 90$

$\begin{array}{lr}\text { A Appendices } & 99\end{array}$

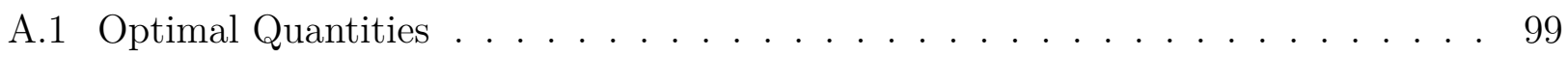

A.2 Own-Price Elasticity Parameter . . . . . . . . . . . . . . . 101

A.3 Homogeneity . . . . . . . . . . . . . . . . . . . . . 101

A.4 First Order Conditions Satisfied . . . . . . . . . . . . . . . . 102

A.4.1 Before Investment . . . . . . . . . . . . . . . . . . . . . . . 102

A.4.2 After Incumbent Invests . . . . . . . . . . . . . . . . 103 
A.5 Finite difference approximation 


\section{List of Figures}

2.1 Evolution of Industry . . . . . . . . . . . . . . . . . . . . . . . . 18

3.1 Preemption Payoffs and Thresholds . . . . . . . . . . . . . . . 36

3.2 Value of Market Participants for Different Business Structures . . . . . . . . . 39

3.3 Value in Delaying the Exercising of the Growth Option . . . . . . . . . . . . 42

3.4 Cannibalization of Assets-in-Place . . . . . . . . . . . . . . . . 46

3.5 Optimal Incumbent Design for Firm Value . . . . . . . . . . . . . . . . 49

3.6 Firm-level Expected Rate of Return . . . . . . . . . . . . . . . . . . . 53

4.1 Preemption Payoffs and Thresholds with Inefficient Production Costs . . . . . 57

4.2 Cannibalization Rates with Inefficient Production Costs . . . . . . . . . . . . 59

4.3 Optimal Incumbent Design with Inefficient Production Costs . . . . . . . . . . 61

4.4 Firm-level Expected Rate of Return with Inefficient Production Costs . . . . . . 63

4.5 Preemption Payoffs and Thresholds with Increased Sensitivity _. . . . . . . 65

4.6 Value of Market Participants with Increased Sensitivity . . . . . . . . . . . 67

4.7 Value in Delaying with Increased Sensitivity . . . . . . . . . . . 70

4.8 Cannibalization Rates with Increased Sensitivity . . . . . . . . . . . . 71

4.9 Optimal Incumbent Design with Increased Sensitivity . . . . . . . . . . . 72

4.10 Firm-level Expected Rate of Return with Increased Sensitivity . . . . . . . . 74

4.11 Preemption Payoffs and Thresholds with Lower Consumption Intensity . . . . 76

4.12 Value of Market Participants with Lower Consumption Intensity . . . . . . . 78

4.13 Value in Delaying with Lower Consumption Intensity . . . . . . . . . . . 81

4.14 Cannibalization Rates with Lower Consumption Intensity . . . . . . . . . . . 82

4.15 Optimal Incumbent Design with Lower Consumption Intensity . . . . . . . . 84

4.16 Firm-level Expected Rate of Return with Lower Consumption Intensity . . . . . 86 


\section{List of Tables}

3.1 Preemption Thresholds and the Profitability of Pure Disruption . . . . . . . . 37

4.1 Inefficient Costings: Preemption Thresholds and Profitability of Pure Disruption 58

4.2 Increased Sensitivity: Preemption Thresholds and Profitability of Pure Disruption 66

4.3 Lower Intensity: Preemption Thresholds and Profitability of Pure Disruption . . 77 



\section{Introduction}

\subsection{Threat of disruption in the market}

What is the purpose of a going concern? Why do we create entities that will inevitably face a natural death after succumbing to the effects of competition? Businesses rise and fall with the ruins of past incumbents setting the foundations of entrants that will take their place and eventually meet the same fate. Schumpeter (1942) reminds us that with capitalism comes a dynamic system where market environments continually change. He describes the fuel for this continuous change as new and innovative "injections" into the market that stimulate the business lifecycle to both create and destroy going concerns. The idea of this injection destroying old markets to create a new one is what Schumpeter describes as "creative destruction." There is no point in trying to sustain and nurture a dying business indefinitely; but that does not mean there is no reason to delay a firm's inevitable end. There may yet be hope for business owners to extract value before their businesses die and it only becomes a question of how to do this.

We define the incumbent as the firm with assets-in-place producing a product that exists in the market before any "creative destruction" occurs. We then "inject" an innovation into the market that we make available for either an entrant firm or the incumbent to develop. Consumers in the market will react differently to this product depending on whether they are "loyal" or "fickle" in nature. "Fickle" consumers have a higher elasticity of substitution compared to "loyal" consumers and so will act as the fuel for this "injection" into the market. ${ }^{1}$ We consider at what number of "fickle" consumers, if any, would it be optimal to exercise this

\footnotetext{
${ }^{1}$ We highlight the importance of the "fickle" consumers as they more readily transition between substitute goods than "loyal" consumers.
} 
growth option to build the disruptive asset. ${ }^{2}$ It is not only a matter of when, but also how the incumbent reacts to this innovation by structuring their business around this new growth option to maximise firm value. Similar to Lambrecht and Perraudin (2003), we begin with a monopolist case with no threat of preemptive investment by a competitor. The value of a monopolist comes from its position as being the only provider of goods as well as the protection it has from competitors to allow for long-term decision-making. We do not concern ourselves with the number of other firms, but instead their objective functions relative to their relationship with competitors. Rather than the source of uncertainty being other competitors and their cost functions, we focus on the uncertainty of consumers for their products. The entrant will solely focus on developing the growth option worth the present value of the innovation's cash flows.

There are leaders and followers in markets that trade assets; both real and financial. Intuitively it can be assumed that firms would prefer to be the leader in a market to either secure greater market share or lock out competitors. Profitable preemption will occur when the firm finds it more beneficial for them to receive a leader payoff rather than a follower payoff. This defines the preemption threshold for investment where, with complete information, firms seek to wait and then attempt to invest just before their opponent would make their move in the market. We follow a similar approach to Lambrecht and Perraudin (2003) where the first firm to successfully invest obtains the whole post-innovation market and the other firm has perpetually lost the rights to the innovation. This strengthens the preemption threat firms face in our competitive models in order to stimulate competition. We use preemption thresholds to explain investment-timing behaviour around the introduction of an innovation where firms must strategically interact with each other.

To be successful a firm must be dynamic and make decisions allowing them to adapt to the market conditions. These decisions can involve investing in new technologies or even colluding with competitors in order to stay alive. Regardless of the decision, to insure against market risk, the incumbent firm will have to cannibalize their existing assets-in-place when faced with the arrival of the innovation. For a firm to progress, in the face of new technology, they have to sacrifice some capital value in the same industry with which the new technology competes. Not all firms are comfortable with cannibalizing assets already in their possession, as found by

\footnotetext{
${ }^{2}$ We focus on the timing of innovation which Dasgupta et al. (1980) states is when the new technology becomes commercially practicable rather than when the new technology is used.
} 
Kamien and Schwartz (1982) who claim that the challenge of managing displacement threats has often been attributed to an unwillingness to cannibalize existing technology investments. While a firm might be unwilling, it cannot have future investment decisions be influenced by existing assets to the point that it no longer competes in the market to maintain or even grow its market position.

Firm death is a natural process, but knowing it exists and understanding how firms can extract maximum value in the dying stages are two different matters. We seek to identify the underlying factors behind the decisions that will ultimately see firms diminish and determine if there is an optimal strategy for firms to still create and receive value even on the brink of collapse. Firms can sometimes identify that they are nearing the end of their natural life. It may even be in a shareholders' best interests to allow the firm to die rather than continuing to invest in dying technology when they are still able to extract the optimal value from winding up existing assets (Gans, 2016, Chapter 5). Nembhard and Aktan (2010) consider the early termination of a research and development project due to anticipated failure should the research continue. This would be in the best interest of the owners as rather than depleting cash reserves and cannibalizing assets to sustain new potential technologies, the firm instead focuses on maximizing stakeholder value by securing existing assets over potentially profitable ventures. Firms may only consider investing should they exceed some trigger or threshold such as the present value of benefits exceeding costs as found in static discounted cash flow valuation approaches. Swinney et al. (2011) found that the threat of firm failure significantly impacted the dynamics of competition that involved start-ups. This brings us to the question of how disruption can impact the competition between an incumbent and new entrant. Either company could fail, but the incumbent has everything to lose while the entrant has everything to gain by entering and exercising the right to the disruptive innovation. This could explain why the incumbent is willing to commit to forgo the innovation to protect what they currently receive.

\subsection{Responses to the threat of disruption}

We must now consider how firms respond to the threat of disruption. The idea of "creative destruction" presents a market as being dynamic and ever-changing with firms adopting this mind-set surviving and others facing a natural death. Creative destruction can be likened to 
the study of fire ecology where some ecosystems have evolved and become reliant on fire for both growth and renewal for habitats. Natural science believes that ecosystems seek to progress toward an equilibrium and that any disturbance would disrupt the natural order (Connell and Slatyer (1977)). In this study we will view disruption, like a wildfire, as a 'natural disturbance' that drives the evolution of the market allowing it to develop and grow (DellaSala and Hanson (2015, Chapter 2)).

We introduce three responses that an incumbent can use to combat the entrant and maximise firm value. In one response the incumbent manages both the assets-in-place and the growth option under one company to keep everything "internalised." This is the integration approach where the incumbent's objective function is to maximise the combined value of both of the assets' cash flows. The second response has the incumbent creating a spin-off where two independent organisations separately manage the assets with different objective functions. We define this as the skunkworks approach where the incumbent creates an autonomous business unit which we refer to as a "spin-off." The final approach is where the incumbent commits to abandoning the growth option and allows the entrant to invest in the growth option at their own discretion. We refer to this as the pure disruption case where only the entrant can receive value from the growth option.

We will model these "responses" to analyse the events that follow the disruptive event of successful investment in the innovation. We call these examples "responses" as no action can completely eradicate disruption from the market. The firms can only make decisions on how to mitigate the effects of this innovative dilemma.

\subsubsection{Internalise the growth option}

It is up to the incumbent firm to decide how they would prefer to mitigate the risk of disruption in order to extend their lifespan. According to Henderson and Clark (1990), if the incumbent can adapt their "architecture" to efficiently incorporate the innovation, into their existing business, then the optimal solution to minimising disruption risk is internalising. Resources will be shared between "divisions," but new processes and systems needed for the integration may require additional costs to producing the disruptive innovation. In our initial tests we consider an integrated incumbent that is able to produce the innovation just as efficiently as the entrant, 
with no additional costs arising over maximising both assets-in-place and the growth option. Even though we initially set the innovation production costs the same, assuming the incumbent has a high absorptive capacity, there will still be the cost of cannibalizing the assets-in-place in order to support the innovative product.

As an addendum to Gans (2016) we focus on how the integration approach can be explained by an "insurance put option" where assets-in-place are better protected from disruption. By investing just before the entrant and effectively selling a portion of the assets-in-place, the incumbent will be in a much better position to minimise the effects of disruption than had they let the entrant invest in the growth option. ${ }^{3}$ This is because the incumbent can lock-out the potential entrant and reduce the cannibalization effect that would have occured should entry had been successful.

\subsubsection{Spin off the growth option}

Christensen (1997) considers the optimal response to disruption to be the incumbent spinning off the growth option. This spin-off will not share resources with the existing business line. The sole concern of this spin-off will be the production of the disruptive innovation putting it in direct competition with the entrant. While the main business line may not be saved, the value of the innovation could be greater than the value of the assets-in-place lost by investing. There are benefits and costs with creating a skunkworks as an add-on to the mainstream business. No integration costs need to be considered when the growth option is spun off, however this depends on the level of autonomy or independence this business unit will have when in operation. The very idea of skunkworks relies on the principle of independence such that the autonomous business unit itself will behave in a similar manner to any other potential entrant. A spin-off could be used to describe innovative R\&D models that focus on time to develop and learning capabilities, but R\&D is not a focus for this thesis (Beath et al. (1989); Dasgupta and Stiglitz (1980); Femminis and Martini (2011)).

\footnotetext{
${ }^{3}$ Selling a portion of the assets in place is similar to a "synthetic" put option approach which has been used in papers discussing hedging strategy such as Babenko and Tserlukevich (2017).
} 


\subsubsection{Abandon the growth option}

The final response an incumbent can make in our model is to abandon the growth option to push back the entrant's investment threshold. By removing themselves from competition over the growth option, the incumbent removes the binding preemption constraint. The entrant has no reason to try and preempt the incumbent and will invest when it is optimal at a higher number of "fickle" consumers. The incumbent must be able to provide the entrant with a guarantee that they will never attempt to compete with them over the innovation in the future. The entrant otherwise would see this as a ploy by the incumbent to trick them and hence the entrant would still seek to invest earlier therefore defeating the incumbent's genuine purpose for structuring their firm this way. Grenadier and Malenko (2011) found that better-informed firms will have the incentive to mislead the less-informed firms into underestimating the investment opportunity making them delay their investment. In our model this commitment comes in the form of selling crucial assets (land or machinery) needed to make the innovation impossible. A firm could convert the land required for the factory into a block of residential houses as a sign of irreversibility.

When a firm generates most of its value from their assets-in-place then there may be hesitancy in cannibalizing these assets-in-place. Huberts et al. (2015) found that this hesitancy could be reduced by undertaking a small investment first, before making a larger subsequent investment, to delay the entrant and reduce the cannibalization effect. We allow only a lumpsum capex payment that will build a factory to produce the products so we have to find other ways to reduce cannibalization. By abandoning the option to invest, the incumbent can delay the entrant and hence reduce the cannibalization effect. We agree with Huberts et al. (2015) that it is possible to lower the cannibalization effect by reducing competition, but we find a different action to explain the effect. Kamien and Schwartz (1982) also found this hesitancy in their research where managing innovative threats was made difficult by the firm's unwillingness to cannibalize existing technology. While a firm might be unwilling, it cannot have future investment decisions be influenced by "sunk" assets to the point that it no longer competes in the market. We see this in our model when the incumbent is more willing to permanently abandon the growth option to protect the value of the assets-in-place rather than attempting to invest in the growth option. In our case, the unwillingness stems from there not being enough "fickle" 
consumers in the market to justify investment in the innovation.

\subsection{Real options literature and disruption}

We consider the innovative investment problem in a way that reflects the dynamic nature of disruption. This resembles real options and investment-timing theory as there is value in waiting and learning in order to determine the optimal time to invest. In this scenario, firms wish to invest in the disruptive innovation at the optimal time subject to the cannibalization effect, profit and objective functions, and the behaviour of competition in the market.

The initial development of real options came from Myers (1977) who interpreted investing in corporate assets as being similar to exercising a call option. ${ }^{4}$ Real options derive value from an underlying asset and are exercised when this value exceeds the strike price. In our case this strike price is equal to the lump-sum capex required to successfully invest in the innovation. The firm that holds the option can elect to either wait, invest or make a one-off decision to permanently abandon the growth option. McDonald and Siegel (1986) presents a benchmark real options case that considers a single firm with no threat of preemption by rival firms. We treat this approach as a control test to show the effects of disruption in an environment where there is no competition between firms as only the incumbent exists. By incorporating disruption into our model we allow for strategic interaction between firms with their market value determined by real options analysis. Papers such as Smets (1991); Pawlina and Kort (2006); Slater et al. (1998) have used real options analysis to value firms that strategically interact, but they have not done so where an incumbent firm has existing assets-in-place that are threatened by an innovation.

We use real options analysis with investment-timing options to determine the optimal preemption strategy in different market set-ups. This project will investigate various aspects of the economics of innovation, focussing on how incumbent firms should manage the risk of arrival of a disruptive technology (Gans (2016); Lerner (2012)). We modify a standard investment-timing game where two firms compete over who will preempt their competitor and invest first thereby locking out their competitor indefinitely. The modified model will be solved by combining pol-

\footnotetext{
${ }^{4} \mathrm{~A}$ call option being having the right but not the obligation to buy an asset at an agreed price on a particular date.
} 
icy iteration and the projected successive over-relaxation method, extending the approach in Guthrie (2017) to problems with two exogenous state variables.

By introducing competition, the value of investment-timing options can be reduced as firms are forced to engage in preemption games where they consider investing earlier than would be optimal (Grenadier (2002); Aguerrevere (2009)). A firm with existing assets may invest early to protect assets-in-place and lock out competitors whereas an entrant is focused on getting a foot in the door and then expanding. This was modelled by Gilbert and Newbery (1982) who found that an established firm able to defend its monopoly segment against innovative entry will have a greater incentive to protect its monopoly than allowing new entrants to enter. Reinganum (1983) found results such as those from Gilbert and Newbery (1982) are reliant on the degree of uncertainty surrounding the innovation. The more uncertainty surrounding the innovation, and the higher influence the monopoly has, the more likely the market remains a monopoly as the entrant cannot preempt the incumbent and enter the market. In this thesis we find incumbent firms, even when presented with opportunities to perpetually lock out entrant firms, can find it more beneficial to commit to abandoning the growth option rather than attempting to protect it's monopoly position by preempting the entrant.

Lavrutich et al. (2016) shows that a firm in a market-leader position finds it harder to deter eager entrants from entering if the uncertainty about the market participants is high. This can not only come down to uncertainty but also consumer preferences as found in this thesis. Athey and Schmutzler (2001) found that in markets where firms move from weak positions to more powerful positions their increased market share provided benefits to consumers through cost reductions and quality improvements. This goes against the intuition where, as firms become more dominant, we would expect them to exhibit anti-competitive behaviour. In this thesis we find that even though the incumbent may have the stronger position, by being able to profitably preempt the entrant, the incumbent will prefer to engage in anti-competitive behaviour by removing themselves from the competition. While Grenadier (2002) would argue competition reduces option value, Novy-Marx (2007) found that much of the existing literature fails to take into account the effect of opportunity costs, and the firm's size.

The real options literature highlights the need to move beyond a typical static NPV calculation which ignores flexibility and the irreversibility of investment decisions. Adner and 
Levinthal (2004) found that a firm using real options in their valuation approach rather than static models will be more inclined to abandon earlier due to implicit assumptions about abandonment flexibility and "ease of exit." This value derived from decision-making flexibility is why we use real options analysis to value the effect of disruption. Static models provide a now-or-never approach to valuation which does not fit with the disruption story. It is not possible for firms to accurately predict when disruption will occur in the future let alone making investment and financing decisions in the present that will allow them to mitigate disruption risk in the future. This uncertainty, in combination with irreversibility, is where Dixit and Pindyck (1994) considered there to be value in the option to wait before undertaking capital investments that is not incorporated into static cash flow models.

Some models consider the possibility of strategic action to be subject to conditions and not indefinitely available. This is especially true in mining operations where resources (such as mineral and ore deposits), once extracted, cannot be regrown which is examined by Brennan and Schwartz (1985); Tourinho (1979); Dasgupta et al. (1980); Salant (1976). In our model the option can only be exercised once with no subsequent entry allowed. The participating firms recognise this and so understand that the option is not indefinitely available creating urgency over who will preemptively invest before their competitor. Another example can include the idea of patents where there is a finite period where competing firms can be barred from entering the market. Schwartz (2002) values R\&D investments with competitive interactions in a duopoly with a patent-protected phase under imperfect competition in the development and marketing of the resulting product. This is a possible extension to our model where the patent/licensing is merely an additional embedded option where, with some Bayesian probability, the firm receives the ability to exercise the option and rather than paying the lump-sum capex can just authorise other parties to use the technology under a license agreement. In R\&D papers in particular it was found that in winner take all situations, competition becomes similar to a Prisoner's Dilemma case which can result in overinvestment in research (Cockburn and Henderson (1994)). Anton and Yao (1995) found that that a lack of property rights introduces a conflict over incentives as neither party will have the means to prevent the other from pursuing market rewards.

With introducing investment opportunities into a market comes an argument over the risks 
and rewards associated with exercising the rights to these growth opportunities. Carlson et al. (2014) determined that risk and expected return should vary over time and are dependent on whether the firm holds a "leader" or "follower" position in the market. We explore the expected return using elasticities of firm value relative to consumer numbers in the market for all participants across multiple industry structures to determine preemptive investment effects. Aguerrevere (2009) focuses less on hedging effects and more on the impact of systematic risk with the introduction of innovation. As a result of strategic preemptive moves, this competitive pressure can alter the value of the growth option such that they are exposed to more systematic risk. Firms that open themselves to growth opportunities may expose themselves to more risk, but they can also receive greater rewards by doing so.

Although the idea behind real options fits better with the story of investors in the real world there are limitations to the theory. Kasanen and Trigeorgis (1994) explains that by valuing real assets in a similar way to financial options we can determine the present value of project cash flows if they were traded in the market, which is the basis of capital budgeting. Unlike financial options however, Childs et al. (2001) reminds us that the infrequency at which the underlying assets, that provide value to real options, trade can result in imprecise estimates of asset value. While this introduces a noise component to the model this corresponds accurately to the real world where decisions and valuations are not made on a minute-by-minute basis when it comes to large-scale investments.

\subsection{Management literature and disruption}

Our hope with this research is to reinforce management theory with a financial economic analysis to better understand the effects of competition and preemption in a market that becomes subject to a disruptive innovation. By introducing disruption into a market, even incumbent firms with a strong market position can be overwhelmed with the introduction of an innovative good disrupting existing products. Christensen (1997) introduced his theory by looking at how firms focus on consumers by entering the market at the low-end. They do this by offering relatively poor quality products at lower prices to entice consumers, who are price sensitive, away from their current provider before steadily increasing quality and price over time. This theory is customer-driven: the entrant disrupts an incumbent by identifying blind spots in the 
incumbent's product and exploiting them so that consumers would transition to their product. If the incumbent is not careful and is too focused on providing for their traditional customer base then they will more likely be a victim of disruption. Predicting what a consumer will want can be time consuming and costly and may not even result in what a consumer was after in the first place. Adner (2002) considered consumer preferences and looked at characterising consumers by their willingness to pay for performance improvements. We will consider an approach that focuses on a consumer's willingness to substitute between goods based on their sensitivity to price. The traditional customers that Christensen (1997) referenced, we refer to as "loyal" consumers which have a lower elasticity of substitution than the "fickle" consumers who more readily switch to the innovation.

In the skunkworks scenario, the manager of the autonomous unit is in complete control of when to invest in the new technology and his sole concern is maximising the innovation regardless of its effect on the assets-in-place. Aghion and Tirole (1994) followed a similar route by introducing a research unit that performed research for a customer where the value of the innovation for the customer was greater than zero and stochastic in nature. We consider this as a similar approach to an incumbent creating an independent unit for the sole purpose of investigating the new innovation. Huberts et al. (2019) used a similar approach to us by having an existing producer that faced the threat of a potential entrant. They found that it was better to deter entry by timing the investment correctly as opposed to over-investing in a project using a dynamic real options framework. Where we extend on these papers findings is that we directly compare the value of internalising against the value of spinning off in order to see which method benefits the incumbent the most.

Henderson and Clark (1990) took a different route from Christensen and focussed on the supply-side approach to disruption. They looked at the difficulty firms have in adapting to new technologies with their pre-existing systems and processes that define the "architecture" of the firm. Firms that efficiently produce existing products could find they are unable to competitively offer new innovations as their architecture is too rigid. Increased labour hours and complex machinery are just a few examples of what firms face when they develop an innovation that can disrupt existing production capacity. This difficulty in adapting to new technologies was captured by Cohen and Levinthal (1994) who coined the term "absorptive 
capacity" which measures a firm's ability to adopt external technologies. Should a firm have a greater absorptive capacity then they find it easier to assimilate to a changing and innovative economic environment. In our study a high absoptive capacity means a firm will be more likely to follow an integration approach. A firm that has a low absorptive capacity lacks the ability to adapt so will be better off developing a spin-off in response to disruption. Henderson and Clark (1990) did not focus on individual components, but rather the linkages and overall package of producing a new innovation. In this thesis we investigate when the incumbent firm has low absorptive capacity and produces the innovative product at a higher production cost than the entrant. We find that when the incumbent has greater difficulty in assimilating this product into the current business, relative to an entrant whose whole business will be the innovation, they lose their preemptive investment capabilities. At low absorptive capacity it is better for the incumbent to spin off rather than internalise.

By comparing the skunkworks structure to the integration scenario we will look at the combined value of the incumbent and the spin-off against the value of the internalised incumbent. This will tell us which method best benefits the incumbent in terms of overall firm value. With efficient costs, high absorptive capacity, we find that the incumbent receives greater value from internalising rather than spinning off. This result can differ should the incumbent have a low absorptive capacity such that it is more efficient to produce the innovation from an independent division than in-house. The decision to internalise rather than spin off is robust for when the "fickleness" of consumers increases and consumption of the innovative product intensifies.

\subsection{Contributions to the existing literature}

\subsubsection{Extension of real options papers}

When considering investment-timing opportunities and their value using real options analysis, research tends to focus on the competition between firms over the option to invest (McDonald and Siegel (1986); Grenadier (2002)). These papers highlight firms competing over investment opportunities using real options analysis, but they ignore the consequences of innovation on incumbent firms. An established incumbent in the market will hold assets-in-place before any 
investment decision is made, which will be negatively affected when an innovation arrives that produces an imperfect substitute of the existing product.

Some academics such as Berk et al. (1999) and Gomes et al. (2003) recognise firms can own two kinds of assets: assets-in-place (that currently generate cash flows), and growth options that will make positive net-present-value investments in the future, but they leverage the growth option's value on the assets-in-place. Research has predominantly treated a growth option as being an expansion option on the assets-in-place. In our model we consider the growth option as an expansion, not of the assets-in-place, but for a product that opens up a new and innovative portion of the market previously untapped. Rather than the value of the growth option being "leveraged" on existing assets-in-place, in our model the value of both assets-in-place and option is determined by the cash flows calculated from our "output market" equilibrium with the demand drivers $x$ and $y$. We state the incumbent can structure their firm to have both assets-in-place and the growth option, while the entrant will only have access to the option.

By leveraging the growth option on the assets-in-place, papers previously published have found the growth options to be riskier than the assets-in-place as a result of current profits being exposed to productivity shocks as found by Hackbarth and Johnson (2015). We also find growth options to be riskier than assets-in-place, even though we do not leverage the growth option, but this is because of their high elasticities of market value subject to changes in the number of different customer types in the market.

We differ from previous real options papers in that our one-off option to perpetually abandon is not valued using a salvage value, but instead from the assets-in-place now subject to the disruptive influence of the entrant's growth option. The incumbent uses the one-off abandonment option to postpone the effects of disruption on assets-in-place. It is not that the growth option is not profitable, which is usually why most firms may choose to abandon if there are no signs of a market upturn, just that the gain from exercising the growth option does not exceed the value lost for the assets-in-place.

\subsubsection{Firm structure, collusion and best response}

In this thesis we consider firms exploiting the different types of consumers in the market by selectively developing certain products in the market. Should the market feature more "fickle" 
consumers then the innovation will more popular than the existing product and vice versa should there be relatively more "loyal" consumers. Trigeorgis (1996) took a different approach by having additional capital investments leading to an enlarged operation in order to exploit a new and growing market. ${ }^{5}$ To best exploit this, the incumbent can specialise their business structure to suit the distribution of consumer types in the market.

We model different business structures for the incumbent in order to determine which offers the most in terms of market value. We initially consider the best case scenario which feature no binding preemption constraint or competitive entry. We highlight this scenario as best case because it allows the incumbent to retain its monopolist position in the market while at the same time providing access to the previously hidden innovative section of the market. We next consider possible actions the incumbent can take in light of being unable to perpetually lock out the entrant of the market.

Pure disruption highlights a market set-up where the incumbent has committed to not compete with the entrant and will only produce the existing product. This was initially considered to be the worst case scenario for the incumbent as they have essentially withdrawn from competition, and have no ability to preemptively invest just before the entrant. What we find is that the incumbent has an incentive to not compete as they can receive greater market value by putting themselves in what we considered to once be the worst position. Lambrecht and Perraudin (2003) found a similar result using incomplete information where firms invest strategically by colluding to share the surplus created by the real option. We do not allow for this sharing of surplus as the innovative section of the market only has space for one market participant. What we do find is that collusion can exist in a market, even with complete information, when the incumbent elects to abandon the innovative growth option as a sign of commitment to the entrant that there will be no competition over the innovative product. Reinganum (1983) found that incumbents are less likely to invest in the innovative technology and challenge the potential entrant when uncertainty is introduced into an innovation model. We found the incumbent is less likely to invest if there are not enough "fickle" consumers in the market to ensure the gain made from exercising the growth option exceeds the loss in value of the assets-in-place from cannibalization.

\footnotetext{
${ }^{5}$ This could be considered similar to where a firm invests in the existing assets by exercising an expansion option rather than focusing on the disruptive innovation.
} 
We also allow the incumbent to either internalise or spin off the growth option. This allows us to draw direct comparisons over how the incumbent can best combat the threat of innovative entry should there be enough demand for the innovative product. Grenadier and Wang (2005) study how agency conflicts may affect the exercise of real options when the owner of a real option delegates the investment-timing decision to a manager who can exert effort to increase the payoff of the option. In this thesis the agency conflict links to determining whether the decision to internalise or spin off results in the optimal incumbent strcuture. Our focus is on how an incumbent firm can choose their strategy not only for the decision of when to investment, but also how to invest with the optimal structure in which to do so. We are able to provide an explanation to incumbent firms on how to best adapt to innovative entry such that they receive optimal firm value given the market conditions.

\subsubsection{Output Market}

To determine the values of the assets-in-place and growth option, we look at their respective products' (existing and innovative) cash flows in a micro-economic model that calculates the optimal prices and quantities for consumers in the market. The demand functions for consumers are determined by a constant elasticity of substitution (CES) utility function which is subject to the number of "loyal" $(x)$ and "fickle" $(y)$ consumers, that we use as our stochastic parameters. Papers such as Epstein and Zin (1989) and Farmer (1990) have used a CES utility function to derive consumption timing which are subject to exogenous shocks. They allowed for the intertemporal elasticity of substitution and the coefficient of relative risk aversion to be represented by two separate parameters. Instead of relative risk aversion we focus on parameters that reflect elasticities of demand and substitution ( $\alpha$ and $\rho$ respectively). Through our CES utility function we use the parameters for elasticity of substitution $(\rho)$ and consumption intensity $(\delta)$ in order to manipulate consumer preferences to determine optimal invest-timing behaviour. Previous papers have analysed investment-timing problems using inverse demand functions or by including exogenous cash flow shocks in their models (Huberts et al. (2019); Dixit (1992)). We found that customer preferences and their sensitivity to price can play a crucial role in determining a firm's ability to deal with disruptive injections in the market. The number of these different consumer types ("loyal" and "fickle") has typically been ignored as a 
source of stochastic uncertainty.

The choice of stochastic uncertainty in past papers has varied, where some have focused on the timing of investment while others have looked at the revenue and investment stream as being of stochastic nature (Reinganum (1983); McDonald and Siegel (1986)). To the best of our knowledge, we are the first to focus on the number of consumers with different elasticities of substitution in an innovation model. We use them to reflect how firms have to cater to different customer types, and how their willingness to trade between substitute goods fuels the demand in the market. Industries that feature waves of innovation (such as mobile phones and tablets) would see consumers displaying either strong brand loyalty (low relative price sensitivity) or a willingness to readily switch to newly introduced, and cheaper, technologies (higher price sensitivity). These customer types allow us to consider this problem from the perspective of consumers and when a firm should invest given the number of certain customer types in the market. Consumers displaying a higher elasticity of substitution will more readily transition to the innovation when it is introduced to the market and provide an explanation as to why their introduction results in the cannibalization of assets-in-place. 


\section{Model Framework}

\subsection{Model Overview and Assumptions}

We consider two firms that belong in the same industry and each have a perpetual investment opportunity to produce an innovative product that will generate a perpetual cash flow of $\Pi_{2}$. Before investing in this project, the incumbent has assets-in-place that produce a product providing a continuous cash flow of $\Pi_{1}$ while the entrant has no cash flow. Firms are not able to invest successfully more than once in this model and the decision to invest is irreversible and entails a sunk and fixed capex cost of $I .{ }^{1}$ If both firms attempt to invest at the same time, then either one firm or the other will invest immediately with an equal probability of successful investment. The two firms have complete flexibility about when they invest. The incumbent can either delay or invest in the new asset to create the innovation alongside their existing asset.

In our model we let the number of consumers, with constant elasticities of substitution, in the market be stochastic. There will be $x$ units of consumers relatively loyal to their product brand while $y$ units are fickle consumers, with the number of these units ( $x$ and $y$ ) both following geometric Brownian motion processes

$$
\begin{aligned}
& d x=\mu_{x} x d t+\sigma_{x} x d \xi_{x} \\
& d y=\mu_{y} y d t+\sigma_{y} y d \xi_{y}
\end{aligned}
$$

where $d \xi_{x}$ and $d \xi_{y}$ are correlated increments of standard Wiener processes. Both the expected rate of growth $\left(\mu_{x}\right.$ and $\left.\mu_{y}\right)$ and the instantaneous variance $\left(\sigma_{x}^{2}\right.$ and $\left.\sigma_{y}^{2}\right)$ of $x$ and $y$ are constant

\footnotetext{
${ }^{1}$ This winner-take-all approach means we do not allow for subsequent investment which is similar to an innovative product having an infinitely-timed patent protection.
} 
Figure 2.1: Evolution of Industry

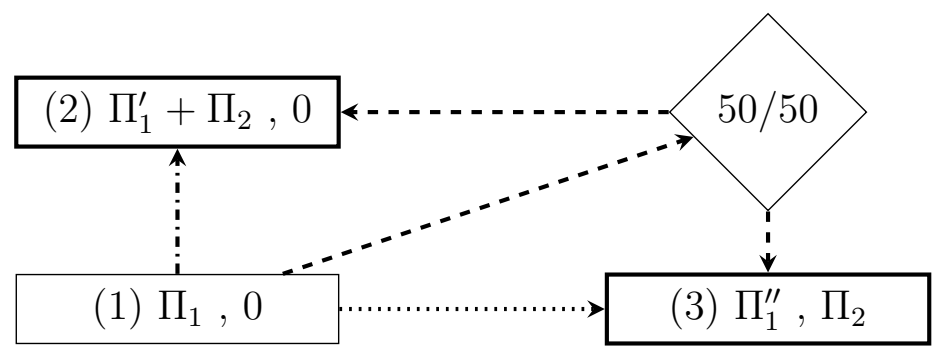

Incumbent Invests

Entrant Invests

Simultaneous Invest

over time. The risk premiums for bearing $x$ - and $y$-risk will be denoted by $\lambda_{x}$ and $\lambda_{y}$ respectively. The risk-free rate will be equal to $r$ and will satisfy $r+\lambda>\mu$ for both $x$ and $y$ risk. Throughout this paper we assume complete and symmetric information such that the numbers of these customer types are directly observable at the same time by both firms.

Time is continuous. At any date $t \geq 0$, the state of the industry is described by $(x, y)$ and whether or not a firm has invested in the innovation. The system starts in Block (1) of Figure 2.1 with the cash flows for the incumbent and entrant being $\Pi_{1}$ and 0 respectively where $\Pi_{1}$ is the net cash flow for the existing product before investment. When both firms delay, they remain in the same block receiving the instantaneous cash flows shown. Should the incumbent invest then we move to the terminal Block (2), with the incumbent's cash flow changing to $\Pi_{1}^{\prime}+\Pi_{2}$ where $\Pi_{1}^{\prime}$ and $\Pi_{2}$ are the net cash flows for the existing product and innovative product respectively after investment. In contrast, the entrant is locked out of the market and receives a cash flow of 0. If the entrant preempts the incumbent we move to Block (3), with the incumbent's cash flow now just equaling the cannibalized $\Pi_{1}^{\prime \prime}$ while the entrant receives the cash flow of $\Pi_{2} \cdot{ }^{2}$ Should both firms simultaneously invest then we move to the $50 / 50$ node where there is a $50 \%$ chance for either firm to successfully invest.

We use $V_{a b}(x, y)$ to denote the market value of firm $a$ when firm $b$ has invested in the growth option. ${ }^{3}$ All firms participating in the market are assumed to be value-maximizing. For our baseline case, prior to investment, the decision-maker chooses whether to pay the sunk cost $I$

\footnotetext{
${ }^{2}$ We use $\Pi_{1}^{\prime}$ and $\Pi_{1}^{\prime \prime}$ to distinguish that the incumbent will be subject to a different cannibalization rate depending on who invests in the innovation.

${ }^{3}$ When we refer to $V_{a}$ this will denote the market value of firm $a$ without investment.
} 
to earn the post-innovation profit or delay further their investment.

\subsection{Market Structure}

In this paper we will discuss four different market structures in which firms may face disruption. We begin with the one "Problem" structure for the market and then follow this with three "competitive response" structures where the incumbent attempts to mitigate disruption risk.

First, we consider the best case (for the incumbent) scenario, where only the incumbent can invest in the growth option. The entrant has effectively abandoned the option to enter the innovative market and has no ability to enter in the future and attempt to preempt the incumbent. This is the best case scenario for the incumbent as they can focus on exercising their option at the optimal time without needing to consider strategic interaction. The incumbent can delay as long as necessary until it is optimal to "self-disrupt." If the firm knows that there is no possibility of competitors preemptively investing, then the value derived from deciding when to invest can be represented by a real option value of being able to indefinitely delay investment until it is optimal to do so. The monopolist does not require any input from their non-existent competitors to determine an optimal threshold of investment and so can delay without fear of being preempted, relative to the more competitive extensions of this model below.

Second, we consider the pure disruption case where the incumbent has committed to abandoning the option to innovate and provides the entrant an opportunity to enter the market with no binding preemption constraint. The incumbent can still influence the output price of the existing product, meaning prices are competitive, but the incumbent can only react to the investment actions of the entrant and their firm value will reflect this. As output prices are now subject to competition, this means that we require a Nash equilibrium be found to determine them. The incumbent in this instance is unable to attempt to preemptively invest in the growth option to protect themselves from disruption risk.

Third, the integration case provides a solution to the incumbent in light of disruption potentially occurring. Both the incumbent and the entrant have the ability to exercise an option and invest in the innovation. The incumbent will manage both assets-in-place and the growth option concurrently to combat the potential new entrant. Both firms will seek to preempt the other and invest in the innovation. When a firm finds it profitable to preempt 
their competitor, such that being a leader provides a greater payoff than being a follower, the firm in question will attempt to invest. Firms, with complete information, will know what the preemption payoffs will be for themselves and their competitors so they will effectively know who will successfully invest in the growth option. In this case as well, a Nash equilibrium is required to be found to determine competitive prices.

Fourth, and finally, we consider the skunkworks case where we allow the incumbent to spin off an independent organisation that will be solely devoted to producing the innovation. This allows the main body of the incumbent to continue focusing on the pre-existing assets-in-place. There is now a possible principal-agent problem as the spin-off and incumbent have separate objective functions each seeking to maximise the present value of their own profit margins. This will create a new conflict between the spin-off and the entrant as the incumbent no longer holds the growth option. From a preemption perspective, we have identical firms (the entrant and spin-off) that should display the same preemption threshold. Will a more specific competition focus, that the spin-off exhibits, provide more value to the incumbent relative to an internalised approach discussed in integration?

\section{3 "Output Market" Equilibrium}

\subsubsection{Demand Function}

We model consumer demand for good 1 (produced by the incumbent's existing factory) and good 2 (produced by the new facility after it has been built). To determine equilibrium cash flows in our model we will create a micro-economic model that features these two goods which are priced competitively, and ultimately determined through a Nash equilibrium. Let $q_{1}$ denote the demand for the existing product while $q_{2}$ denotes the demand for the innovation. We assume consumers maximise the CES utility function

$$
U\left(q_{0} ; q_{1}, q_{2}\right)=q_{0}+\left(\delta q_{1}^{\rho}+(1-\delta) q_{2}^{\rho}\right)^{\frac{\alpha}{\rho}}
$$

where $q_{0}$ is the composite good reflecting all other consumption in the market apart from the existing and innovative products and has been scaled such that its price is 1 . We use $\rho$ and $\alpha$ 
to determine the elasticities of substitution and demand, which equal ${ }^{4}$

$$
\begin{aligned}
\epsilon_{s} & =\frac{1}{1-\rho} \\
\epsilon_{d} & =-\frac{1}{1-\alpha}
\end{aligned}
$$

respectively. "Loyal" consumers will transition between products at a slower rate than "fickle" consumers as a result of changes in the price of substitute goods. This implies that loyal consumers will have a lower elasticity of substitution compared to fickle consumers. Specifically, loyal customers have $\rho=\rho_{x}$ and fickle customers have $\rho=\rho_{y}$, where ${ }^{5}$

$$
-\infty<\rho_{x}<\rho_{y}<1 \text { and } \rho \neq 0 .
$$

The inputs to the utility function in equation (2.2) are determined in the output market at each point in time. That is, there are no linkages across time. Dynamic aspects will appear when we consider the firms' investment-timing game. We use this utility function to describe a system of consumer preferences characterised by an elasticity of substitution between differentiated goods which is constant. This can be used as a function to portray the aggregate consumption in our economy. Each consumer's available budget, $M$, is now divided between expenditure on the differentiated commodities such that

$$
M=q_{0}+p_{1} q_{1}+p_{2} q_{2}
$$

The prices and quantities of the other goods are denoted by $p_{g}$ and $q_{g}$ where $g \in(1,2)$ respectively.

From the utility maximisation problem we determine the quantities for both commodities that maximise utility subject to the budget constraint. ${ }^{6}$ We use the budget constraint to eliminate $q_{0}$ and then take first order conditions of the utility function for both $q_{1}$ and $q_{2}$. After setting these equal to zero, we eventually find that the optimal quantities demanded by "loyal"

\footnotetext{
${ }^{4}$ Refer to Appendix A.2 for derivation of own-price elasticity.

${ }^{5}$ The closer $\rho$ gets to 1 the more the consumer consider the goods to be perfect substitutes.

${ }^{6}$ The details are covered in Appendix A.1.
} 
consumers for goods 1 and 2 are therefore

$$
\begin{aligned}
& q_{x 1}=\left[\frac{p_{1} p_{2}^{\frac{\alpha-\rho_{x}}{1-\rho_{x}}} \delta^{\frac{1-\alpha}{\rho_{x}-1}}\left(p_{1}^{\frac{\rho_{x}}{1-\rho_{x}}}(1-\delta)^{\frac{1}{1-\rho_{x}}}+p_{2}^{\frac{\rho_{x}}{1-\rho_{x}}} \delta^{\frac{1}{1-\rho_{x}}}\right)^{\frac{\rho_{x}-\alpha}{\rho_{x}}}}{\alpha}\right]^{\frac{1}{\alpha-1}} \\
& q_{x 2}=\left[\frac{p_{1}^{\frac{\alpha-\rho_{x}}{1-\rho_{x}}} p_{2}(1-\delta)^{\frac{\alpha-1}{1-\rho_{x}}}\left(p_{1}^{\frac{\rho_{x}}{1-\rho_{x}}}(1-\delta)^{\frac{1}{1-\rho_{x}}}+p_{2}^{\frac{\rho_{x}}{1-\rho_{x}}} \delta^{\frac{1}{1-\rho_{x}}}\right)^{\frac{\rho_{x}-\alpha}{\rho_{x}}}}{\alpha}\right]^{\frac{1}{\alpha-1}} .
\end{aligned}
$$

For "fickle" consumers we find the optimal quantities are derived from the same equation but with $\rho_{y}$ replacing $\rho_{x}$. Equation (2.4) shows us that the two consumer types will typically demand different quantities of the goods. This makes the profit flows of goods 1 and 2 functions of $x$ and $y$ which provide strong micro-economic foundations for the model. This is a realistic approach to take as some consumers might purchase based on the relative prices of the goods, but another group would consider brand loyalty more important than price. It is only worth launching a new good once the number of "fickle" consumers in the market $(y)$ becomes large enough.

\subsubsection{Output Price Determination}

We need to determine output prices in three situations. First, before investment, where only good 1 is produced. Second, after investment by the incumbent, so that the incumbent produces goods 1 and 2. Third, after investment by the entrant, where the incumbent produces good 1 and the entrant produces good 2.

In the industry, a firm's objective is to maximise their profit function at each point in time. ${ }^{7}$ We use $\Pi_{g}$ to denote the instantaneous profit flow received by producing good $g \in(1,2) .{ }^{8} \mathrm{Up}$ until now, we used this as a placeholder, but now we can derive it as a function of $x$ and $y$. We know that before entry only the incumbent exists in the market and so maximises their profit function of

$$
\Pi_{1}=\left(p_{1}-c_{1}\right) D_{1}^{(x, y)}
$$

\footnotetext{
${ }^{7}$ When we analyse the investment game, the firms will maximise their market value, which we take to be the present value of their net cash flows.

${ }^{8}$ We are able to calculate the total profit flow in the market as our demand function is homogeneous to degree one as explained in Appendix A.3.
} 
where

$$
D_{1}^{(x, y)}=x q_{x 1}+y q_{y 1}
$$

by setting the price of good 1 at $p_{1}=\frac{c_{1}}{\alpha}$ which we prove in Appendix A.4. ${ }^{9}$

By investing in the innovation the incumbent's objective function is now ${ }^{10}$

$$
\Pi_{1}^{\prime}+\Pi_{2}
$$

where the incumbent produces both products and the entrant is perpetually locked out of the market. After successful entry into the innovative market the monopolist will set prices of the goods as

$$
p_{g}=\frac{c_{g}}{\alpha}
$$

where $c_{g}$ denotes the cost of producing good $g \in\{1,2\} .{ }^{11}$

If the entrant invests in the growth option before the incumbent, their profit function equals

$$
\Pi_{2}=\left(p_{2}-c_{2}\right) D_{2}^{(x, y)}
$$

where

$$
D_{2}^{(x, y)}=\left(x q_{x 2}+y q_{y 2}\right)
$$

The incumbent chooses $p_{1}$ to maximise $\Pi_{1}^{\prime \prime}$, given the entrant's choice of $p_{2}$. The entrant chooses $p_{2}$ to maximise $\Pi_{2}$ given the incumbent's choice of $p_{1}$. These prices are a function of both $x$ and $y$, which is to be expected. More "loyal" consumers in a market would mean firms have high brand loyalty and so can raise prices higher than their competition. Should the distribution of consumers move towards favouring $y$, then firms will find the market is more sensitive to competitive price changes which will heavily impact their objective functions.

\footnotetext{
${ }^{9}$ Before the introduction of the innovative technology the price of good 2 is effectively $p_{2}=\infty$.

${ }^{10}$ This will be true for the integration case. However, we find that for the skunkworks case that participating firms will have different objective functions.

${ }^{11}$ Refer to Appendix A.4 for details.
} 


\subsection{The Underlying Valuation Equation}

In "real-time" a firm will consider its investment decision over each continuous time interval, $d t$. We begin by considering a perpetual option whose payoff depends on the number of "loyal" and "fickle" customers in the market which are $x$ and $y$ respectively. Let $V(x, y)$ be the market value of the firm. Since there are two sources of uncertainty, we look at the risk neutral processes for $x$ and $y$

$$
\begin{aligned}
& d x=\left(\mu_{x}-\lambda_{x}\right) x d t+\sigma_{x} x d \xi_{x} \\
& d y=\left(\mu_{y}-\lambda_{y}\right) y d t+\sigma_{y} y d \xi_{y} .
\end{aligned}
$$

Because we are looking at a perpetual option there is no explicit appearance of time in the model so $\frac{\partial V}{\partial t}$ does not feature in our valuation equation. ${ }^{12}$ The processes for $x$ and $y$ are time-homogeneous, meaning the calendar time does not affect the evolution of the process. This time-homogeneity property means that at a given time, $t$, the investment-timing decision depends only on the current value of the state $(x, y)$, not on the calendar date $t$.

$d V$ is the change in the value of $V$ caused by the stochastic change in $x$ and $y$ within an infinitesimal time increment $d t$. We now use the Ito Lemma involving two variables

$$
E^{*}[d V]=\left[\frac{1}{2} \sigma_{x}^{2} x^{2} V_{x x}+\rho_{x y} \sigma_{x} \sigma_{y} x y V_{x y}+\frac{1}{2} \sigma_{y}^{2} y^{2} V_{y y}+\left(\mu_{x}-\lambda_{x}\right) V_{x} x+\left(\mu_{y}-\lambda_{y}\right) V_{y} y\right] d t
$$

Because we use the risk-neutral process to calculate $E^{*}[d V]$, we require that

$$
r V d t=\Pi_{a} d t+E^{*}[d V]
$$

which shows the instantaneous cash flow received from the existing asset plus the expected change in the value of future cash flows. We now arrive at the differential equation

$$
\frac{1}{2} \sigma_{x}^{2} x^{2} V_{x x}+\rho_{x y} \sigma_{x} \sigma_{y} x y V_{x y}+\frac{1}{2} \sigma_{y}^{2} y^{2} V_{y y}+\left(\mu_{x}-\lambda_{x}\right) x V_{x}+\left(\mu_{y}-\lambda_{y}\right) y V_{y}-r V+\Pi_{a}=0 .
$$

\footnotetext{
${ }^{12}$ If time were to appear explicitly then this would mean the option is dependent on a time to maturity.
} 
We will refer to the LHS of equation (2.6) as $\mathcal{L} V$ from now on. This will be useful when we analyse the problems facing the owners of the two firms in the next section.

We use equation (2.6) in multiple places, with a different $\Pi_{a}$ in each case. For example should the incumbent invest in the innovation then we have

$$
\Pi_{a}=\Pi_{1}^{\prime}+\Pi_{2}
$$

where the non-homogeneous term equals the net cash flows for the incumbent post-investment. As the entrant is locked out of the market, their non-homogeneous term will be 0. Should the entrant, or spin-off, invest in the innovation then the non-homogeneous term's for their partial differential equations will equal $\Pi_{2}$ and $\Pi_{1}^{\prime \prime}$ respectively. Before any investment occurs the incumbent receives a net cash flow of $\Pi_{a}=\Pi_{1}$ while the entrant and spin-off receive nothing.

\subsection{Backward Induction}

We begin with the terminal states, that have bold borders, in Figure (2.1); that is those after investment has occurred as a result of successful entry by either the incumbent or entrant into the innovative section of the market. ${ }^{13}$ We can then solve backwards through the model until we reach the initial Block (1) such that we focus on decisions in terms of present values. We deal with the terminal states first as we know the cash flows of the firms following successful investment. We can then value both firms by the present value of cash flows generated by the assets the firms have in place.

\subsubsection{After Investment}

We first consider the situation after one firm invests, which removes the opportunity for any other firm to invest in the innovation. There are three possibilities to consider that differ according to the firm that invests. First, the incumbent could invest and lock out all other entrants from investing. Second, the entrant could preempt the incumbent and invest so that the incumbent is locked out. Finally, there will be the instance when the spin-off invests before

\footnotetext{
${ }^{13}$ Successful entry will be defined as when the disruptive innovation is available to consumers and $\Pi_{2}$ is generated.
} 
the entrant. This final case is similar to the second scenario where the incumbent loses the rights to the growth option, but now the entrant is also locked out and the spin-off now controls the innovation.

\subsubsection{After the Incumbent Invests}

After the incumbent has invested into the market they remain a perpetual monopolist and deny the entrant any future opportunities to enter the market. Following successful investment the incumbent has no actions available to them apart from waiting and receiving instantaneous cash flows. The value of the entrant is $V_{e i}(x, y)=0$ and the value of the incumbent is $V_{i i}(x, y)$. The incumbent receives the instantaneous cash flow as shown in Block (2).

As the incumbent is the only participant in the market, with no binding preemption constraint, there is no need to determine a Nash equilibrium for competitive prices in the market. From Section 2.3.2, the incumbent sets $p_{1}=c_{1} / \alpha$ and $p_{2}=c_{2} / \alpha$, so that its net cash flows equals $\Pi_{1}^{\prime}+\Pi_{2}$ as previously stated in Section 2.4. The value of the incumbent satisfies the equation $\mathcal{L} V_{i i}=0$, which has the closed form solution

$$
V_{i i}(x, y)=\left(p_{1}-c_{1}\right)\left(\frac{x q_{x 1}}{r+\lambda_{x}-\mu_{x}}+\frac{y q_{y 1}}{r+\lambda_{y}-\mu_{y}}\right)+\left(p_{2}-c_{2}\right)\left(\frac{x q_{x 2}}{r+\lambda_{x}-\mu_{x}}+\frac{y q_{y 2}}{r+\lambda_{y}-\mu_{y}}\right)
$$

\subsubsection{After the Entrant Invests}

Following the entrant successfully investing we find ourselves at Block (3) in Figure 2.1 where the only behaviour that either firm can exhibit is to wait. Both the incumbent and the entrant now exist in the industry as active participants. From Section 2.3.2, the output prices are determined by a Nash equilibrium where $p_{1}$ and $p_{2}$ are functions of $x$ and $y$. As stated in Section 2.4, the net cash flow for the incumbent equals $\Pi_{1}^{\prime \prime}$, to reflect the partially cannibalized assets-in-place, while the entrant receives $\Pi_{2}$

The value for the entrant is determined by the partial differential equation of $\mathcal{L}_{e} V_{e e}$ which has the non-homogeneous term of $\Pi_{a}=\Pi_{2} \cdot{ }^{14}$ As a result of the entrant investing before the incumbent is able to invest, the incumbent's value is also subject to the partial differential equation. We solve the value of the entrant and incumbent, $V_{e e}$ and $V_{i e}$ respectively, numerically

\footnotetext{
${ }^{14}$ In Appendix A.5 we explain how we solve the partial differential equation using the successive over-relaxation method.
} 
to satisfy the partial differential equations

$$
\begin{aligned}
\mathcal{L}_{e} V_{e e} & =0 \\
\mathcal{L}_{i} V_{i e} & =0
\end{aligned}
$$

where the non-homogeneous term for the incumbent is $\Pi_{a}=\Pi_{1}^{\prime \prime}$ as they are now in the optimal stopping region.

\subsubsection{After the Spin-Off Invests}

With the introduction of the spin-off, we effectively have three competitors in the same industry where two compete over the innovative portion of the market-space. From Section 2.4 we remember that after the spin-off invests in the innovation they generate a net cash flow of $\Pi_{2}$ while the incumbent will receive the cannibalized $\Pi_{1}^{\prime \prime}$, and the entrant receives 0 . These cash flows will be the non-homogeneous terms for the respective firms should the spin-off invest in the innovation. Similar to Section 2.5.1.2, the spin-off and incumbent will see their output prices determined by a Nash equilibrium so that they maximise $\Pi_{2}$ and $\Pi_{1}^{\prime \prime}$ respectively.

Should the spin-off invest then we solve the value of the spin-off and the incumbent, $V_{s s}$ and $V_{i s}$ respectively, numerically to satisfy the partial differential equations

$$
\begin{aligned}
V_{e s} & =0 \\
\mathcal{L}_{i} V_{i s} & =0 \\
\mathcal{L}_{s} V_{s s} & =0
\end{aligned}
$$

where we know from before that, with no existing assets before investment, the entrant is worth nothing. As this is post investment the firms are now perpetually "waiting" with no further action available to any of them. This is similar to Section 2.5.1.2 in that the spin-off behaves as the entrant would upon successful entry, but now the spin-off receives the rewards and the entrant is locked out of the market.

\subsubsection{Before Any Investment}

Now that we have considered what happens after investment, it is time to consider what happens before investment. Consider the incumbent's investment-timing problem in an arbitrary non- 
terminal state $(x, y)$ such that no investment has yet taken place. The incumbent's optimal policy will depend on the actions of the entrant and vice versa. In order to determine the equilibrium policies we use best response iteration. For such states, we begin the process with a guess of the incumbent's equilibrium policy to determine a starting point for the model. ${ }^{15}$ We then calculate the entrant's optimal investment policy given the actions of the incumbent. After this, we temporarily assign the investment policy of the entrant in order to calculate the incumbent's optimal investment policy, given the action the entrant has "chosen." This is repeated for all possible actions a firm can take and is then considered from the incumbent's perspective. We continue iterating like this until convergence is achieved when the changes in both firm's value functions become smaller than a threshold that we arbitrarily set. We have constructed an equilibrium where the policies do not change from one iteration to the next such that each firm's investment policy is a best response to its rival's policy. As the two firms' policies depend only on the current levels of $x$ and $y$ and the cash flows of the assets, this is a Markov-perfect equilibrium.

An important step in these calculations is determining a firm's optimal investment policy, given a specified investment policy for the rival firm. Due to the variety of actions available to the firms in this model we need to calculate the firm's best response for all values of the exogenous state variables $x$ and $y$. We can say that when it is optimal for the firm to delay exercising, the value of the option for the participating firms satisfies the partial differential equation (2.6). Because of the complexity of this equation we cannot obtain an analytical solution and instead must solve the value of the option numerically on a grid representing $(x, y)$-space. Typically, the value of the option is determined based on whether it is optimal to delay investment or invest immediately. We have two regions to consider; the continuation region and the stopping region. Should the investor find themselves in the stopping region then they will act without delay and attempt to invest immediately receiving the net present value of the project. Investment occurs at the first moment when the states $(x, y)$ crosses the investment threshold into the stopping region.

The preemption game is played in continuous time by each firm waiting until "just before" a rationally expected preemption threshold for the rival firm is reached. This preemption

\footnotetext{
${ }^{15}$ In our model our guess will be a now-or-never decision such that investment will only occur with a positive NPV or otherwise delay.
} 
threshold is determined by symmetric, rational expectations concerning the revenue from the project, according to Equation (2.1). The solution to firm a's optimal preemptive-investment decision can be characterised by thresholds such that firm a will choose to invest immediately once the state variables reach certain values. For convenience in displaying results we focus on the $y^{*}$ threshold for different $x$ values to show the effects of consumer distribution. This preemption game is simultaneously a game for winning the opportunity to invest in the growth option immediately and indefinitely securing monopolist's rights to the innovative market. As we do not allow for subsequent entry, the initial "winner" is guaranteed to remain a monopolist for the innovative section of the industry.

\subsubsection{Best Response with no Strategic Interaction}

We can use the linear complementarity problem to determine the value of the real option to invest when there is no strategic interaction in the best case and pure disruption scenarios. In these cases the firm holding the growth option is not under threat of being preempted so their actions are not a response to those of other firms. We know that the option value in best case solves the following partial differential variational inequalities

$$
\begin{gathered}
\mathcal{L} V_{i} \leq 0 \\
V_{i} \geq V_{i i}-I \\
\mathcal{L} V_{i} \cdot\left(V_{i}-\left(V_{i i}-I\right)\right)=0
\end{gathered}
$$

where $V_{i i}$ denotes the value immediately after investment, calculated in Section 2.5.1.1. The entrant's option value in pure disruption can be found by solving the partial differential variational inequalities by replacing $V_{i}$ with $V_{e}$, and $V_{i i}$ with $V_{e e}$. Equation (2.10) shows that equality always holds for either equation (2.8) or (2.9). This is because a firm is either in the continuation region or stopping region. Equation (2.8) holds with equality when the firm is in the continuation region while equality for equation (2.9) occurs when the firm is in the stopping region. Equation (2.9) states the value of the real option is always at least equal to its exercise payoff. As the real option has an early exercise right, the option cannot be worth less than the stopping payoff otherwise the firm would immediately invest. 


\subsubsection{Incumbent's Best Response with Strategic Interaction}

Consider the position of the incumbent when they play a preemption game with the entrant where the value of their real option is determined by the strategic interaction of the market participants. We start at a grid point $(x, y)$ where the entrant tries to build the new innovative technology. If the incumbent does not attempt to invest in the innovative technology immediately, or abandons the option altogether, then its value equals $V_{i e}(x, y)$ subject to the instantaneous cash flows shown in Block (3). In contrast, if the incumbent attempts to build the new innovation then its expected payoff equals ${ }^{16}$

$$
\frac{1}{2}\left(V_{i i}(x, y)\right)+\frac{1}{2}\left(V_{i e}(x, y)\right)
$$

which is shown by the "50/50" diamond node in Figure 2.1. If the incumbent's policy is a best response to the entrant's, then the following inequalities must hold:

$$
\begin{aligned}
V_{i}(x, y) & \geq V_{i e}(x, y) \\
V_{i}(x, y) & \geq \frac{1}{2}\left(V_{i i}(x, y)\right)+\frac{1}{2}\left(V_{i e}(x, y)\right) \\
0 & =\left[V_{i}(x, y)-V_{i e}(x, y)\right] \cdot\left[V_{i}(x, y)-\left(\frac{1}{2}\left(V_{i i}(x, y)\right)+\frac{1}{2}\left(V_{i e}(x, y)\right)\right)\right] .
\end{aligned}
$$

Either the first or second condition will hold with equality which is described by the bottom condition.

We also need to consider the incumbent's problem at grid points where the entrant decides to not try and build the innovative technology such that they remain in Block (1). If the incumbent does not attempt to build the innovative technology, then its payoff is determined by the partial differential equation $\mathcal{L} V_{i}=0$ in which the non-homogeneous term is $\Pi_{1}$ as shown in Block (1). In contrast, if the incumbent attempts to build the innovative technology then its payoff equals $V_{i i}(x, y)$ with the relevant cash flows in Block (2) of Figure 2.1. Therefore, the

\footnotetext{
${ }^{16}$ This is the equally-weighted average of the incumbent's payoff if it is able to invest and its payoff if the entrant is able to invest instead.
} 
following inequalities must hold if the incumbent's policy is a best response to the entrant's:

$$
\begin{aligned}
\mathcal{L} V_{i} & \leq 0 \\
V_{i}(x, y) & \geq V_{i i}(x, y)-I
\end{aligned}
$$

with one or the other holding with equality at each grid point.

We calculate each firm's best response by solving systems of variational inequalities. This involves specifying an initial estimate of a firm's value function at each grid point and then cycling through the grid, updating the estimate of the value function one grid point at a time, until the value function converges. The updating formula differs according to whether or not the other firm is trying to build the innovative asset at that particular grid point. ${ }^{17}$

\subsubsection{Entrant's Best Response with Strategic Interaction}

The entrant's best response to the incumbent's policy can be calculated similarly. That is, we specify an initial estimate of the entrant's value function at each grid point and then cycle through the grid, updating the estimate of the value function one grid point at a time, until the value function converges. The updating formula differs according to whether or not the incumbent is trying to build the innovative technology at that particular grid point. If the incumbent is trying to build the innovative technology, then our updated estimate of $V_{e}(x, y)$ is the maximum of $V_{e i}(x, y)$ and

$$
\frac{1}{2}\left(V_{e e}(x, y)\right)+\frac{1}{2}\left(V_{e i}(x, y)\right) .
$$

If the incumbent is not trying to build any new capacity immediately, then our updated estimate of $V_{e}(x, y)$ is the maximum of the solution to $\mathcal{L} V_{e}=0$ and $V_{e e}(x, y)$.

\subsubsection{Spin-Off's Best Response with Strategic Interaction}

In the skunkworks approach, we have to consider the spin-off's best response to the entrant's policy. As before, we start with an initial estimate of the spin-off's value function at each grid point and then cycle through the grid until there is convergence of the value function. If the

\footnotetext{
${ }^{17}$ We impose the numerical boundary conditions $V\left(x_{j n+1}, y_{j}\right)=2 V\left(x_{j n}, y_{j}\right)-V\left(x_{j n-1}, y_{j}\right)$ at the right-hand grid point, $\left(x_{j n+1}, y_{j}\right)$ and $V\left(x_{j}, y_{j n+1}\right)=2 V\left(x_{j}, y_{j n+1}\right)-V\left(x_{j}, y_{j n-1}\right)$ at the left-hand grid point, $\left(x_{j}, y_{j n+1}\right)$.
} 
entrant attempts to invest in the factory that will produce the innovative product, then our updated estimate of $V_{s}(x, y)$ is the maximum of $V_{s e}(x, y)$ and

$$
\frac{1}{2}\left(V_{s s}(x, y)\right)+\frac{1}{2}\left(V_{s e}(x, y)\right)
$$

where $V_{s e}(x, y)=0$. If the entrant does not try to build any new capacity immediately, then our updated estimate of $V_{s}(x, y)$ is the maximum of the solution to $\mathcal{L} V_{s}=0$ and $V_{s s}(x, y)$.

\subsection{Markov Perfect Equilibria}

Similar to Carlson et al. (2014) and Pawlina and Kort (2006) we find three Markov-perfect equilibria that exist in our model. We assume that once a firm has invested in the innovation by exercising the growth option this opportunity is no longer available to other competitors. Should both firms attempt to invest simultaneously in the innovation, only one firm will successfully invest with a probability of $50 \%$ while the other firm misses out. We therefore agree with both Carlson et al. (2014) and Pawlina and Kort (2006) that a random equilibrium exists, but only one firm expands and receives the innovation rather than both.

Our second Markov-perfect equilibrium is the preemptive leader-follower equilibrium where the leader is chosen in advance by its ability to invest just before its competitor. For instance the entrant will seek to invest when their preemption payoff is non-negative. The incumbent will attempt to exercise their growth option just before the threat of the entrant preempting them is realised. The entrant will be a threat to the incumbent when they can profitably attempt to invest in the growth option. We find this equilibrium to be the most common and will feature prominently in this thesis.

Our final equilibrium refers to the nonpreemptive leader-follower equilibrium where the leader is determined endogenously before the game begins. This equilibrium is found when conditions and parameters are set such that only one participant will ever exercise the growth option and so the decision to invest is not influenced by the threat of preemption. In Carlson et al. (2014) the endogenously chosen leader for this Markov-perfect equilibria is followed by their competitor, but this is not allowed in our model as subsequent investment in the growth option is not possible. Following results from our baseline chapter, we will look at comparative 
statics to determine when a nonpreemptive equilibrium would occur and for what parameter changes.

Carlson et al. (2014) find a fourth Markov-perfect equilibria which is the simultaneous leader-follower equilibrium. We only allow one firm to expand and produce the innovation, not both, and so this equilibrium is not referenced in our research.

\subsection{Expected Rate of Return}

We calculate systematic risk, which cannot be diversified away, in terms of elasticities of the firms' value functions. These are measures of the relative sensitivity of the different firms' values to changes in the economic variables of $x$ and $y$. As shown by Guthrie (2011) the expected rate of return from owning a firm that satisfies Equation (2.6) equals

$$
\begin{aligned}
E[\tilde{r}]=\frac{1}{V}\left(\Pi_{a}+\frac{E[d V]}{d t}\right) & =\frac{1}{V}\left(\Pi_{a}+\mu_{x} x V_{x}+\mu_{y} y V_{y}+\frac{1}{2} \sigma_{x}^{2} x^{2} V_{x x}+\rho_{x y} \sigma_{x} \sigma_{y} x y V_{x y}+\frac{1}{2} \sigma_{y}^{2} y^{2} V_{y y}\right) \\
& =r+\lambda_{x} \frac{V_{x}}{V} x+\lambda_{y} \frac{V_{y}}{V} y .
\end{aligned}
$$

Equation (2.13) shows that the expected rate of return is equal to the risk free rate plus the elasticities of the firm value with respect to the demand drivers $x$ and $y$ which are multiplied by their respective $\lambda$ 's. We will only show the expected rate of return in the waiting region as a return over $d t$ units of time does make sense in the stopping region as stopping is instantaneous. In the stopping region the event of investing happens instantaneously which means $d t$ is not a factor. It can therefore only be defined in the region of waiting and for all other events it will be declared a null value. 


\section{Firm Behaviour with Disruption}

\begin{tabular}{cccccccc}
\hline$\mu_{x}=\mu_{y}$ & $\lambda_{x}=\lambda_{y}$ & $\sigma_{x}=\sigma_{y}$ & $\rho_{x y}$ & $\rho_{x}$ & $\rho_{y}$ & $\delta$ & $c_{2}^{i}=c_{2}^{s}$ \\
\hline 0.02 & 0.05 & 0.2 & -0.5 & 0.7 & 0.8 & 0.5 & 0.8 \\
\hline
\end{tabular}

In this chapter, we aim to determine whether the incumbent is better off abandoning, internalising or spinning off the growth option. Analysing this behaviour will allow us to determine the optimal business structure for the incumbent to effectively compete against the entrant and minimise the effects of disruption. We first look at the investment-timing problem of the participants for the different market structures and number of "loyal" consumers. We then look at the decomposition of the incumbent to determine the effect preemption has on its assets-inplace and growth option. To finish the chapter we look at the expected rate of return in the continuation region for all participants. We explore this behaviour in greater detail in Chapter 4 which focuses on varying the characteristics of disruption to determine the robustness of our findings in this chapter.

The above table gives an explanation of the parameter values used in this chapter. The first four columns are for parameters that feature in the risk neutral processes for $x$ and $y$. For our baseline case we set the expected growth rates, volatilities and risk premiums of $x$ and $y$ equal to each other. The $\rho_{x y}$ shows that there is a negative correlation between the number of "loyal" and "fickle" consumers.

The $\rho$ values are parameters of the elasticity of substitution for the number of "loyal" and "fickle" consumers in the market. At these values the elasticities of substitution for "loyal" and "fickle" consumers are 3.33 and 5 respectively. "Fickle" consumers receive their name from having a higher elasticity of substitution than "loyal" consumers, so that they more readily 
switch between substitute products. As both elasticities exceed 1, they are considered elastic such that a small change in price of substitute goods causes a higher change in the quantity demanded and vice versa. The "fickle" consumers will have a higher propensity to transition to the innovative product, but this does not mean the "loyal" consumers will remain with the existing product. The "loyal" consumers require a more significant change in the price of the substitute good, relative to "fickle" consumers, before transitioning to the same extent.

The $\delta$ value shows the intensity of consumer spending on the existing product in the market with the intensity of the innovative product being $1-\delta$. In our baseline case, consumers readily spend their income equally between the existing product and the innovation such that neither product has a clear and dominant market position over the other. The final column shows the production cost for the innovative product. In our baseline case we say that the internalised incumbent can produce the innovative product at the same cost as the entrant (and hence the spin-off). This is done to focus on the comparison between the integration and skunkworks approaches and to determine the optimal strategy.

\subsection{Investment Problem}

In our model we present four market structures; best case, pure disruption, integration and skunkworks. In each of these market structures the number of participants and holders of the growth option varies.

In the best case structure the incumbent maximises their value without threat of preemption from the entrant. The entrant has effectively abandoned the growth option and can never enter the market again. For pure disruption we consider the situation when the incumbent has effectively abandoned the growth option and only the entrant is an active participant in the market. The entrant does not face a preemption threat from the incumbent and so, as in the best case scenario, it is merely a waiting game. The value maximisation and policy problems encountered by market participants in the above structures did not need to take into account the threat of preemption, which only arises when there is more than one market participant that holds the growth option. An integrated incumbent is subject to the threat of preemption as they compete over the rights for the growth option with the entrant. The incumbent can also create a spinoff that competes with the entrant over who holds the growth option. This is 
Figure 3.1: Preemption Payoffs and Thresholds

$X=20$

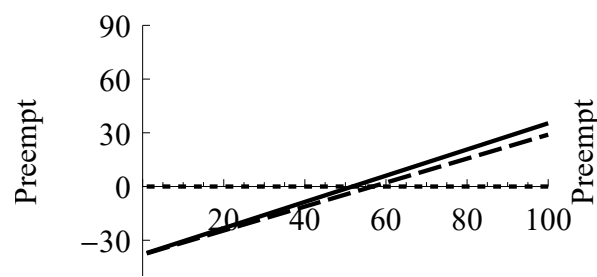

Fickle Customers (y)

$$
X=50
$$

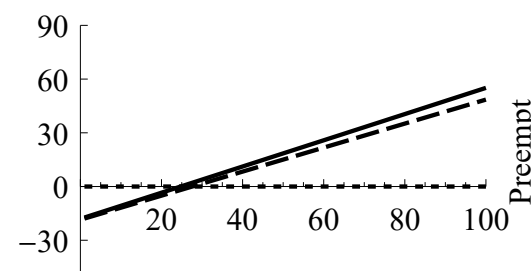

Fickle Customers (y)
$\mathrm{X}=100$

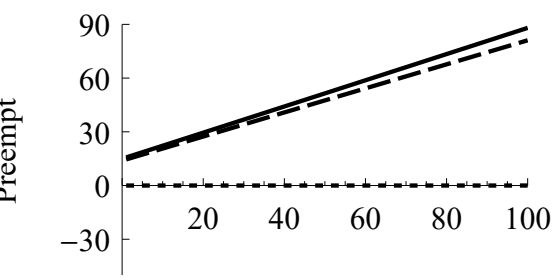

Fickle Customers (y)

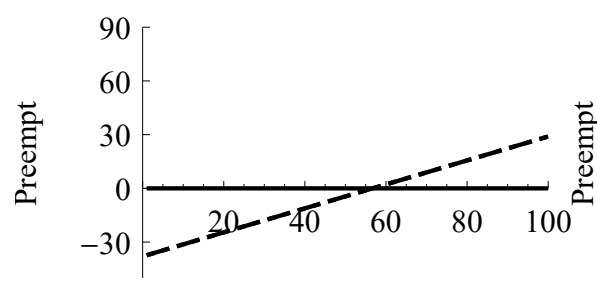

Fickle Customers (y)

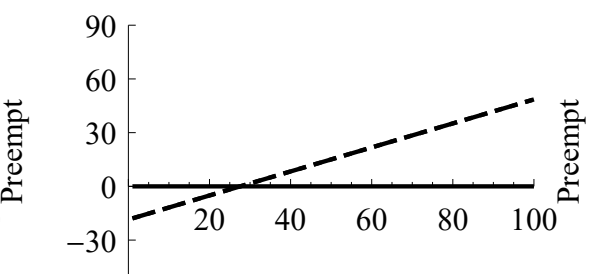

Fickle Customers (y)

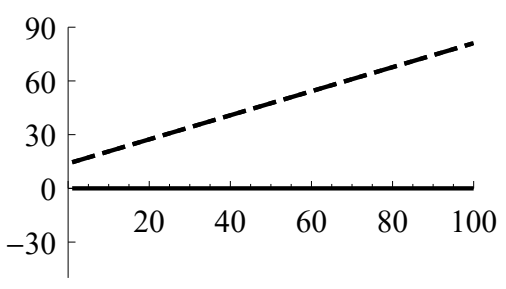

Fickle Customers (y)

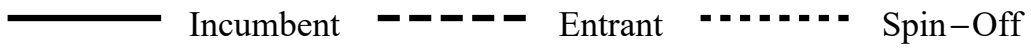

The preemption payoffs for the incumbent, entrant and spin-off are plotted against the number of "fickle" consumers, $y$, for different levels of "loyal" consumers, $x$, in the market. The top row focuses on competition between the incumbent and entrant, while the bottom row looks at when the spin-off and entrant compete over the growth option. When the preemption payoff reaches the horizontal axis, the firm, from that value of $y$, can profitably preempt their competitor and invest in the growth option.

similar to the pure disruption example, but the entrant is now subject to a binding preemption constraint as it competes against the spin-off over ownership of the innovation.

\subsubsection{Preemption payoffs}

Figure 3.1 allows us to explore preemption behaviour by displaying the difference between the leader and follower payoffs. From the difference of these two payoffs we can determine the preemption thresholds when there is a binding preemption constraint. We define the preemption payoff as the follower payoff deducted from the leader payoff. A firm will find it possible to profitably exercise their growth option when their leader payoff exceeds their follower payoff. 
Table 3.1: Preemption Thresholds and the Profitability of Pure Disruption Baseline Case

\begin{tabular}{ccccccc}
\hline & \multicolumn{3}{c}{ Preemption Threshold } & & \multicolumn{2}{c}{ One-Off Intersection } \\
\cline { 2 - 3 } \cline { 6 - 6 }$x$ & $y_{i}^{*}$ & $y_{e}^{*}$ & $y_{s}^{*}$ & & $y_{\text {int }}$ & $y_{s k}$ \\
\hline 20 & 51.73 & 56.70 & 56.70 & & 70.39 & 75.00 \\
30 & 42.73 & 46.97 & 46.97 & & 58.04 & 62.27 \\
50 & 24.72 & 27.58 & 27.58 & & 37.50 & 40.00 \\
70 & 6.65 & 8.26 & 8.26 & & 21.13 & 25.00 \\
100 & - & - & - & - & - \\
\hline
\end{tabular}

1. The preemption threshold looks at the level of $y$ for which the incumbent, entrant, and spin-off finds it profitable to preempt their competitors

2. The one-off intersection considers the highest $y$ value for which the market value of the incumbent in the pure disruption structure exceeds those in the integration and skunkworks scenarios.

Using our notation, the preemption payoff of the incumbent can be written as

$$
V_{i i}(x, y)-V_{i e}(x, y)
$$

and for the entrant equals

$$
V_{e e}(x, y)-V_{e i}(x, y)
$$

where $V_{e i}(x, y)=0$ as the entrant receives no value as a follower. ${ }^{1}$ The preemption threshold is the smallest $y$ value where the preemption payoff is greater than or equal to 0 . The graphs in Figure 3.1 plot these payoffs as functions of $y$, for the levels of $x$ indicated at the head of each column. The solid curve shows the preemption payoff for the incumbent in integration while the dashed and dotted curves are for the entrant and spin-off respectively when they are subject to a binding preemption constraint. Figure 3.1 does not display preemption payoffs for when there is only one firm in the market that can exercise the growth option. For instance, in the best case scenario the incumbent can only ever be a leader whereas in pure disruption it can only have a follower payoff. In integration the incumbent and entrant seek to preempt each other with both delaying until their leader payoff exceeds their follower payoff. In the skunkworks case the leader and follower payoffs are reserved for the spinoff and new entrant while the incumbent can only receive a follower's payoff similar to pure disruption.

\footnotetext{
${ }^{1}$ In our model, as the spin-off is identical to the entrant, $V_{i e}(x, y)=V_{i s}(x, y)$ and $V_{e i}(x, y)=V_{s i}(x, y)$. We specify this to show the entrant and spin-off have identical leader and follower payoffs such that they have the same preemption threshold.
} 
The top row of graphs in Figure 3.1 plot the preemption payoffs for the incumbent in order to determine when it will be profitable to preempt the entrant and secure the growth option. We can find this preemption threshold in Table 3.1 which provides the numerical results displayed in Figure 3.1. In this table the incumbent's preemption threshold is given by $y_{i}^{*}$ while the entrant and spin-off are denoted by $y_{e}^{*}$ and $y_{s}^{*}$ respectively. For instance, at $x=20$, the incumbent can profitably invest in the growth option when $y \geq 51.73$. However, rather than immediately investing at that value of $y$ they can delay investing until just before $y=56.70$ which is the entrant's preemption threshold. At this point it will be more profitable for the incumbent to be the leader, relative to their preemption threshold, in the market and they can still invest just before the entrant. There is no way the entrant can profitably preempt the incumbent in this baseline case. As the incumbent has internalised the assets-in-place and the growth option the incumbent is concerned with maximising their combined value. There is more to lose for the incumbent than the entrant, as if they fail to invest then they not only lose the rights to the innovation, but may also subject the assets-in place to a higher cannibalization rate. This creates a greater urgency for the incumbent to preempt the entrant.

The bottom row of Figure 3.1 plots the preemption payoffs for the entrant against the number of "fickle" consumers in the market. The graphs in this row show that regardless of the level of $x$, the spin-off will simultaneously attempt investment alongside the entrant. Both firms find it profitable to attempt to invest in the growth option for the same value of $y$. The entrant and spin-off are aware that should they fail in entering the market then they receive no value. As neither can afford to delay they attempt investment simultaneously and rely on a $50 \%$ chance that they will successfully invest in the growth option. For them, the importance of "fickle" consumers cannot be understated as their market value is completely reliant on consumers transitioning away from the existing product to the new innovative product. The "fickle" consumers are those that more readily transition between products relative to "loyal" consumers who switch at a slower rate. These "fickle" consumers drive the value of the growth option which is the only asset the entrant and skunkworks derive market value from. They will wait until there are enough consumers in the market who have a greater propensity to switch from the existing product to the innovation before committing to investment. The incumbent already receives value from "loyal" and "fickle" consumers from their assets-in-place, and seeks 
Figure 3.2: Value of Market Participants for Different Business Structures
$\mathrm{X}=20$
$\mathrm{X}=50$
$X=100$
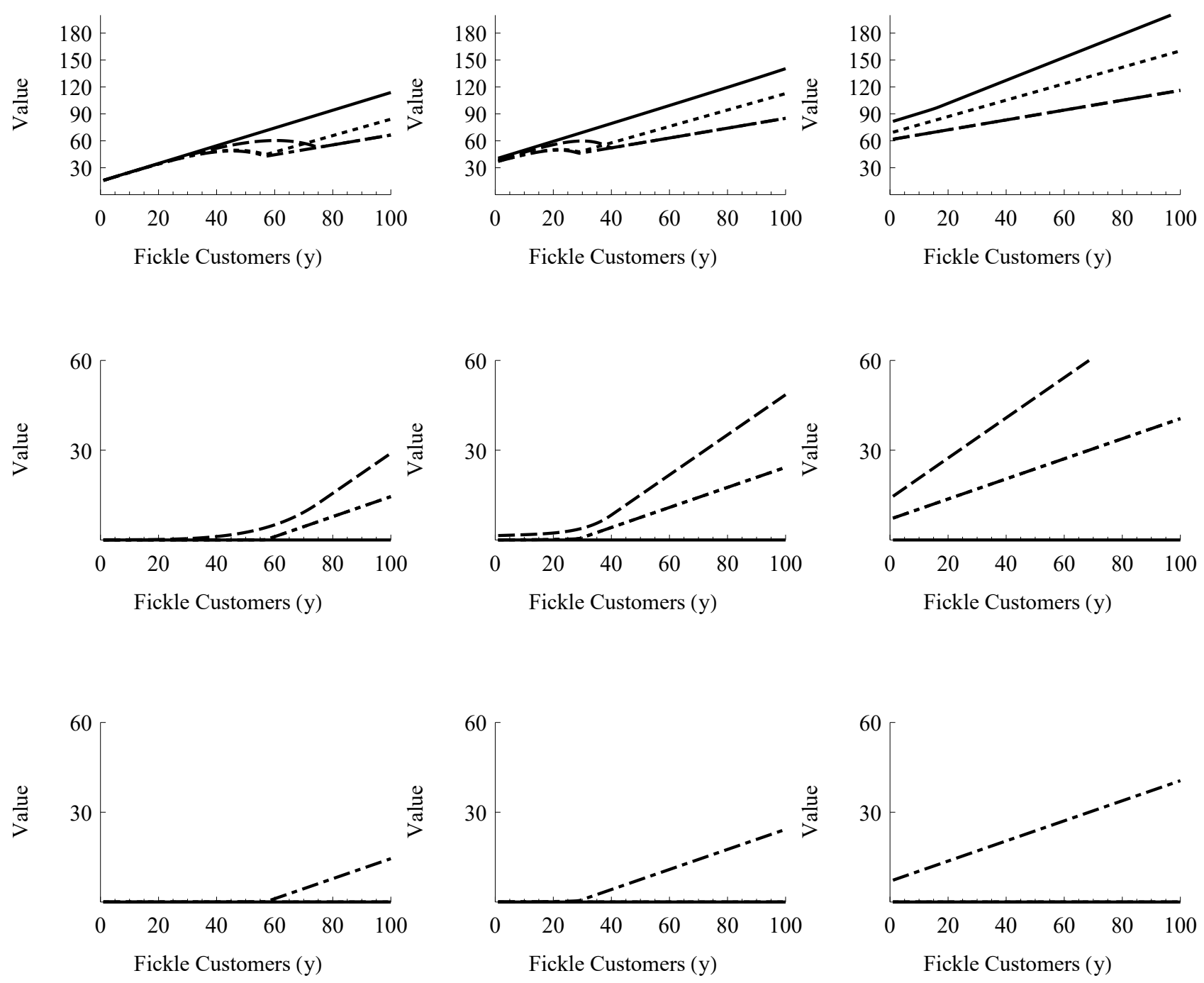

Best case

Pure disruption

Skunkworks

Market values for the incumbent, entrant and spin-off are plotted against the number of "fickle" consumers, $y$, for different numbers of "loyal" consumers in the market. The top row shows the values for the incumbent, followed by the entrant and spin-off respectively. The values shown depend on the market structure.

to retain these customers for as long as possible. Should they invest then this is not a problem as they remain a monopolist and lock out their competitors indefinitely.

When $x$ is low the firms require a greater number of "fickle" consumers in order to be profitable in their attempt at successfully investing in the innovation. As the number of "loyal" consumers rise in the market, the firms require fewer "fickle" consumers to profitably invest. When we reach $x=100$ in Table 3.1, all participating firms find it profitable to immediately, 
and simultaneously, invest in the growth option, regardless of the number of "fickle" consumers. As the number of "loyal" consumers rises in the market the importance and relevance of the "fickle" consumers diminishes. Market participants place more value on "loyal" consumers as they are less likely to switch to a competitor's product. When $x$ is low firms require a greater number of "fickle" consumers to induce investment. They cannot afford to delay indefinitely as the preemption constraint is binding, so we still have a trigger point of $y^{*}$ when investment will occur. Firms are willing to wait for longer in the hope that either $x$ or $y$ rises. Consumer numbers rising shows that the market is in an upturn, so even if loyal consumer numbers remain fixed, rising $y$ will eventually result in investment by a market participant.

\subsubsection{Market values}

Figure 3.2 compares the market values for all market participants across the different possible business structures for varying levels of $x$. The incumbent's results are displayed in the first row. The concave nature of the value function for the incumbent reflects the existence of bad news that will negatively impact their business. In our model this news is that the innovation is becoming more appealing and the growth option will soon be exercised by either the incumbent or its competitor. The incumbent in the best case scenario (solid curve) has the highest value for all levels of $x$ and $y$ relative to the other market structures. This makes sense as the incumbent's choice of investment threshold is not constrained by a preemption threat. In the pure disruption model (dashed curve) the incumbent takes on a passive role in the market and is not a preemptive threat to the entrant. This means that the entrant can delay as long as it needs to before it reaches its optimal investment threshold. As a result of the incumbent not being able to preempt the entrant, the entrant waits for a higher $y$ value before investing in the innovation. This provides a benefit to the incumbent as by removing themselves from contention the entrant will wait longer to exercise their growth option than if they were under the threat of preemption.

The integration case (dotted curve) introduces the possibility of preemption by either the incumbent or entrant so that it is no longer feasible for either participant to delay as long as necessary for their optimal investment threshold. Because the incumbent can exercise the growth option, the entrant feels threatened by the idea that the incumbent could invest just 
before them. This compared with the pure disruption case shows how the threat of preemption can lower the value of firms as a result of bringing the investment threshold forward to where it is less than optimal. By not having the growth option to exercise in the pure disruption case, the incumbent preserves greater value over $y$ than in other market structures. This is shown in Figure 3.2 where the solution for the market value of the incumbent in pure disruption is only second to the monopolist example until a certain value of $y$ displayed in Table 3.1. For instance when $x=20$, the market value of the incumbent in pure disruption will be greater than the market value for the same firm in integration when $y<70.39$. As $x$ rises this intersection point occurs at a lower number of "fickle" consumers, showing that as the demand drivers experience a market upturn, the growth option becomes more valuable and likely to be exercised rather than abandoned.

When a spin-off is introduced (dash-dotted curve), it competes with the entrant over the right to solely invest in the innovation. The incumbent no longer has the power to preemptively invest, similar to the pure disruption model. As the spinoff is identical to the entrant, the investment threshold reaches a low enough $y$ that the optimal policy of both firms is to simultaneously attempt to invest, leading to a 50/50 chance of successful investment for either firm. The incumbent's value is solely derived from assets-in-place and, as they have no rights for the growth option, the value of the incumbent falls below the integration value. When the optimal stopping region is reached in pure disruption, the value of the incumbent is the same in the skunkworks model. The only difference between these two scenarios is that with a binding preemption constraint (skunkworks), the entrant and is compelled to invest in the growth option at a lower number of "fickle" consumers. This is detrimental to the incumbent's value as their assets-in-place are heavily cannibalized for a lower value of $y$ than if there was no binding preemption constraint.

The second and third rows of Figure 3.2 show the entrant and spin-off values respectively. The convex nature of the payoff curves means that approaching the investment threshold presents good news to both the entrant and spin-off. When there is no binding preemption constraint in the pure disruption case, we see the entrant receives greater value as they can delay until the optimal investment threshold is reached. In the skunkworks scenario, both the entrant and spin-off will attempt to simultaneously invest in the growth option so that only one 
Figure 3.3: Value in Delaying the Exercising of the Growth Option
$X=20$
$X=50$
$X=100$

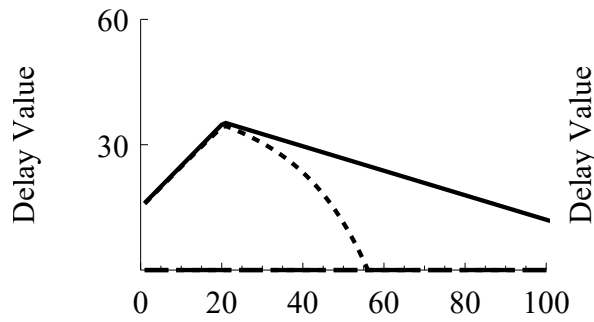

Fickle Customers (y)

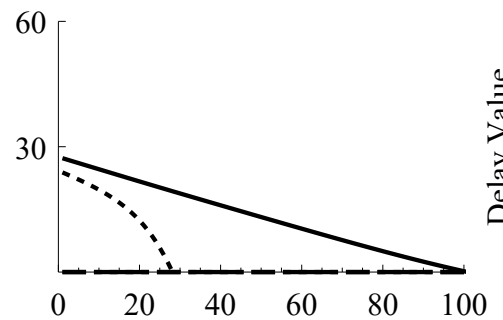

Fickle Customers (y)

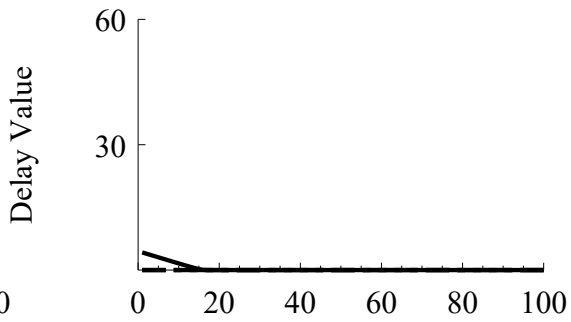

Fickle Customers (y)

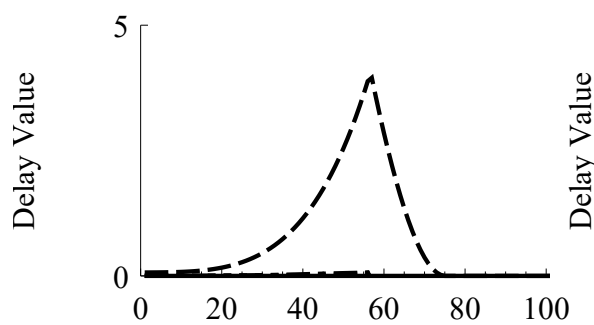

Fickle Customers (y)

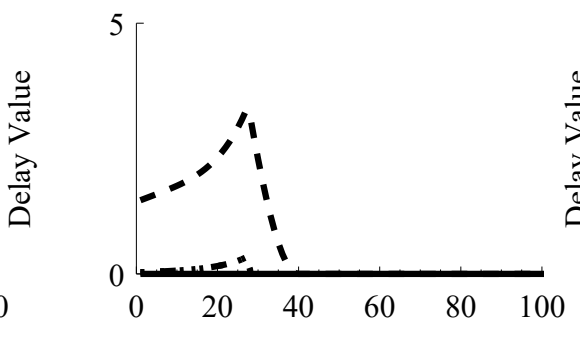

Fickle Customers (y)

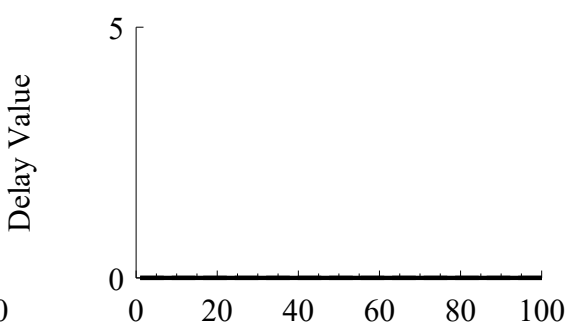

Fickle Customers (y)
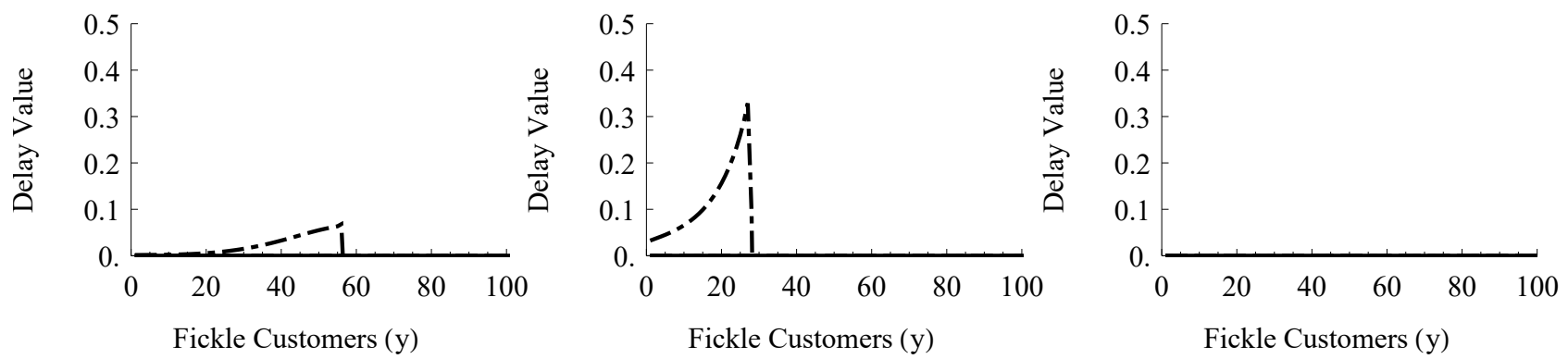

Best case

Pure disruption

The value of delaying exercising the growth option is plotted against $y$ for different values of the number of "loyal" consumers, $x$. The top row displays graphs for the incumbent, while the second and third row are for the entrant and spin-off respectively. We can determine this value using dynamic real options analysis. This value is the difference between our calculation of firm market value minus the value of a now-or-never option to invest.

of them will control the innovation. There is no ability for the spin-off or the entrant to collude in this market to share the market surplus created by the growth option. The final row of Figure 3.2 reflects how the spin-off's value, in the skunkworks structure, is identical to the entrant's, and that by existing they reduce the entrant's value through the threat of preemption. There is no intersection to consider for the entrant as their firm value in pure disruption will always 
exceed that found in either integration and skunkworks. As $y$ increases, the market value for the entrant in the integration and skunkworks cases are nearly equal. In the integration case the incumbent will preempt the entrant while in the skunkworks case the spin-off and entrant will attempt to invest simultaneously with a random winner being decided. They will attempt to invest simultaneously such that their market value is

$$
\frac{1}{2}\left(V_{e e}(x, y)\right)+\frac{1}{2}\left(V_{e i}(x, y)\right)
$$

where $V_{e i}(x, y)=V_{e s}(x, y)=0$. Regardless of whether the entrant is in an integration or skunkworks market structure their preemption payoff is the same, meaning that the market value of the entrant in the optimal stopping region will be the same. The pure disruption curve for the entrant is the solution for a call option, as expected with no competition or preemption impact. $^{2}$

\subsubsection{Real options analysis compared to static models}

Figure 3.3 reports the value of the option to delay investment by looking at the difference between a firm's market value, calculated using real options analysis, and the value of the firm if it had a "now-or-never" investment option. Whenever this difference is positive, there is value in delaying as opposed to immediately investing in the innovation. The first row of Figure 3.3 shows the delay option's value for the incumbent in the best case and integration examples where they have the right to exercise the growth option. The best case scenario for higher values of $y$ clearly shows more value in delaying than in the integration case. In the best case scenario the incumbent can delay as long as it desires until their optimal investment threshold is reached due to the lack of a binding preemption constraint. This is shown when $x=20$ where the value in delaying always exceeds the value received should the incumbent attempt to immediately invest. The preemption constraint is not binding in this scenario which explains why the value of delaying is much higher than for the integration case. When $x=100$,

\footnotetext{
${ }^{2}$ When looking at the entrant's curve in the skunkworks structure, the rigidity (i.e. lack of smoothness) points to a now-or-never option perspective. This makes sense as with identical preemption thresholds, logic points to a random Markov-perfect equilibrium where both participants invest with a shared $50 \%$ probability of success.
} 
the incumbent in the best case scenario is the only market participant who receives more value from delaying, rather than immediately investing, if only for low values of $y$.

With preemptive investment being made possible in the integration case, there is no value in delaying for high values of $y$. Competition creates urgency in the market so that firms hasten their attempts to invest in the growth option and be the only provider of the innovative product. We see this in Figure 3.3 where the value of delaying for the incumbent in the integration case drops to zero more suddenly than in the best case scenario. In these cases where the preemption constraint is binding, as $x$ rises, the value in delaying investment diminishes as it becomes more likely that the entrant will seek to invest and preempt the incumbent. The incumbent can afford to delay for a greater number of "fickle" consumers compared to the entrant as seen by the preeemption payoffs in Figure 3.1.

The second row of Figure 3.3, which plots the entrant's option to delay value, shows us that the entrant finds the most value in delaying when they have no binding preemption constraint in the pure disruption model. In other industry structures where the entrant holds the growth option, the value in delaying is positive but near zero and hence cannot be viewed in Figure 3.3. This makes sense, as in Figure 3.1 we saw that the entrant's preemption threshold occurred at a higher $y$ relative to the incumbent. The entrant is aware that the incumbent can profitably invest just before them and sees no value in delaying investment for the integration structure. When the entrant has no binding preemption constraint (pure disruption) there is no value in the option to delay when $x=100$. This is a different result to when it is the incumbent that does not have a binding preemption constraint. This introduces the idea that having assets-inplace increases the willingness for the incumbent firm to delay. They are forced to consider the trade-off, when they attempt to invest, between the value received by the growth option and value lost by cannibalization of assets-in-place. Should a firm possess no assets-in-place then their only concern is the growth option and the obvious cause of action when $y$ is suitably high is to immediately invest.

Finally, the third row of graphs shows the spin-off, who can attempt to invest in the skunkworks model. The value in delaying investment for the spin-off is the same as the entrant's because they are identical. As the spin-off is subject to a binding preemption constraint they find little value in delaying. Both the entrant and spin-off in the skunkworks set-up know 
that they will both find it profitable to attempt investment at the same time. According to Figure 3.1 they have the same preemption threshold and so with no value in delaying they will simultaneously invest with a $50 \%$ chance of success.

\subsection{Decomposed Value Comparison}

The market value of the incumbent, for the best case and integration structures, is a combination of the values for the assets-in-place and the growth option. We consider the effect preemption can have on the value of each component. By separating the assets-in-place and the growth option, we can determine the size of the cannibalization effect to see how investing can be detrimental to existing assets. If the incumbent refuses to internalise they can choose to delegate ownership and management of the growth option to an independent spin-off. We compare the values in this case to when the incumbent decides to internalise, which allows us to assess the benefits and costs of delegating rather than internalising.

\subsubsection{Cannibalization of Assets-in-Place}

It is not only the threat of preemption, but also the threat of disrupting assets-in-place that means the incumbent receives more value by delaying than the entrant does. By investing in the growth option, the successful firm will begin producing the innovative product which behaves as an imperfect substitute for the existing product. The incumbent's objective function, when it has the right to exercise the growth option, is to maximise the combined value of the assets-inplace and the growth option. There is a balance the incumbent must maintain where they seek to minimise the damage to assets-in-place while maximising the value of the growth option. We express this damage to assets-in-place as cannibalization which occurs when a new product is introduced that causes consumers to transition away from the existing product.

Cannibalization reflects the willingness of the incumbent to sacrifice part of its existing asset to ensure the growth of the new technology. It is unlikely a company would willingly cannibalize their entire asset-in-place until there were enough consumers more willing to transition from the existing product to the new product ( $y$ units of "fickle" consumers). Cannibalization can be found by looking at the value of the assets-in-place with and without investment. When we consider the best case scenario the incumbent does not invest to preempt, and in doing 
Figure 3.4: Cannibalization of Assets-in-Place
$X=20$
$X=50$
$X=100$
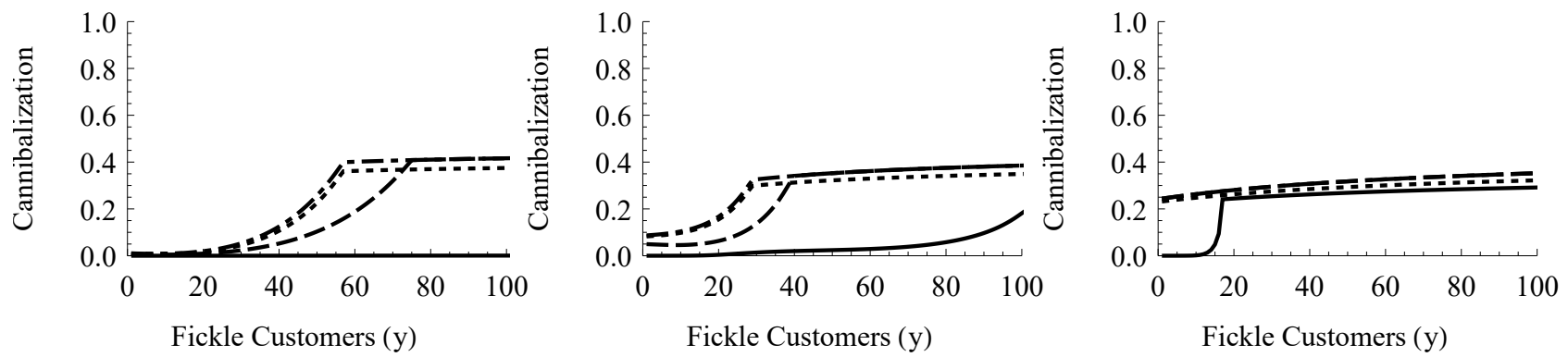

Best case

Pure disruption

Integration

Skunkworks

The rate of cannibalization is plotted against the number of "fickle" consumers in the market, $y$. The cannibalization rate reflects the loss in value of the assets-in-place by choosing to invest in the growth option rather than remaining as a monopoly. Cannibalization occurs in situations where there are binding preemption constraints (best case and pure disruption) and those where there are not (integration and skunkworks).

so, eliminate the competition, but to increase the total value of the firm. In this scenario the incumbent will wait until the value of the growth option exceeds the cannibalized value of the assets-in-place. With no binding preemption constraint, or competition, we would not expect to see the incumbent cannibalizing their assets-in-place until there is a sufficient number of "fickle" consumers in the market.

In order to calculate the ratio of cannibalization we decompose the value of the incumbent into the value of assets-in-place and the growth option. The cannibalization ratio is the decrease in value of the assets-in-place, with and without investing in the growth option. This is represented as a percentage and equals the present value loss in assets-in-place value because of successful investment divided by the present value of the assets-in-place without investment.

Figure 3.4 displays the cannibalization ratio for all market structures plotted against the number of "fickle" consumers in the market to show the effect of disruption on assets-in-place. If we first look at best case (the solid curve), when $x=20$ there is near-zero cannibalization of assets-in-place as there are not enough "fickle" consumers in the market to consider investing. When we reach $x=50$, the cannibalization ratio becomes apparent when there are a high number of "fickle" consumers in the market. At this level of "loyal" consumers, the value received by delaying investment begins to drop and immediately investing becomes more appealing to the 
incumbent. ${ }^{3}$ The cannibalization ratio is an increasing function of $y$ as with a greater number of "fickle" consumers, more customers in the market readily switch to the innovation resulting in the assets-in-place losing value. What we are doing is considering how the presence of an innovation affects the assets-in-place compared to when no innovation exists.

In Figure 3.4 we also consider the impact competition can have on the cannibalization ratio. Once again, the basis of these results is the difference in the value of assets-in-place depending on whether or not the innovation is present in the market. The pure disruption case (dashed curve) exposes the incumbent to a higher cannibalization rate than the best case for all values of $x$ and $y$. This is to be expected as the incumbent does not hold the growth option and so cannot preempt the entrant to try and minimise disruption of assets-in-place. The incumbent can only influence the price of the existing product in pure disruption to maximise the value of their assets-in-place. As more "fickle" consumers enter the market the cannibalization ratio for pure disruption rises sharply at the investment threshold, and continues to increase in the optimal stopping region. The cannibalization rates for pure disruption and skunkworks are the highest for the incumbent following successful investment by one of their competitors. In both these cases the incumbent cannot preempt their competitors.

As the number of "loyal" consumers $(x)$ increases, the cannibalization ratio tends to decrease for all industry structures. With a greater number of "loyal" consumers, more customers will have a lower propensity to switch to the innovative product meaning greater retention in the existing product's profit flows such that cannibalization is lower. With more loyal consumers in the market, entry will lead to a smaller reduction in profit, so that the effect of cannibalization becomes slightly smaller. At $x=100$, only the incumbent in best case does not attempt to immediately invest in the growth option as they still have value in delaying investment until a sufficient number of "fickle" consumers enter the market.

The integration case in Figure 3.4 (dotted curve) has the second lowest cannibalization post-investment, being only beaten by the best case scenario. By having the option to delay, as shown by Figure 3.3, the incumbent in integration is able to wait until just before the entrant will attempt to invest and preempt them. This practice of "self-disruption" has been explained in previous literature by Henderson and Clark (1990) and Gans (2016) who claim through

\footnotetext{
${ }^{3}$ We see this behaviour in Figure 3.3 where with more "loyal" consumers the incumbent becomes less inclined to delay.
} 
preemptive investment, incumbent firms are better protected from the effects of disruption. We find this to be true for when there are a higher number of "fickle" consumers in the market, but it is not always in the best interests of the assets-in-place to hasten the arrival of investment.

From Figure 3.4 we see potential in the incumbent committing to abandoning the growth option so the entrant to delay the arrival of the innovation. If the incumbent treated the pure disruption scenario as a one-off irreversible option to abandon the growth option there would be a benefit for the incumbent to exercise this option, until a certain $y$ value, to exercise this one-off option. This commitment delays the effect of cannibalization felt by the incumbent and should $y$ not exceed the thresholds found in Table 3.1, it will be in the incumbent's best interests to perpetually abandon the option. While the integration structure offers a lower plateau, the binding preemption constraint means the cannibalization effect is higher before the investment threshold than for those cases where the constraint is not binding.

Cannibalization occurs regardless of whether it is the incumbent or entrant that invests. It is clear that the incumbent has an incentive to preempt the entrant to avoid cannibalizing their assets-in-place more than necessary. Because of competition and preemption, the incumbent knows that it is unlikely they will ever get the chance to invest optimally so it only becomes a matter of determining for the earliest values of $y$ as to when the entrant will consider investing (when their preemption payoff becomes non-negative) and then investing just before.

\subsubsection{Incumbent Design}

How should the incumbent design their firm in such a way to maximise total firm value? By directly comparing the skunkworks and integration structures we can determine, from the incumbent's perspective, what the optimal business structure is.

We can first look at the comparison from an agency problem perspective. We have the spinoff (agent) which has been set up by the incumbent (principal) to solely manage the innovation to compete with the entrant. We define the agency problem as the decrease in the value of the incumbent as a result of creating a spin-off rather than internalising the growth option. Not only do we look at the overall market value loss, but we also consider the difference in values of the decomposed assets-in-place and the growth option depending on the incumbent's structure. 
Figure 3.5: Optimal Incumbent Design for Firm Value

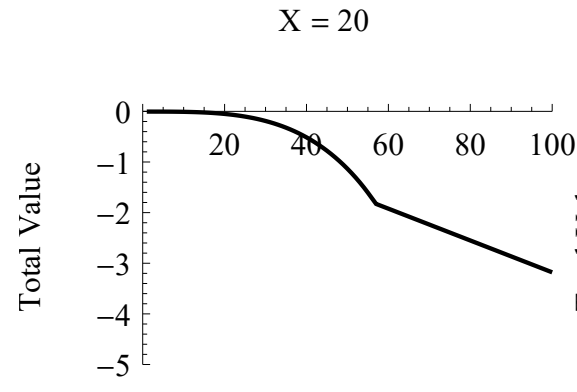

Fickle Customers (y)

$$
X=50
$$

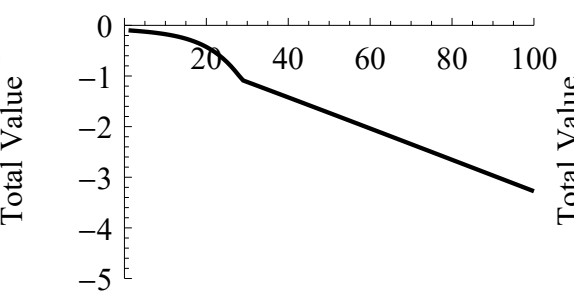

Fickle Customers (y)
$\mathrm{X}=100$

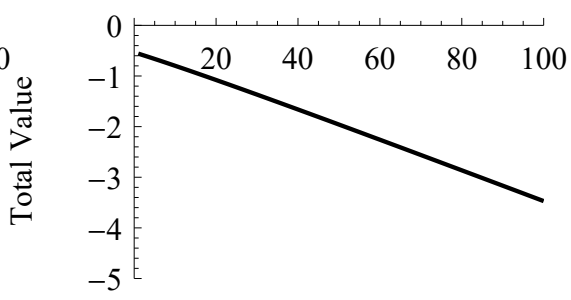

Fickle Customers (y)

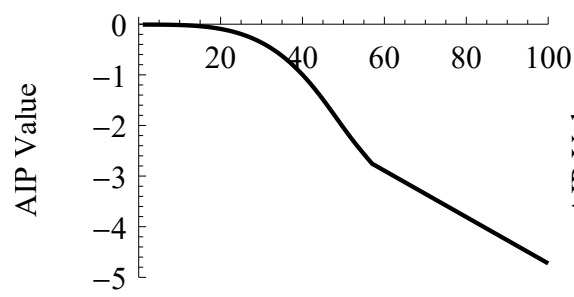

Fickle Customers (y)

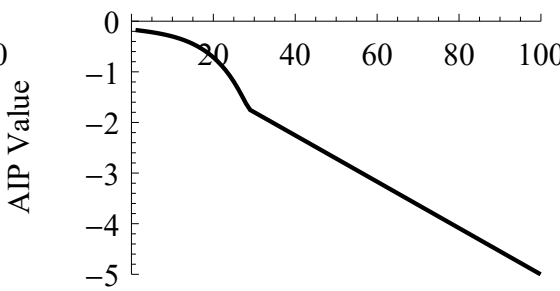

Fickle Customers (y)

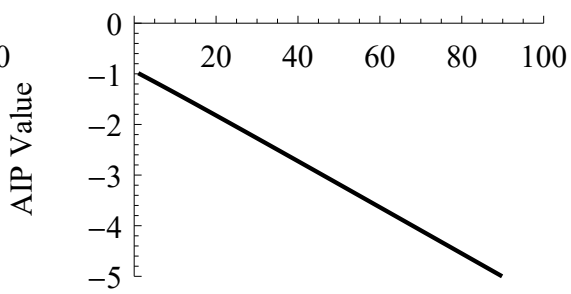

Fickle Customers (y)

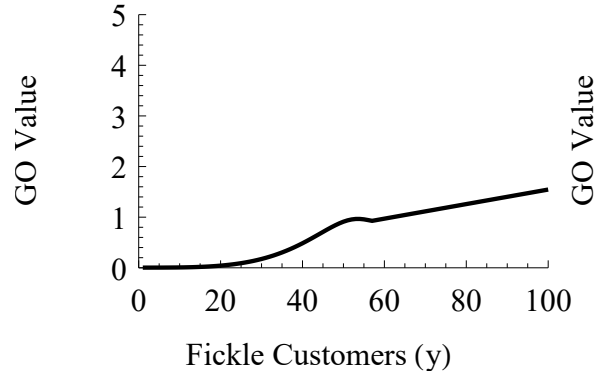

Fickle Customers (y)

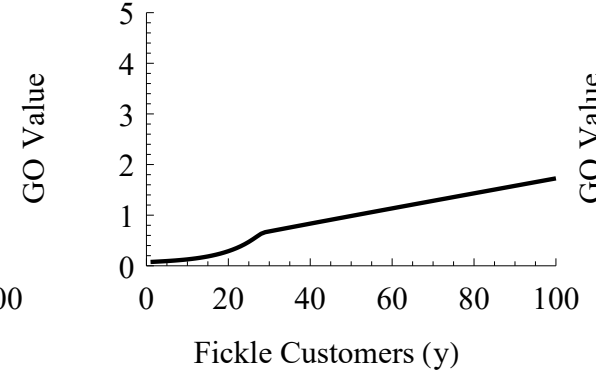

Fickle Customers (y)

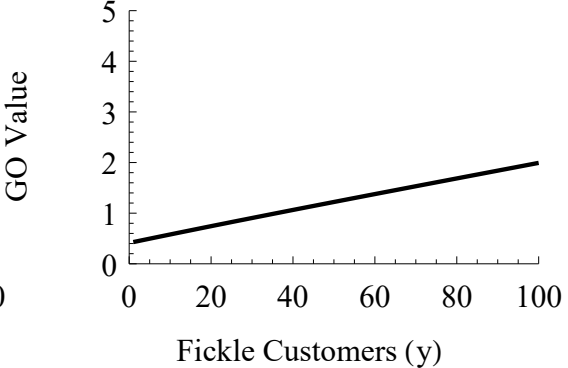

Fickle Customers (y)

Cost of Spin-Off

The difference in the incumbent's value between integration and skunkworks is plotted against the number of "fickle" consumers in the market, $y$ for different values of $x$. The top row looks at the total value of the internalised incumbent deducted from the combined value of the incumbent and its spin-off. The next row focuses on the difference in value of the assets-in-place depending on whether the incumbent decides to follow the integration or skunkworks structure. The final row looks at the change in value of the growth option value for the two structures.

In this instance we compare the value of the internalised incumbent with the spin-off variation to see how the decomposed assets are affected.

Figure 3.5 shows the agency problem that arises when the incumbent chooses a manager to focus on the innovation, allowing the incumbent firm to devote their resources to the assets- 
in-place. The top row plots the difference in market value for the incumbent to determine whether the integration or skunkworks structure provides the most value to the incumbent. The second and third row in Figure 3.5 shows the difference in value of the assets-in-place and growth option respectively between the integration and skunkworks structure. To ensure complete independence from the incumbent, the spin-off has the same demand function and production costs as the entrant. We take the solution for the combined value of the incumbent and spin-off in the skunkworks case and then subtract the market value of the incumbent in the integration case. This will determine the loss in value should a manager be chosen rather than an integrated approach.

The top row of Figure 3.5 shows that the incumbent's market value is greater when the assets-in-place and growth option are internalised than when they are managed separately. The difference in total value gets stronger as we increase $y$. The incumbent in integration makes preemptive investment decisions based on maximising the combination of assets-in-place and the growth option. In skunkworks, the spin-off makes their preemptive investment-timing decision based on maximising the value of the growth option. By ignoring the effect investment can have on the assets-in-place, the cannibalization effect is stronger in the skunkworks scenario and becomes more pronounced as the number of "fickle" consumers in the market rises and the firms move closer to the investment threshold. The incumbent maximises the growth option in both integration and skunkworks. The only difference is that in integration this is traded-off against the reduction in value of the assets-in-place. It is what makes a skunkworks structure useful that causes detriment to the incumbent, by ignoring the impact on the assets-in-place. This change in value occurs as we see the assets-in-place lose more value, as the number of "fickle" consumers increases, than is gained by the growth option.

The curvature of the line in all rows of Figure 3.5 represents the lead up to investment and the straight line shows where the incumbent is in the optimal stopping region. We use the second and third rows of Figure 3.5 to break down the effect the structure of a firm has on the values of the assets-in-place and the growth option respectively. As expected, the presence of a spin-off has a negative impact on the assets-in-place. The spin-off's objective is the innovation where they only receive value by preempting the entrant and investing. They are not concerned with protecting the value of the assets-in-place and their investment-timing decision is not hinged 
on being optimal for the assets-in-place. As a stark comparison to the other rows of Figure 3.5, the final row shows the spin-off maximises the value of the growth option more effectively than the incumbent in integration. It does this by displaying a positive difference such that the combined value of the incumbent and spin-off exceeds that of the internalised incumbent This is not a surprising result as their firm value is solely derived from maximising the growth option's value. This increase in value for the growth option, that the incumbent receives by creating a spin-off rather than internalising, is exceeded by the value lost for the assets-in-place resulting in a net loss for the incumbent.

At the very least this proves that by taking the skunkworks approach the growth option will benefit more than if it was integrated with the incumbent's assets-in-place. In terms of total firm value, the integration approach noticeably provides the incumbent with greater value relative to the spin off. An obvious solution would be to just internalise the growth option with the assets-in place and run an integrated business. This would ensure the objective function of the business is to maximise the overall value of the firm. The cost of integrating (new machinery and labour training hours) may be too much of a strain on the incumbent which we analyse in Chapter 4 using sensitivity analysis.

Rather than considering incumbent design from an agency problem perspective we could consider an "insurance put option" approach to mitigate disruption risk as raised by Gans (2016, Chapter 7). The incumbent, when they possess the growth option, is essentially paying the lump-sum capex plus the loss in value of the assets-in-place. In return they receive the value of the new facility. Gans (2016) considered the idea of an insurance put option where the incumbent sacrifices a portion of their assets-in-place to preempt their competitors and invest. The premium for this insurance is the loss in value of the assets-in-place. Rather than creating a spin-off to focus on the growth option, the incumbent can decide when to invest knowing that they do so to optimise the combined return for the assets-in-place and the growth option. Suppose we look at the preemption curves in Figure 3.1 for $x=50$. We see that by self-disrupting the incumbent has a preemption threshold of $y_{i}^{*}=24.72$ while the skunkworks can profitably preempt the entrant at $y_{s}^{*}=27.58$. The internalised incumbent can profitably preempt the entrant while the spin-off can only invest at the same time and have a $50 \%$ chance of success. Only the internalised incumbent can preemptively invest with the intention 
of preserving the existing assets' value. Suppose the value of cannibalization and lump-sum capex does not exceed the value of the growth option. Where would the benefit be then in effectively "selling" the cannibalized portion of the assets-in-place to receive the present value of the growth option? Rather than investing to receive the growth option present value, the incumbent is investing to protect and insure their assets-in-place. This is displayed in Figure 3.5 where the incumbent is able to retain greater value in their assets-in-place by being able to preempt than if they took a passive approach letting the spin-off compete in their stead.

We then question, from the incumbent's perspective, what is the best design approach to take? Both agency and "insurance put option" perspectives would agree that integration provides the most protection to assets-in-place and results in the lowest cannibalization. While the growth option does receive greater value by spinning off rather than internalising, this does not exceed the value of the assets-in-place that would be lost. The present value of the growth option is not enough to exceed the lump sum capex plus the loss in value of the assets-in-place by investing.

\subsection{Firm-level expected rate of return}

Risk features in our model through exposure to the demand drivers, $x$ and $y$. The returns for participating firms may be high or low, as a reflection of the systematic risk the firms are exposed to. The expected return provides an incentive to investors to invest and trade in the market. We use this section to determine exposure to risk at a firm level.

We recall the formula for the expected return as

$$
E[\tilde{r}]=r+\lambda_{x} \frac{V_{x}}{V} x+\lambda_{y} \frac{V_{y}}{V} y
$$

which shows the expected rate of return is a combination of the risk-free rate, $r$, plus the risk premiums for bearing $x$ - and $y$-risk. The way we have calculated the expected return means that we only analyse the continuation region for the market participants. ${ }^{4}$ From the elasticities of market values to changes in $x$ and $y$ and the risk free rate, $r$, we determine the expected return.

\footnotetext{
${ }^{4}$ The reason for this was outlined in Section 2.7 which highlighted the inappropriateness of $d t$ in the optimal stopping region.
} 
Figure 3.6: Firm-level Expected Rate of Return
$X=20$
$X=50$
$X=100$

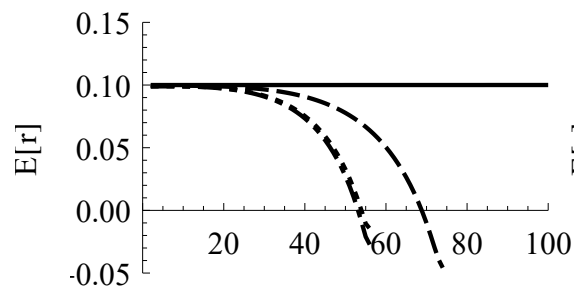

Fickle Customers (y)

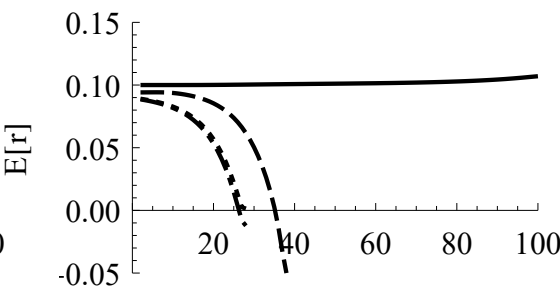

Fickle Customers (y)

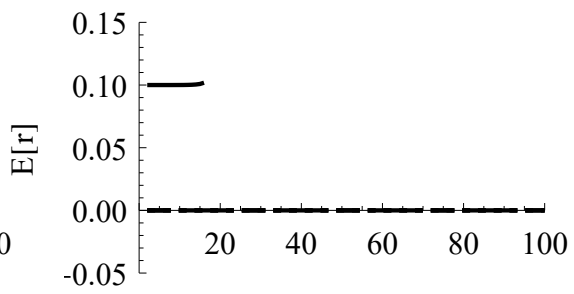

Fickle Customers (y)

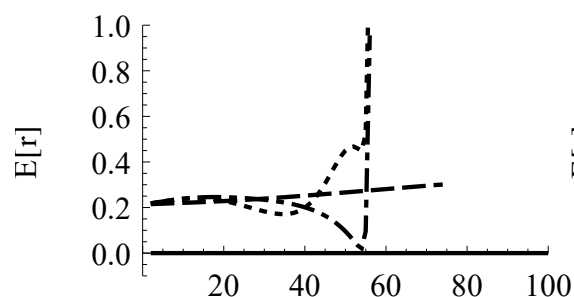

Fickle Customers (y)

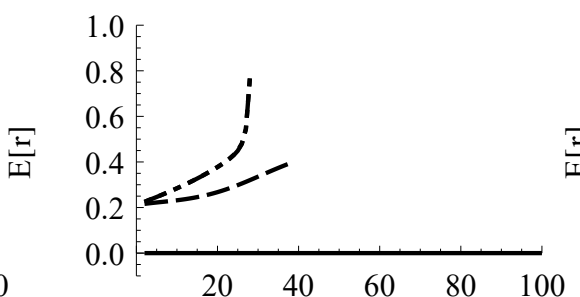

Fickle Customers (y)

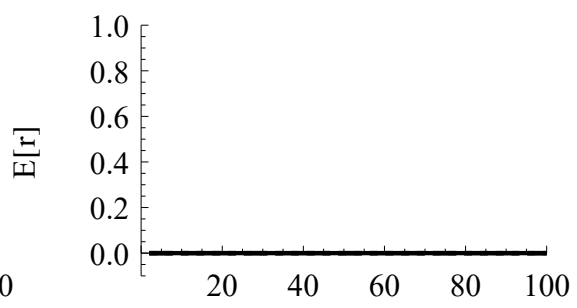

Fickle Customers (y)

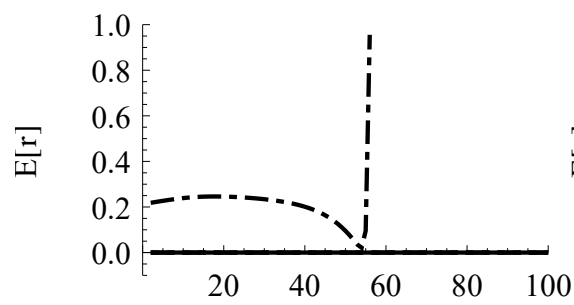

Fickle Customers (y)

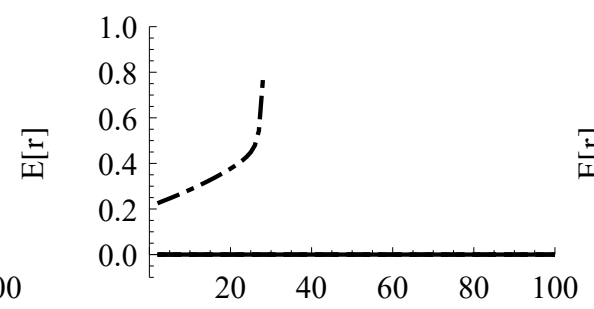

Fickle Customers (y)

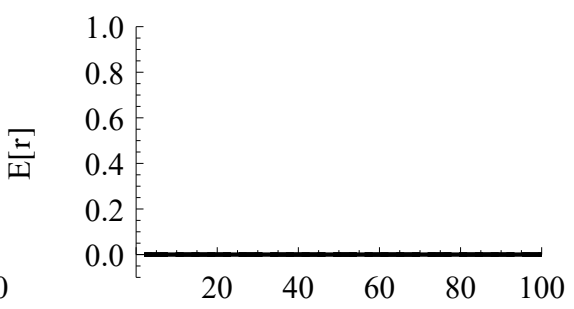

Fickle Customers (y)

The firm level expected return is plotted aginst the number of "fickle" customers, $y$, for different numbers of "loyal" consumers, $x$, in the market. The top row shows the incumbent's expected return for the four different market structure, while the next two rows are for the entrant and spin-off respectively.

Figure 3.6 compares the expected returns for firms across the different business structures plotted against the number of "fickle" consumers in the market for different numbers of loyal consumers, $x$, in the market. We start in the top row of graphs with the incumbent and consider the effect business structures, as well as the demand drivers $x$ and $y$, can have on the expected 
rate of return. In the best case scenario the expected return remains constant at $10 \%{ }^{5}$ The pure disruption model sees the expected return decreasing as more "fickle" consumers enter the market. The difference in this structure compared to the best case is that the incumbent can only change the output price, but otherwise has no way to protect the value of the assets-inplace from disruption. As more "fickle" consumers enter the market, and the growth option becomes more valuable for immediate exercising, the assets-in-place lose market value and are less exposed to $x$ - and $y$-risk. The integration and skunkworks structures have a binding preemption constraint with the only difference being whether the growth option is internalised or spun off. While competition does cause the expected return to drop for the incumbent, when the threat of preemption is present in the industry the expected rate of return for the incumbent declines more steeply before becoming negative. ${ }^{6}$

Regardless of who is successful in the skunkworks case, after simultaneous investment the outcome is still the same for the incumbent. As we increase $x$ the ordering of the curves does not change, instead the investment thresholds occur for less "fickle" consumers meaning the expected return drops faster. We see the result of cannibalization causes the incumbent's market value to be increasingly sensitive to changes in $y$ such that the expected return declines more steeply. As $x$ increases, the growth option is more likely to be exercised for smaller values of $y$ in competitive and preemptive markets. By introducing competition and preemption, the presence of the growth option decreases the incumbent's exposure to systematic risk by making the market value of the incumbent more sensitive to changes in the demand drivers ( $x$ and $y$ ). While exposure to risk is falling, this is a result of a greater loss in market value for a smaller change in the number of "fickle" consumers resulting from cannibalization. The pure disruption structure means the incumbent can earn an expected return above the risk-free rate for a higher number of "fickle" consumers. Only in the best case scenario does the incumbent receive an expected return higher than the risk free rate for higher levels of $y$. In all other cases the effects of competition and preemption lowers the incumbent's exposure to risk and their "reward" for bearing $x$ - and $y$-risk.

From the entrant's perspective, shown in the middle row of graphs in Figure 3.6, our first

\footnotetext{
${ }^{5}$ In the best case scenario the elasticities are constant, so that increasing $y$ does not affect the expected return.

${ }^{6}$ Increased demand boosts profitability in short-term, but also means investment (and hence cannibalization), will occur sooner. The second effect dominates, so that the firm's value actually falls. That is, the elasticity of market value in equation (3.6) is negative.
} 
observation is that for all values of $x$ and $y$ the entrant is exposed to significant risk as a result of exposure to the demand drivers. The expected return values for the entrant are of a much higher magnitude than those found for the incumbent. The entrant's value is derived solely from the risky growth option and it will always be more sensitive to changes in the number of "loyal" and "fickle" consumers in the market as it cannot hedge itself using assets-in-place. In pure disruption the entrant faces no threat of preemption, but is still subject to competitive pricing. With no threat of preemption the entrant can delay until it is optimal for them to invest. The entrant, across all market structures, tends to have their expected return rising as the number of "fickle" consumers in the market increase. With more "fickle" consumers entering the market, the value of the growth option rises markedly which is reflected in the expected return. Initially the growth option is worth nothing so while it appears the entrant is due to receive a significant "reward" for bearing $x$ - and $y$-risk at a firm-level, it is actually just a reflection of a significant change in market value following an increase in consumers who have a higher propensity to transition from the existing product to the innovative product.

The integration and skunkworks structures feature competitive pricing and binding preemption constraints, so that the optimal stopping region occurs for smaller numbers of "fickle" consumers $(y)$. The spin-off, in the final row of Figure 3.6, features an identical curve to the entrant for the skunkworks industry structure. Both the entrant and spin-off face identical exposure to risk and react the same as their competitor would. This competition and preemption approach only strengthens the desire to invest as soon as it is profitable. This could be the reasoning why the incumbent is willing to commit to competitors that, should they be unable to keep a competitor from ever holding the growth option in the first place, they will never compete with them and instead focus on assets-in-place. We know from previous sections that in the integration case (where the incumbent preempts) and in the skunkworks case (where simultaneous investment occurs), the entrant is not guaranteed to secure the innovative growth option. 


\section{Characteristics of Disruption}

In this chapter we consider three parameters that influence the characteristics of disruption. Henderson and Clark (1990) remind us that firms may find it difficult to internalise additional products into their existing business which we examine as inefficiencies of architectural innovation. The propensity of "fickle" consumers to switch to the innovative product may be higher than in the baseline case which we highlight as the vulnerability of assets-in-place. Finally, we target consumer preferences by having customers favour the innovation over the existing product which focuses on the importance of assets-in-place. By altering these three parameters we test the robustness of the results in Chapter 3 to determine how the threat of disruption can vary depending on different situations.

\subsection{Inefficiences of architectural innovation}

\begin{tabular}{ccccccccc}
\hline$\mu_{x}=\mu_{y}$ & $\lambda_{x}=\lambda_{y}$ & $\sigma_{x}=\sigma_{y}$ & $\rho_{x y}$ & $\rho_{x}$ & $\rho_{y}$ & $\delta$ & $c_{2}^{i}$ & $c_{2}^{s}$ \\
\hline 0.02 & 0.05 & 0.2 & -0.5 & 0.7 & 0.8 & 0.3 & $\mathbf{0 . 8 0}+\mathbf{0 . 0 8}$ & 0.8 \\
\hline
\end{tabular}

Suppose the incumbent has difficulty integrating the innovative product into the current business. In our baseline case we assumed that the incumbent could develop the innovative product at the same production cost as an entrant. This may not be possible as the innovative product could require additional costs to manufacture the product "in-house" alongside the existing product (e.g. existing labour forced to receive specialised training or additional electricity costs to power machines operating at higher output). These additional costs are borne by the innovative product as it is because of its existence, being produced alongside the existing product, 
Figure 4.1: Preemption Payoffs and Thresholds with Inefficient Production Costs

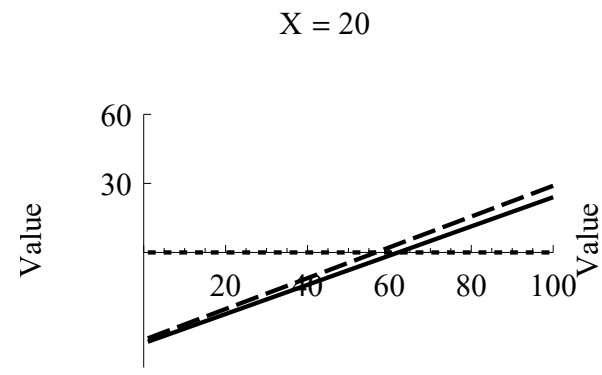

Fickle Customers (y)

$$
X=50
$$

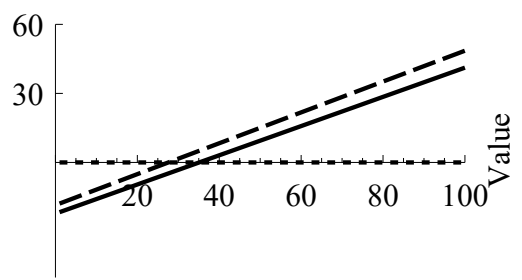

Fickle Customers (y)

$$
X=100
$$

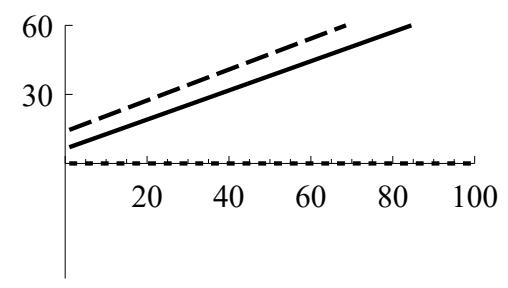

Fickle Customers (y)

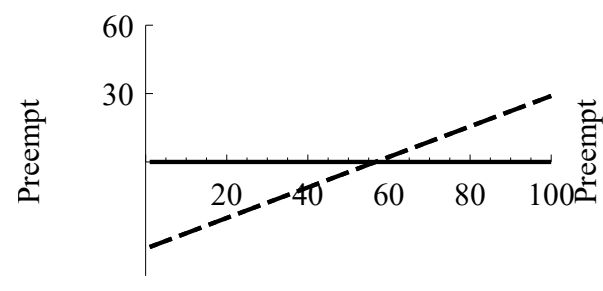

Fickle Customers (y)

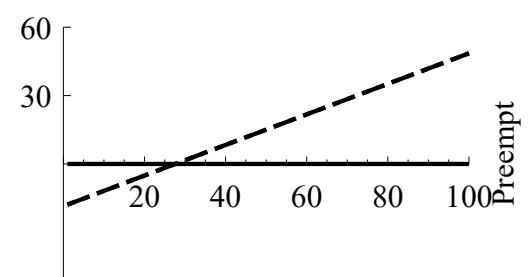

Fickle Customers (y)

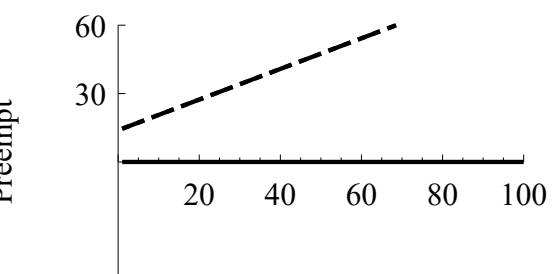

Fickle Customers (y)

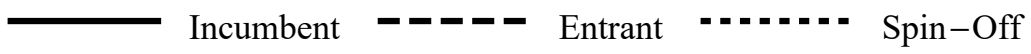

The preemption payoffs for the incumbent, entrant and skunkworks are plotted against the number of "fickle" consumers $(y)$ in the market at any given time. The top row shows the preemption payoffs in the integration structure while the bottom row shows the skunkworks structure. Where the preemption curves cross the horizontal axis is where the firm begins to profit from investing in the growth option.

that the incumbent now faces additional costs. We treat this as the incumbent having a higher production cost than the entrant and spin-off where

$$
c_{2}^{i}>c_{2}^{e}=c_{2}^{s}
$$

The entrant and spin-off have the same production cost of 0.80 for the innovative product, which we have kept constant from the baseline chapter. We have kept these constant as the entrant and spin-off do not have to manage both assets-in-place and the growth option. This section focuses on how lowering the absorptive capacity can impact the timing of the investment decision for the incumbent in the best case and integration structures.

We start with the behaviour of the market participants as shown in Figure 4.1 which reflects the preemption payoffs for the incumbent, entrant and spin-off against the number of "fickle" 
Table 4.1: Inefficient Costings: Preemption Thresholds and Profitability of Pure Disruption Panel A: Variation

\begin{tabular}{ccccccc}
\hline & \multicolumn{3}{c}{ Preemption } & & \multicolumn{2}{c}{ One-Off Intersection } \\
\cline { 2 - 4 } \cline { 6 - 6 }$x$ & $y_{i}^{*}$ & $y_{e}^{*}$ & $y_{s}^{*}$ & & $y_{\text {int }}$ & $y_{s k}$ \\
\hline 20 & 62.17 & 56.70 & 56.70 & & 75.62 & 75.00 \\
30 & 53.15 & 46.97 & 46.97 & & 62.54 & 62.27 \\
50 & 35.11 & 27.58 & 27.58 & & 40.90 & 40.00 \\
70 & 17.05 & 8.26 & 8.26 & & 25.16 & 25.00 \\
100 & - & - & - & & - & - \\
\hline
\end{tabular}

Panel B: Baseline Case

\begin{tabular}{cccccc}
\hline & \multicolumn{3}{c}{ Preemption } & & \multicolumn{2}{c}{ One-Off Intersection } \\
\cline { 2 - 4 }$x$ & $y_{i}^{*}$ & $y_{e}^{*}$ & $y_{s}^{*}$ & & $y_{\text {int }}$ \\
\hline 20 & 51.73 & 56.70 & 56.70 & 70.39 & $y_{s k}$ \\
30 & 42.73 & 46.97 & 46.97 & 58.04 & 75.00 \\
50 & 24.72 & 27.58 & 27.58 & 37.50 & 62.27 \\
70 & 6.65 & 8.26 & 8.26 & 21.13 & 40.00 \\
100 & - & - & - & - & 25.00 \\
\hline
\end{tabular}

1. The preemption threshold looks at the level of $y$ for which the incumbent, entrant, and spin-off finds it profitable to preempt their competitors

2. The one-off intersection considers the highest $y$ value for which the market value of the incumbent in the pure disruption structure exceeds those in the integration and skunkworks scenarios.

consumers in the market. As a result of raising the incumbent's production costs by $10 \%$ the entrant finds it profitable to invest in the innovation for a lower number of "fickle" consumers in the market relative to the incumbent. This is not surprising as the internalised incumbent faces higher production costs relative to the entrant in producing the innovation. This result is binding regardless of the number of "loyal" consumers $(x)$ in the market. If we look at $x=50$ in Table 4.1 we see that the entrant can profitably invest in the growth option after 27.58 "fickle" consumers enter the market. The incumbent can only profitably enter after 35.11 "fickle" consumers. The entrant can now profitably preempt the incumbent within the range of $27.58 \leq y<35.11$. This is a significant change from the baseline case where it was the incumbent who could profitably preempt the entrant between $24.72 \leq y<27.58$. The entrant can now afford to delay investment such that, even though they find it profitable to invest in the growth option after $y=27.58$, they will now delay investing until just before $y=35.11$ as they can afford to do so.

The spin-off has the same production cost of $c_{2}$ as the entrant, and so we still have the random Markov-perfect equilibrium. Both the entrant and spin-off will have the same preemption 
Figure 4.2: Cannibalization Rates with Inefficient Production Costs
$X=20$
$\mathrm{X}=50$
$X=100$
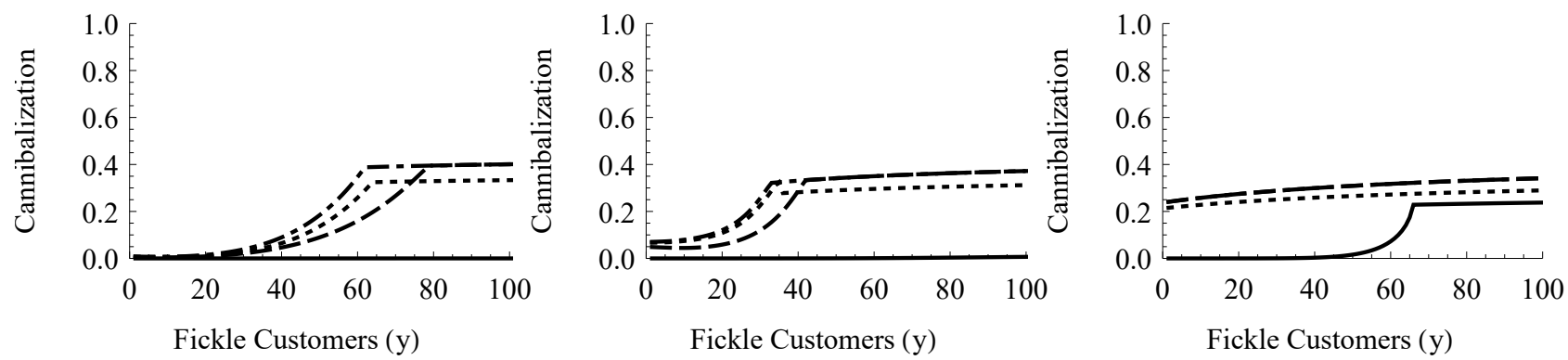

Best case

Pure disruption

Integration

Skunkworks

The rate of cannibalization is plotted against the number of "fickle" consumers in the market, $y$. The cannibalization rate reflects the loss in value of the assets-in-place by choosing to invest in the growth option rather than remaining as a monopoly. Cannibalization occurs in situations where there are binding preemption constraints (best case and pure disruption) and those where there are not (integration and skunkworks).

threshold such that they will invest simultaneously with a $50 \%$ chance of successfully investing. In the baseline case, when $x=20$ the preemption threshold for the entrant and spin-off was 56.70. As this has not changed the entrant can capitalise on the inefficiencies of the incumbent by profitably investing. It is because the incumbent now finds it relatively more expensive to produce the innovation that the preemptive investment power has switched.

As the incumbent knows the entrant can profitably invest just before them, the appeal of the one-off abandonment option becomes more attractive to the incumbent. We know this as the market value of the incumbent in pure disruption exceeds that of the market values for the incumbent in integration and skunkworks structures for a higher number of "fickle" consumers than in the baseline case. Table 4.1 shows us that in the variation case, the incumbent at $x=50$ only finds it more profitable to internalise the growth option rather than abandoning it when $y>40.90$. The decision to spin off the growth option rather than abandoning it becomes profitable when $y>40.00$. The highest $y$ value where the pure disruption scenario provides greater value to the incumbent than the skunkworks scenario $\left(y_{s k}\right)$ result does not change from our baseline case. This makes sense as it is only the internalised production cost raised and not the skunkworks production cost. Compared with the baseline case, increasing the internalised production cost has meant the one-off option to abandon becomes more valuable to the incumbent compared to competing either by internalising or spinning off the growth option. 
From this behaviour we can determine that if the incumbent firm displays signs of inefficiency then they must either find a way to lock out the competitor from ever possessing the growth option (best case) or commit to perpetually abandon their rights to the growth option.

Figure 4.2 plots the cannibalization rates for the incumbent, who is now subject to a higher innovative production cost, against the number of "fickle" consumers in the subject. When we consider cannibalization rates for the incumbent in Figure 4.2, we first look at the best case scenario where for both $x=20$ and $x=50$ the cannibalization rate effectively remains at 0 . There is no real desire for the incumbent to invest when there are few "loyal" consumers in the market. The value of the assets-in-place lost does not exceed the value gained by investing in the growth option. This makes sense as in the best case scenario the incumbent can afford to delay as long as necessary until there are enough"loyal" and "fickle" consumers to ensure the firm makes an overall net gain from investing in the growth option. In the baseline case, the best case incumbent willingly cannibalizes their assets-in-place by $19.27 \%$ when there are 100 "fickle" consumers, this does not occur in the increased $c_{2}$ case. When we look at $x=100$ in the baseline case, cannibalization rises significantly at the investment threshold which occurs just before $y=18$. By increasing the production cost by $10 \%$ the incumbent's investment threshold occurs at a much higher number of "fickle" consumers in the market to outweigh the loss in value by higher costs.

In pure disruption and skunkworks, the increased production cost of the incumbent does not affect their profit functions and so the cannibalization rates are the same in the baseline as they are in the variation case. This is to be expected as with no binding preemption constraint in the pure disruption model and with the spin-off having a different production cost to the internalised incumbent, cannibalization rates should not differ as a result of $c_{2}^{i}$ increasing. The focus for cannibalization is on the internalised incumbent in the integration structure relative to the other structures an incumbent can be. By increasing the production cost of $c_{2}^{i}$ the incumbent realises they require more "fickle" consumers in the market before the growth option becomes profitable to justify investment. In this variation we see that although integration and skunkworks both have binding preemption constraints, the former results in less cannibalization for the incumbent. The entrant knows that in integration they can preempt the incumbent while in skunkworks they find themselves in a random Markov-perfect equilibrium. 
Figure 4.3: Optimal Incumbent Design with Inefficient Production Costs
$\mathrm{X}=20$
$\mathrm{X}=50$
$X=100$

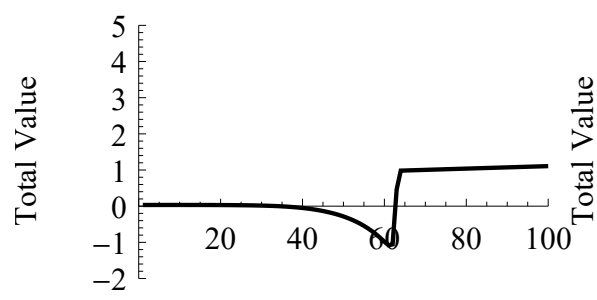

Fickle Customers (y)

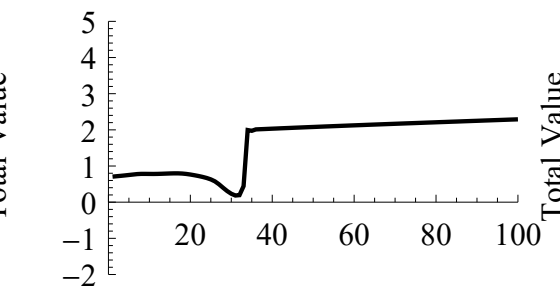

Fickle Customers (y)

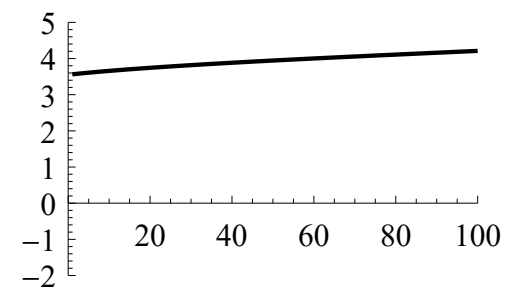

Fickle Customers (y)

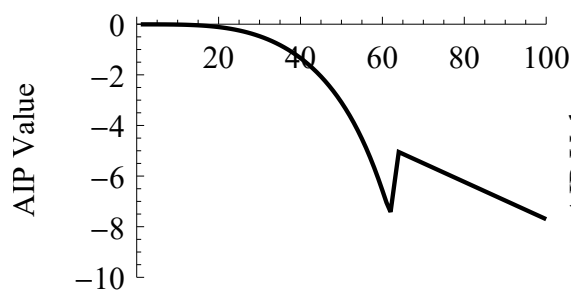

Fickle Customers (y)

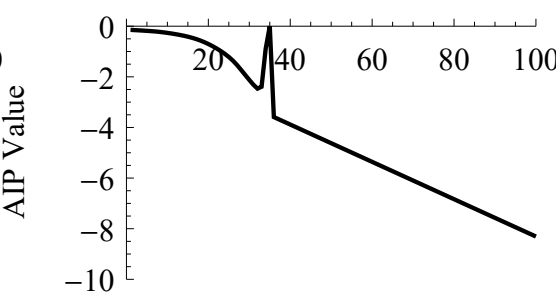

Fickle Customers (y)

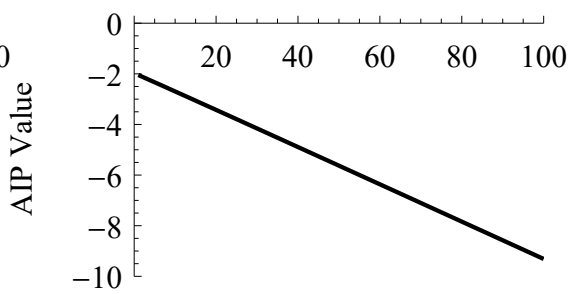

Fickle Customers (y)

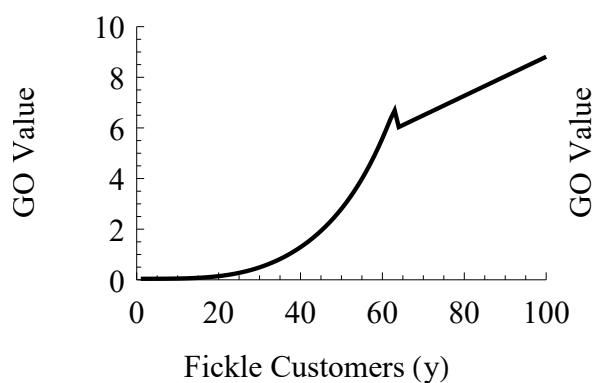

Fickle Customers (y)

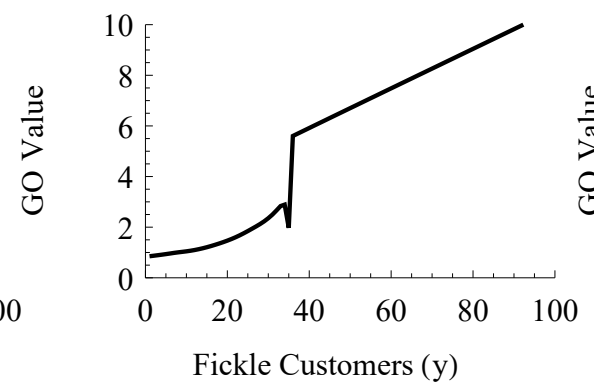

Fickle Customers (y)

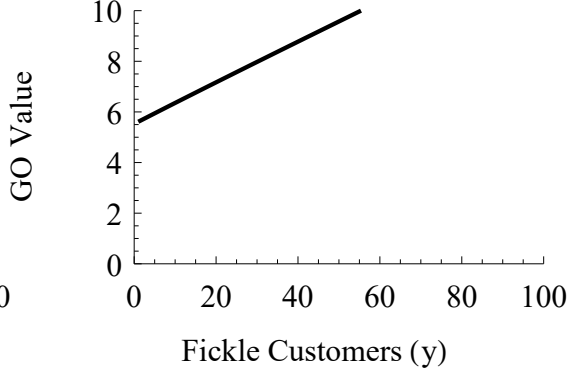

Fickle Customers (y)

Cost of Spin-Off

The difference in value of the incumbent in integration and skunkworks is plotted against the number of "fickle" consumers in the market, $y$ for different values of $x$. The top row looks at the total value of the internalised incumbent deducted from the combined value of the incumbent and its spin-off. The next row focuses on the difference in value of the assets-in-place depending on whether the incumbent decides to follow the integration or skunkworks structure. The final row looks at the change in value of the growth option value for the two structures.

The entrant in integration can afford to delay just before the incumbent would attempt to invest while in skunkworks the entrant cannot afford to do this and will attempt to invest simultaneously with the spin-off. With the entrant being able to profitably preempt the incumbent in integration, the incumbent knows they will lose the investment-timing game and be left 
with only the cannibalized assets-in-place. There is no desire for the incumbent to hasten the arrival of the disruptive innovation and so make every effort to minimise the cannibalization effect. While the incumbent will lose the investment-timing game they can delay the cannibalization effect by committing to the one-off option to abandon, removing the binding preemption constraint which hastens the arrival of the innovation.

We now consider the impact this higher production cost has on the optimal incumbent design. Figure 4.3 considers the overall and decomposed differences in value for the incumbent between skunkworks and integration against the number of "fickle" consumers in the market. The first row of graphs in Figure 4.3 tells us that from an overall market value perspective, the higher production cost for an internalised incumbent has resulted in the combined market value of the spin-off and incumbent being greater than the market value of the internalised incumbent. The second row tells us the value of assets-in-place is still greater in the internalised structure than skunkworks, while the final row of graphs shows the spin-off still extracts greater market value from the growth option. In contrast to the baseline case, the loss in value from the assetsin-place is now exceeded by the gains in market value of the growth option should the incumbent create a spin-off rather than internalise. This makes sense as the incumbent can avoid a higher production cost should they elect to spin off the growth option rather than internalising it. The spin off will have a lower $c_{2}$, as it need not concern itself with the assets-in-place, and can compete more effectively with the entrant over the growth option rights. The skunkworks structure allows the spin-off to compete more effectively over the growth option product than if they were to internalise. We agree with Henderson and Clark (1990) that a firm's architecture can play a significant role in minimising disruption where efficient firms are able to profitably preempt their competitors and invest. The incumbent's inefficient architecture in this case has resulted in them losing the advantage found in the baseline case. The incumbent can no longer preempt the entrant and so, with low absorptive capacity, it is no longer feasible to consider internalising over spinning off the growth option.

The "insurance put option" approach relies on the assumption that the incumbent is able to preempt the entrant in the market to exercise the growth option. Increasing the internalised production cost for the incumbent means they have lost the ability to profitably preempt the entrant, so the insurance put approach is no longer available for the incumbent. Even though 
Figure 4.4: Firm-level Expected Rate of Return with Inefficient Production Costs
$X=20$
$X=50$
$X=100$

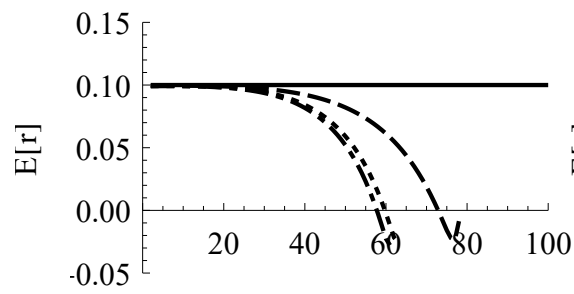

Fickle Customers (y)

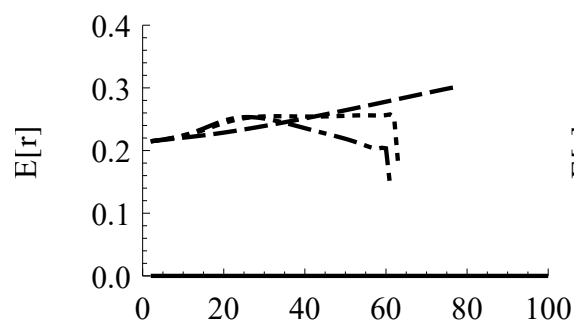

Fickle Customers (y)

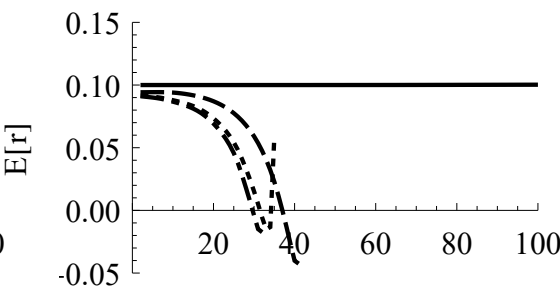

Fickle Customers (y)

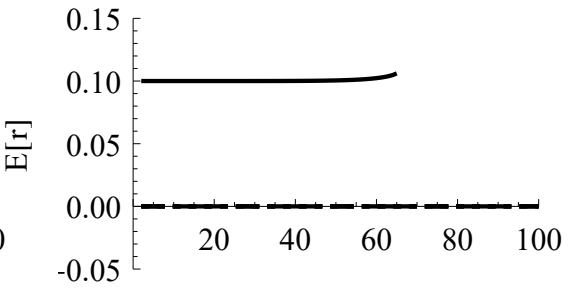

Fickle Customers (y)
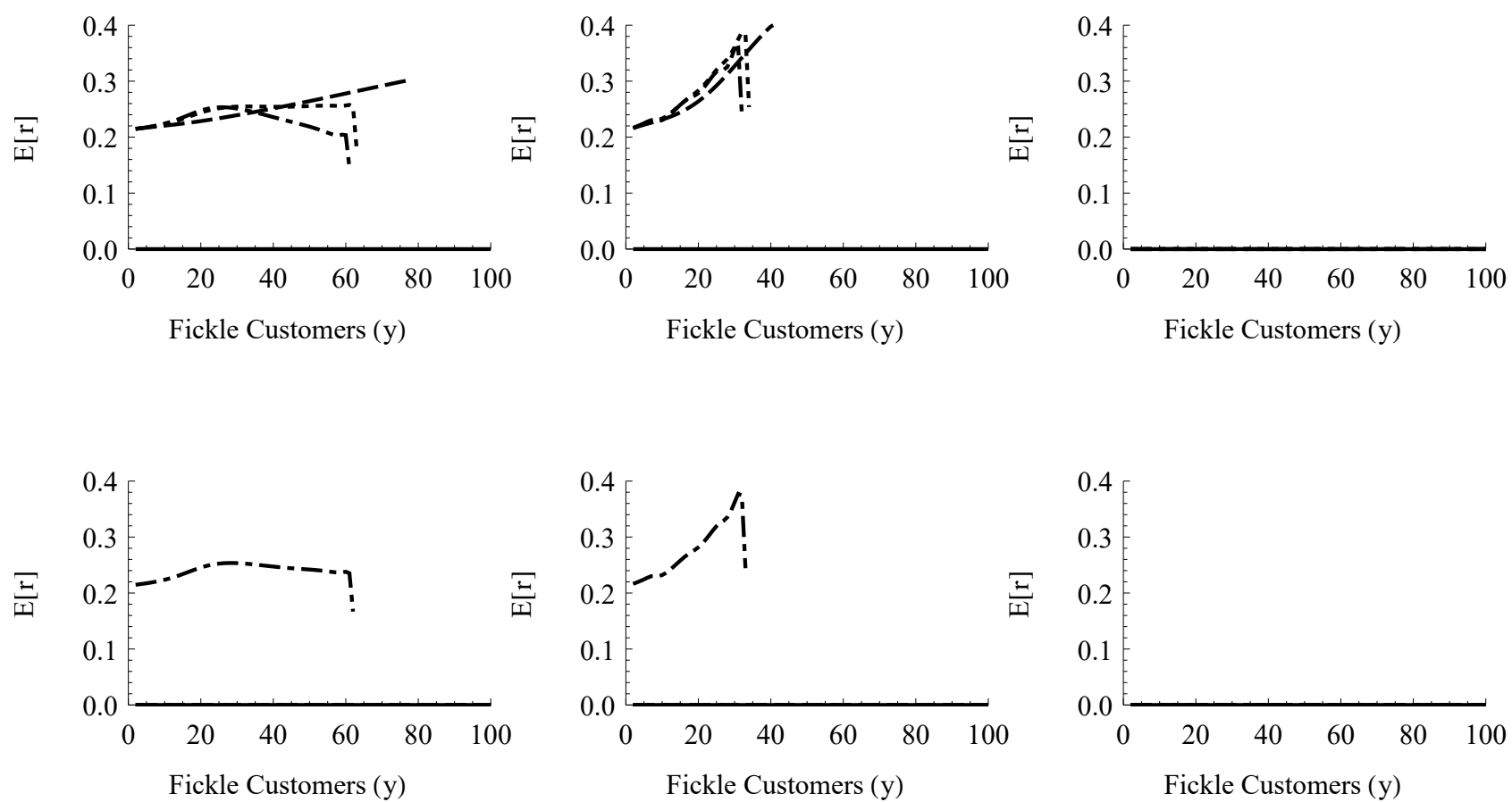

Best case

Pure disruption

The firm level expected return is plotted aginst the number of "fickle" customers, $y$, for different numbers of "loyal" consumers, $x$, in the market. The top row shows the incumbent's expected return for the four different market structures, while the next two rows are for the entrant and spin-off respectively.

preemptive investment is not profitable for the incumbent, cannibalization can still be reduced by committing to abandonment for low numbers of "fickle" consumers. With preemptive investment unavailable to the incumbent in order to protect the value of the assets-in-place when the incumbent has inefficient internalised production costs, the incumbent will find it best to make a commitment they will not compete over the growth option.

Figure 4.4 plots the firm-level expected return against the number of "fickle" consumers 
in the market. The top row of graphs display the incumbent's expected return while the subsequent rows depict the entrant and spin-off respectively. A significant change, compared to the baseline, in Figure 4.4 is that the entrant's expected return is more elastic in nature in the integration case. As the entrant can now profitably preempt the incumbent in this case, the market value of the entrant is less sensitive to changes in the number of "fickle" consumers in the market. The entrant can now afford to delay until just before the incumbent's preemption threshold before investing in the growth option. The entrant now effectively receives a smaller premium for bearing systematic risk resulting in a lower firm-level expected return. The pure disruption and skunkworks cases do not change which makes sense as they will not be affected by a change in the incumbent's internalised production cost due to the incumbent not holding the growth option.

\section{Summary of inefficiences}

Higher internalised production costs mean that the incumbent can no longer profitably preempt the entrant. The incumbent, relative to the baseline case, requires more "fickle" consumers to be present in the market to make it more profitable to internalise or spin off rather than exercise their one-off option to abandon. If enough "fickle" consumers enter the market such that the incumbent will not commit to abandoning the growth option, then the incumbent will decide to spin off rather than internalise the growth option. If the incumbent internalises the growth option the assets-in-place are still better protected, and the spin-off better maximises the growth option value, but now the gain from the growth option exceeds the losses from the assets-in-place. Should the cost of producing the innovation for the internalised incumbent be sufficiently higher than the entrant, we would reach a nonpreemptive Markovperfect equilibrium. This is where the incumbent will never attempt to invest in the innovation as market conditions make it unsuitable for the incumbent to ever profitably invest in the innovation, let alone being able to invest just before the entrant. 
Figure 4.5: Preemption Payoffs and Thresholds with Increased Sensitivity

$$
\mathrm{X}=20
$$

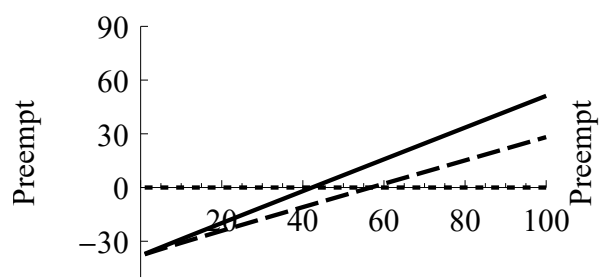

Fickle Customers (y)

$$
\mathrm{X}=50
$$

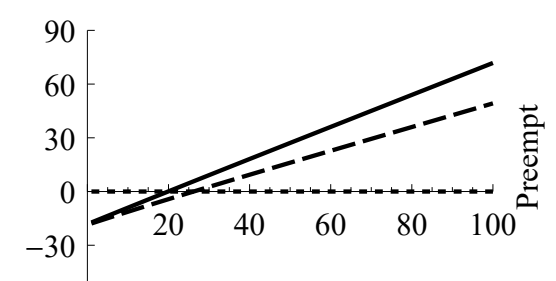

Fickle Customers (y)
$\mathrm{X}=100$

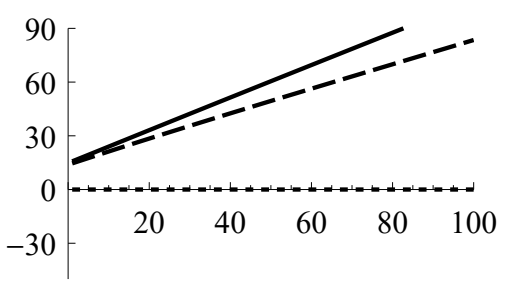

Fickle Customers (y)

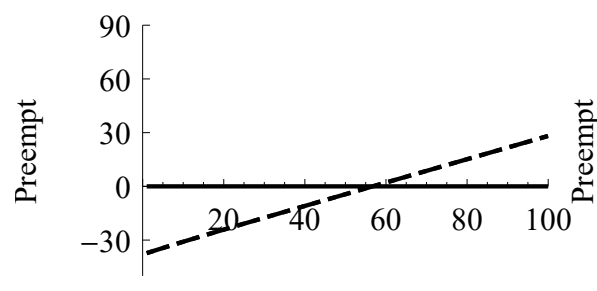

Fickle Customers (y)

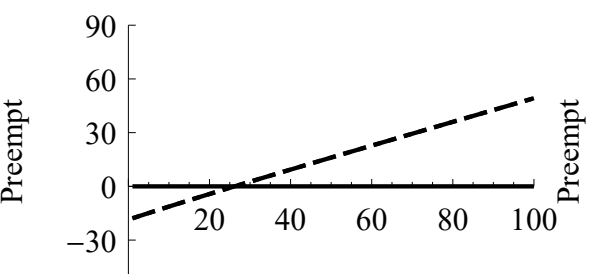

Fickle Customers (y)

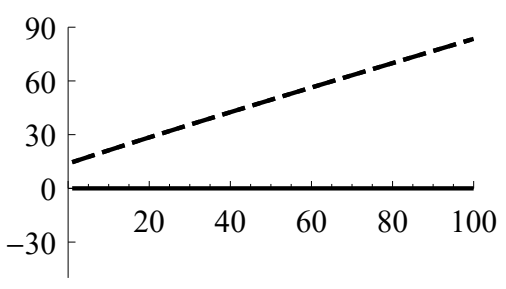

Fickle Customers (y)

The preemption payoffs for the incumbent, entrant and skunkworks are plotted against the number of "fickle" consumers $(y)$ in the market at any given time. The top row shows the preemption payoffs in the integration structure while the bottom row shows the skunkworks structure. Where the preemption curves cross the horizontal axis is where the firm begins to profit from investing in the growth option.

\subsection{Vulnerability of assets-in-place}

\begin{tabular}{cccccccc}
\hline$\mu_{x}=\mu_{y}$ & $\lambda_{x}=\lambda_{y}$ & $\sigma_{x}=\sigma_{y}$ & $\rho_{x y}$ & $\rho_{x}$ & $\rho_{y}$ & $\delta$ & $c_{2}^{i}=c_{2}^{s}$ \\
\hline 0.02 & 0.05 & 0.2 & -0.5 & 0.7 & $\mathbf{0 . 8}+\mathbf{0 . 1}$ & 0.5 & 0.8 \\
\hline
\end{tabular}

In this section we increase the sensitivity of "fickle" consumers' demand to changes in the price of substitute goods. We do this to focus on the elasticities of substitution that play a significant role in determining the "output market" equilibrium. For the baseline case we had $\rho_{x}=0.7$ and $\rho_{y}=0.8$. Now we increase $\rho_{y}$ to 0.9 , so that "fickle" consumers now have a greater propensity to transition away from the existing product relative to the baseline case. This can provide insight into the way elasticities of substitution affect our results. Remembering the elasticity 
Table 4.2: Increased Sensitivity: Preemption Thresholds and Profitability of Pure Disruption Panel A: Variation

\begin{tabular}{ccccccc}
\hline & \multicolumn{3}{c}{ Preemption } & & \multicolumn{2}{c}{ One-Off Intersection } \\
\cline { 2 - 4 }$x$ & $y_{i}^{*}$ & $y_{e}^{*}$ & $y_{s}^{*}$ & & $y_{\text {int }}$ & $y_{s k}$ \\
\hline 20 & 42.25 & 56.73 & 56.73 & 69.66 & 75.00 \\
30 & 34.68 & 46.20 & 46.20 & 56.48 & 60.00 \\
50 & 19.89 & 26.19 & 26.19 & 35.70 & 38.00 \\
70 & 5.44 & 7.61 & 7.61 & & 19.98 & 23.00 \\
100 & - & - & - & - & - \\
\hline
\end{tabular}

Panel B: Baseline Case

\begin{tabular}{cccccc}
\hline & \multicolumn{3}{c}{ Preemption } & & \multicolumn{2}{c}{ One-Off Intersection } \\
\cline { 2 - 4 }$x$ & $y_{i}^{*}$ & $y_{e}^{*}$ & $y_{s}^{*}$ & & $y_{\text {int }}$ \\
\hline 20 & 51.73 & 56.70 & 56.70 & 70.39 & $y_{s k}$ \\
30 & 42.73 & 46.97 & 46.97 & 58.04 & 76.83 \\
50 & 24.72 & 27.58 & 27.58 & 37.50 & 62.27 \\
70 & 6.65 & 8.26 & 8.26 & 21.13 & 40.00 \\
100 & - & - & - & - & 25.00 \\
\hline
\end{tabular}

of substitution as $\epsilon_{s}=\frac{1}{1-\rho}$, by increasing $\rho_{y}$ from 0.8 to 0.9 we have increased the elasticity of substitution for "fickle" consumers from 5 to 10 while keeping the "loyal" consumers $\epsilon_{s}$ at 3.33. With a perfect substitute having an elasticity of substitution of $\epsilon_{s}=\infty$, "fickle" consumers now consider the innovative product to be more of a perfect substitute to the existing product relative to the baseline case.

When we consider the behaviour of the market participants we first look at the preemption payoffs and thresholds, which are displayed in Figure 4.5, plotted against the number of "fickle" consumers in the market. The incumbent's preemption threshold occurs for a smaller number of "fickle" consumers in the market compared to the baseline case. In Table 4.2 at $x=20$, the incumbent's preemption threshold is 42.25 compared to the baseline's value of 51.73. As we increase the number of "loyal" consumers $(x)$ in the market, the preemption threshold continues to be lower compared to the baseline case. The incumbent finds that by having "fickle" consumers more readily transitioning from the existing product to the innovative product, they find it profitable for a lower number of "fickle" consumers to preempt the entrant. Changing the elasticity of substitution for "fickle" consumers from 5 to 10 makes the growth option more valuable, compared to the baseline case, as "fickle" consumers now consider it easier to substitute the innovative product for the existing product. When we look at the entrant's and 
Figure 4.6: Value of Market Participants with Increased Sensitivity

$X=20$

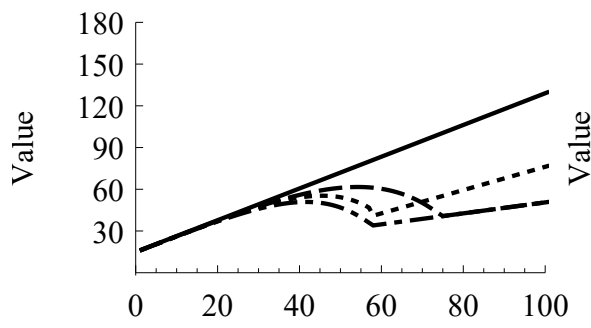

Fickle Customers (y)
$\mathrm{X}=50$
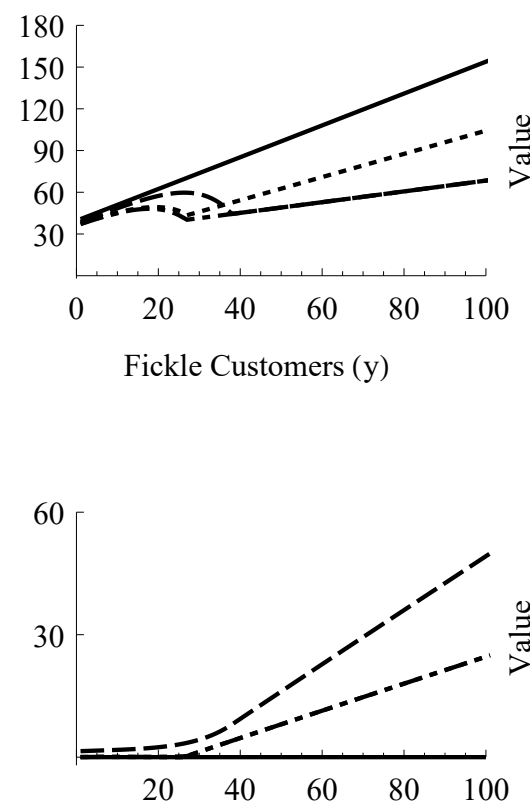

Fickle Customers (y)
$\mathrm{X}=100$
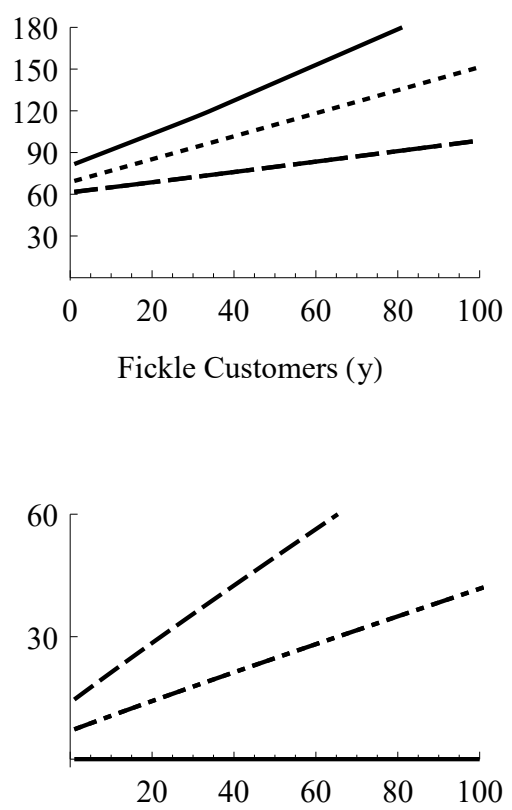

Fickle Customers (y)

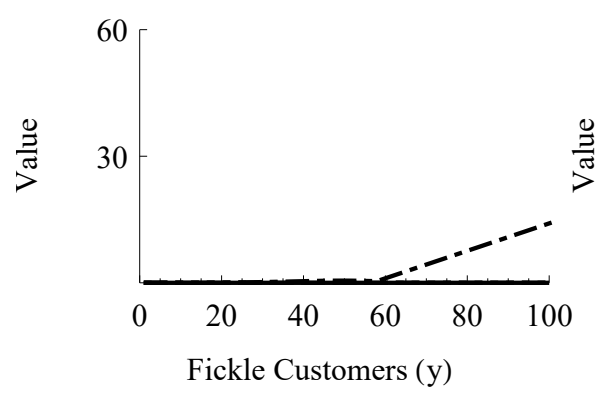

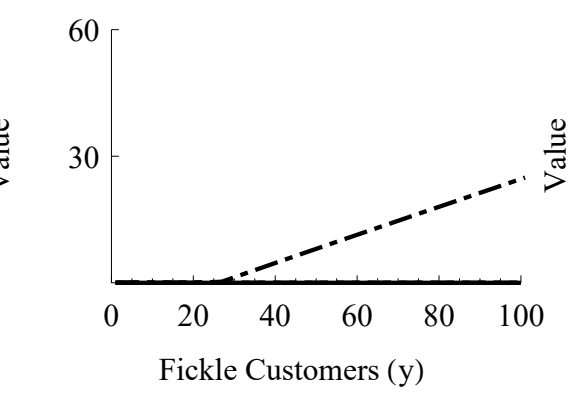

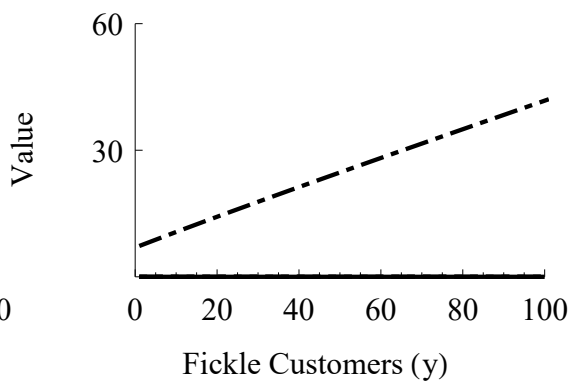

Best case

Pure disruption

Integration

Skunkworks

Market values for the incumbent, entrant and spin-off are plotted against the number of "fickle" consumers, $y$, for different numbers of "loyal" consumers in the market. The top row shows the values for the incumbent, followed by the entrant and spin-off respectively. The values shown depend on the market structure.

spin-off's preemption thresholds in Table 4.2 (reported as $y_{e}^{*}$ and $y_{s}^{*}$ ) we note that they change very little from the results found in the baseline case. For instance at $x=20$ the entrant has a preemption threshold of $y_{e}^{*}=y_{s}^{*}=56.73$ compared to the value of 56.70 in the baseline case. Therefore by increasing the sensitivity to changes in the price of substitute goods for $y$ units of "fickle" consumers, the preemption threshold for the incumbent drops noticeably, while their competitor's threshold drops by a miniscule amount. 
The only thing that differentiates the incumbent and entrant is that the incumbent has assets-in-place while the entrant can only derive value from the growth option. If the incumbent successfully invests then they become a perpetual monopolist, and are the only providers of the existing and innovative products receiving a payoff of $V_{i i}(x, y)$. If the entrant invests, they receive the leader payoff of $V_{e e}(x, y)$ and produce the innovative product while the incumbent continues to produce the existing product. The incumbent can either be a leader and secure both the assets-in-place and the growth option or be locked out and only produce the existing product. The entrant and spin-off are not as sensitive to changes in the elasticity of substitution for the "fickle" consumers as their value is solely derived from the growth option. It would appear that doubling the elasticity of substitution for "fickle" consumers is not sufficient for the entrant and skunkworks to have a significantly lower preemption threshold as seen with the incumbent. The incumbent needs to manage both products simultaneously if they are to become the leader in the market. As the "fickle" consumers more readily switch from the existing product to the innovation, then the growth option becomes more valuable to the incumbent, while at the same time the assets-in-place lose value as a result of cannibalization. The incumbent finds it more affordable to preempt the entrant for lower "fickle" consumer numbers in order to better protect their assets-in-place and capitalise on the rising profitability of the growth option. Once the incumbent becomes the leader they control both products and do not care whether consumers switch between them, their profitability and value will still rise.

Table 4.2 considers the number of "fickle" consumers at which the value of the incumbent in integration and skunkworks structures exceeds that in pure disruption ( $y_{\text {int }}$ and $y_{\text {sk }}$ respectively). With "fickle" consumers more readily transitioning away from the existing product, the one-off option to perpetually abandon provides greater value than integration and skunkworks for a lower number of "fickle" consumers in the market. For $x=50$ in Table 4.2 in the baseline case, pure disruption was more profitable than integration until $y_{\text {int }}=37.50$, but with a higher $\epsilon_{s}$ for "fickle" consumers this has dropped to $y_{\text {int }}=35.70$. By increasing the elasticity of substitution of "fickle" consumers, the incumbent finds it more profitable to internalise rather than commit to abandoning the growth option for a lower number of "fickle" consumers in the market. With "fickle" consumers more readily switching to the innovative product, the incumbent recognises that as the existing and innovative products move closer to becoming perfect substitutes, it 
is better to preemptively invest in the innovation rather than trying to deter competition by perpetually abandoning the growth option.

Figure 4.6 plots the values of the firms in the different market structures against the number of "fickle" consumers in the market. The top row of graphs present the firm value of the incumbent depending on their structure, while the second and thrid rows do the same for the entrant and spin-off respectively. From the top row of graphs we can see where the pure disruption curve (dashed) intersects with both the integration (dotted) and skunkworks (dash dotted) curves which were presented in Table 4.2. We can clearly see that before these intersection points it can be considered better for the incumbent to perpetually abandon the growth option rather than attempt to preempt the entrant or spin off the growth option.

Even with an increase in the elasticity of substitution of "fickle" consumers from 5 to 10 , the market values of the incumbent, entrant and spin-off are not significantly different from those in the baseline case shown by Figure 3.2. Although the incumbent finds it profitable to invest in the innovation for a lower number of "fickle" consumers, the incumbent will still delay investing until just before the entrant's preemption threshold. As the entrant's preemption threshold is nearly the same as in the baseline case, the incumbent will delay investing until just before the same $y$ value found in the baseline case. The incumbent can afford to profitably invest in the innovation for a lower number of "fickle" consumers, but their investment-timing behaviour is the same as in Chapter 3 so their firm value will also be similar to the baseline case.

Although we increased the elasticity of substitution for "fickle" consumers, the second and third rows show that the market values of the entrant and spin-off respectively in Figure 4.6 are essentially the same as Figure 3.2 in the baseline case. It would appear that the entrant and spin-off are indifferent to changes to increasing the elasticity of substitution for "fickle" consumers above the baseline value of $\epsilon_{s}=5$. "Fickle" consumers have reached a sufficient elasticity of substitution such that any increase has little effect on the firm value of the entrant or spin-off. With similar preemption thresholds to the baseline case, the entrant will be unable to profitably preempt the incumbent (integration), and will attempt to invest simultaneously with the spin-off (skunkworks). The entrant's behaviour is therefore nearly the same as seen in the baseline case which expalins why there is no increase in firm value even for the pure 
Figure 4.7: Value in Delaying with Increased Sensitivity
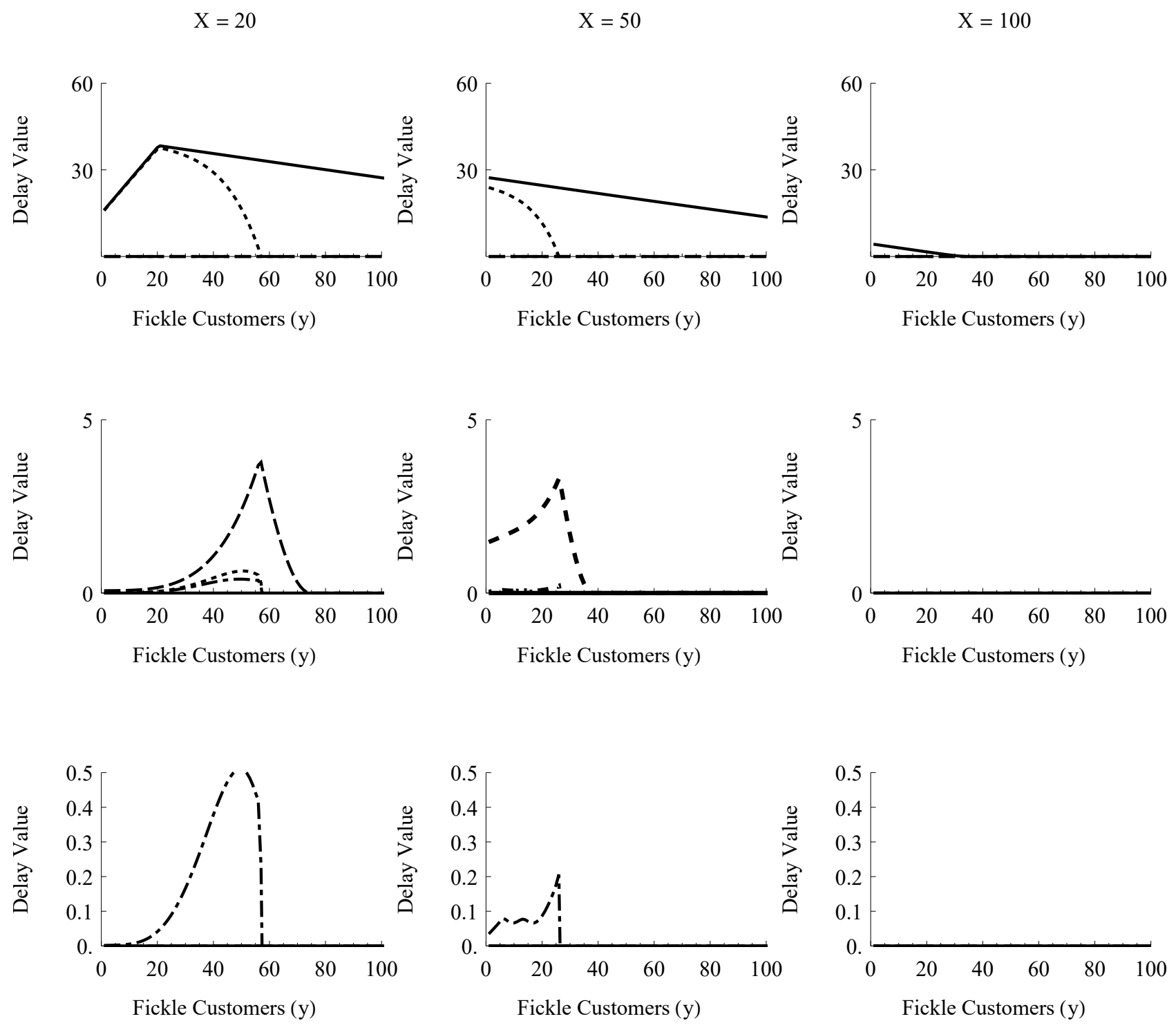

Best case

Pure disruption

The value of delaying exercising the growth option is plotted against $y$ for different values of the number of "loyal" consumers, $x$. We can determine the value that would be ignored had we chosen a static discounted cash flow approach rather than a dynamic real options analysis. This value is the difference between our calculation of firm market value and the value of a now-or-never option to invest.

\section{disruption case.}

Figure 4.7 plots the value of delaying against the number of "fickle" consumers in the market when the elasticity of substitution for "fickle" consumers is 10 rather than 5 as in the baseline case. The top row displays the incumbent's value in delaying while the subsequent rows show the entrant and spin-off respectively. In the best case scenario the incumbent receives a greater 
Figure 4.8: Cannibalization Rates with Increased Sensitivity

$X=20$

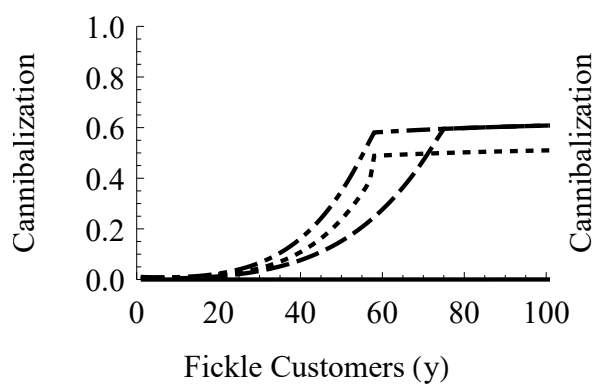

$\mathrm{X}=50$

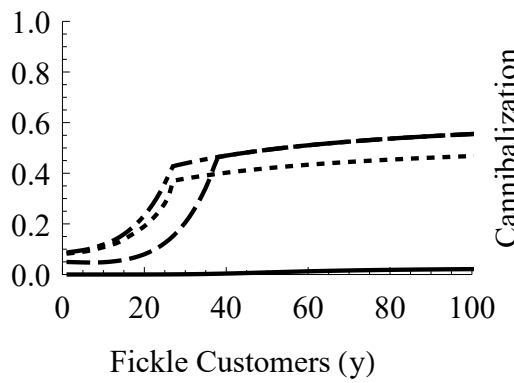

$\mathrm{X}=100$

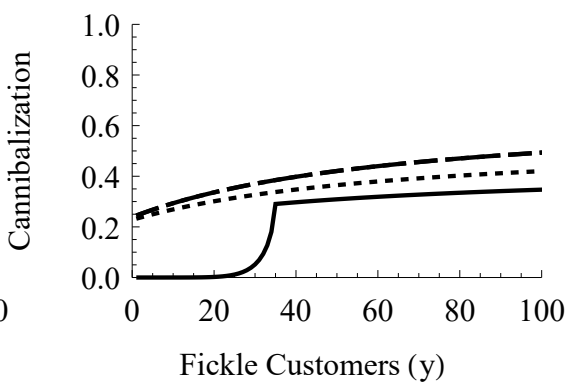

Best case

Pure disruption

Integration

Skunkworks

The rate of cannibalization is plotted against the number of "fickle" consumers in the market, $y$. The cannibalization rate reflects the loss in value of the assets-in-place by choosing to invest in the growth option rather than remaining as a monopoly. Cannibalization occurs in situations where there are binding preemption constraints (best case and pure disruption) and those where there are not (integration and skunkworks).

value in delaying such that they will not consider investing immediately until there are 100 "loyal" consumers in the market when the curve finally intersects with the horizontal axis. With no binding preemption constraint, the incumbent can afford to delay in the best case scenario to maximise the value of both the assets-in-place and the growth option. This results in a higher value in delaying to both protect the assets-in-place and capitalise on the consumer preferences for the growth option. Comparing Figure 4.7 with Figure 3.3, from the baseline case, we see the incumbent in the integration structure will immediately invest in the growth option, rather than delay, at approaximately the same $y$ value. For integration the incumbent can profitably invest in the growth option earlier than in the baseline case meaning the option to delay has a greater value. While the incumbent has a lower preemption threshold, the entrant can only attempt to profitably invest in the growth option at a number of "fickle" consumers similar to that found in the baseline case. This is why the value in delaying drops to zero, shown in Figure 4.7, for the same $y$ value as in the baseline case (Figure 3.3), but the value in delaying before this point is higher.

The graphs in the second and third rows of Figure 4.7 show the value in delaying for the entrant and spin-off respectively. These can be explained by the preemption thresholds shown in Figure 4.5. The entrant and spin-off, whether the elasticity of substitution for "fickle" consumers is 5 or 10 , find it profitable to attempt to invest in the growth option for a similar 
Figure 4.9: Optimal Incumbent Design with Increased Sensitivity

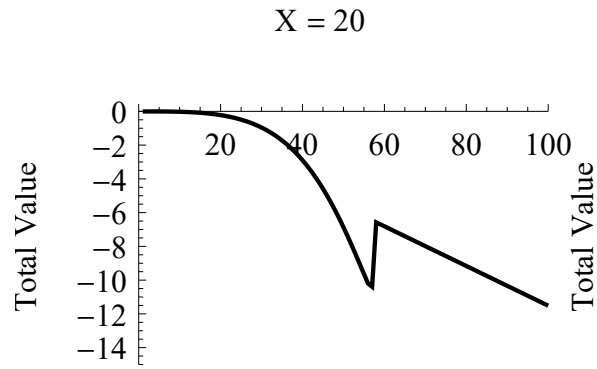

Fickle Customers (y)

$$
X=50
$$

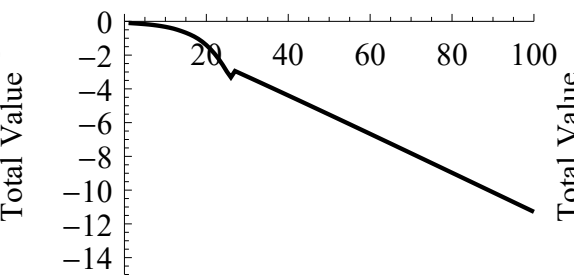

Fickle Customers (y)
$\mathrm{X}=100$

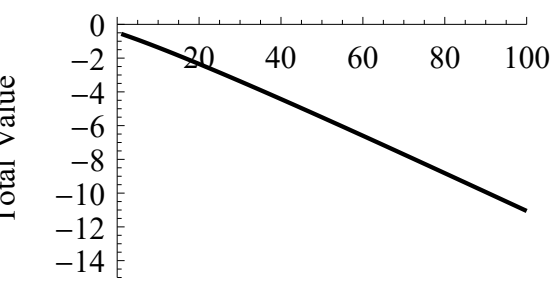

Fickle Customers (y)

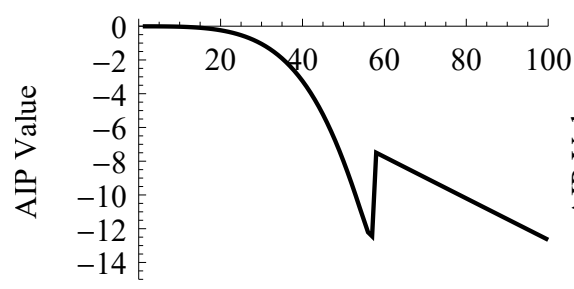

Fickle Customers (y)

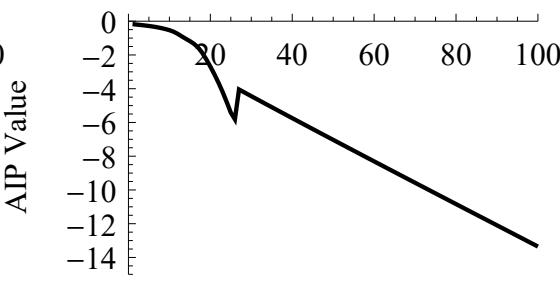

Fickle Customers (y)

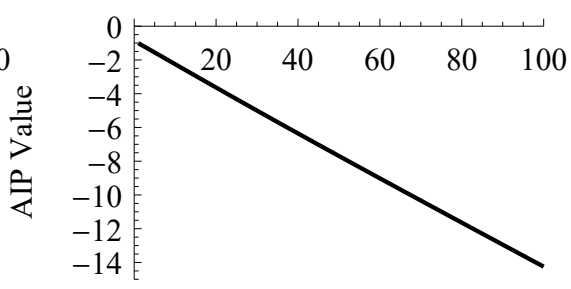

Fickle Customers (y)

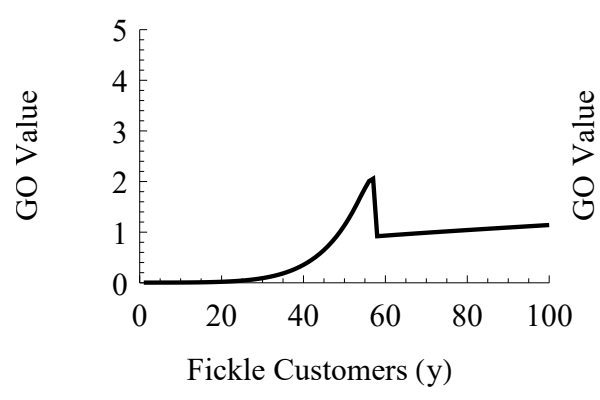

Fickle Customers (y)
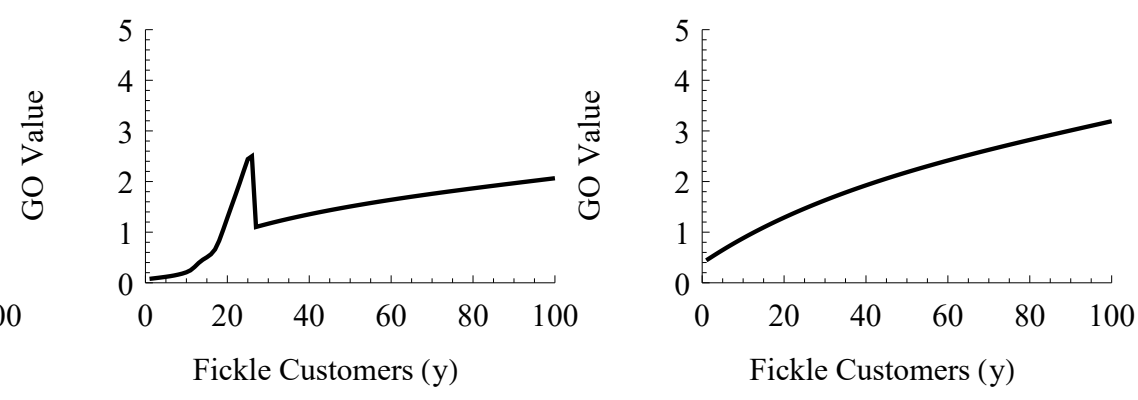

The difference in value of the incumbent in integration and skunkworks is plotted against the number of "fickle" consumers in the market, $y$ for different values of $x$. The top row looks at the total value of the internalised incumbent deducted from the combined value of the incumbent and its spin-off. The next row focuses on the difference in value of the assets-in-place depending on whether the incumbent decides to follow the integration or skunkworks structure. The final row looks at the change in value of the growth option value for the two structures.

$y$ value. Their behaviour is nearly identical to that in the baseline case, as shown by their preemption payoffs, and so they do not see any substantial value in delaying the exercising of the growth option should the elasticity of substitution for "fickle" consumers increase.

Figure 4.8 displays the rate at which assets-in-place are cannibalized, by attempting to 
invest in the growth option, against the number of "fickle" consumers in the market. When we compare Figure 4.8 with the baseline Figure 3.4, the rate of cannibalization is noticeably higher across the different business structures. As "fickle" consumers more readily switch between substitute goods, the incumbent experiences a greater loss in the value of their assets-in-place. If the incumbent were to spin off the growth option they would experience a greater rate of cannibalization than any other structure. The skunkworks structure provides the incumbent with no preemptive measure to protect the assets in place while at the same time hastens the attempts of investment due to the binding preemption constraint. The incumbent faces declining cash flow from their existing product, and has no ability to preempt the entrant, which exposes them to a greater cannibalization ratio. In integration the incumbent can afford to delay investment much longer than in the baseline case, and can minimise cannibalizing their assetsin-place while still managing to invest just before the entrant. As the "fickleness" of $y$ units of consumers rises, the incumbent's assets-in-place are better protected by internalising rather than spinning off. Pure disruption still minimises the cannibalization of the assets-in-place, by reducing the competition effect at low values of $y$, but this effect has slightly diminished by increasing the elasticity of substitution for "fickle" consumers.

With Figure 4.9 we see how the incumbent's structure can affect their value depending on whether they internalise or spin off. The top row plots the overall difference in value by subtracting the value of the incumbent in integration from the combined value of the incumbent and its spin-off in the skunkworks approach. The next two rows decompose the value of the incumbent into assets-in-place and the growth option respectively to determine which structure provides the most value. The top row of Figure 4.9 shows us that there is no change to the integration approach providing greater market value than the skunkworks structure.

From the second and third rows in Figure 4.9 we see the assets-in-place retain greater value in integration, while the skunkworks structure generates the most value from the growth option for the incumbent. If the incumbent decides to spin off the growth option, rather than internalise it, then they will find their assets-in-place are even more worse off relative to the baseline case. We can tell this by comparing Figures 3.5 and 4.9 and looking at the vertical axis to see the loss in value of the assets-in-place by choosing to spin off rather than internalise. By increasing the elasticity of substitution the integration approach becomes even more appealing 
Figure 4.10: Firm-level Expected Rate of Return with Increased Sensitivity
$X=20$
$X=50$
$X=100$

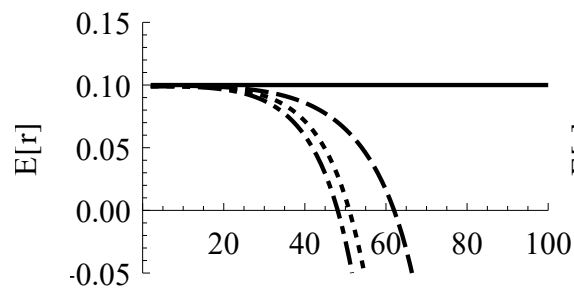

Fickle Customers (y)

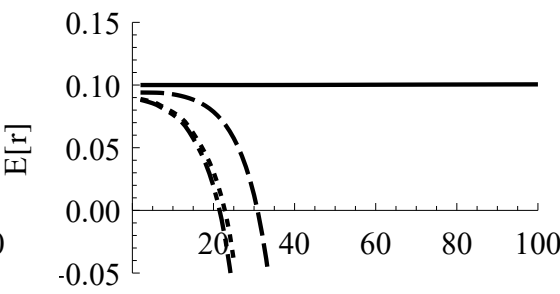

Fickle Customers (y)

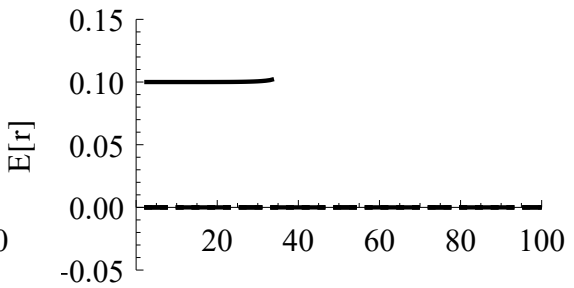

Fickle Customers (y)

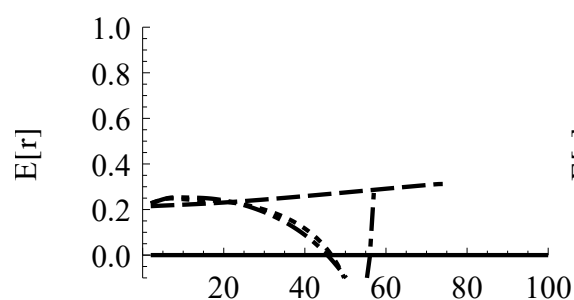

Fickle Customers (y)

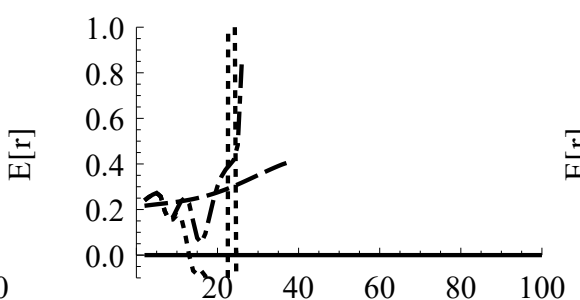

Fickle Customers (y)

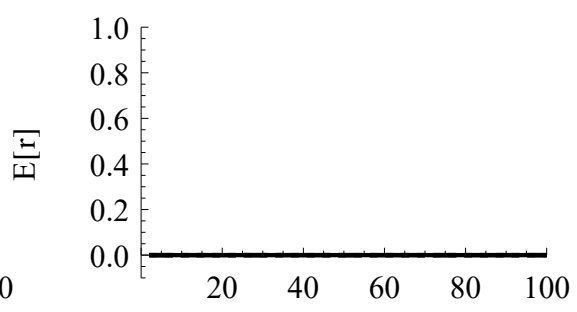

Fickle Customers (y)

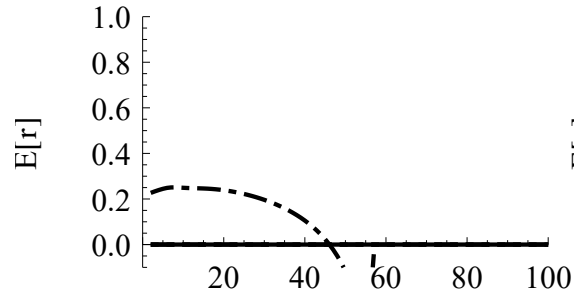

Fickle Customers (y)

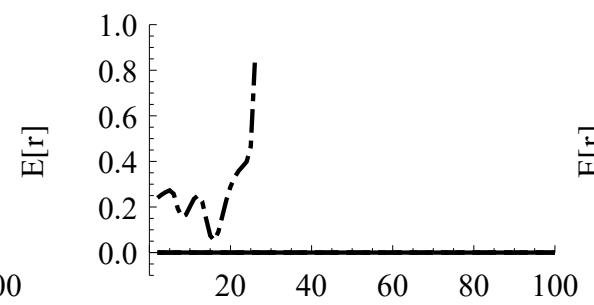

Fickle Customers (y)

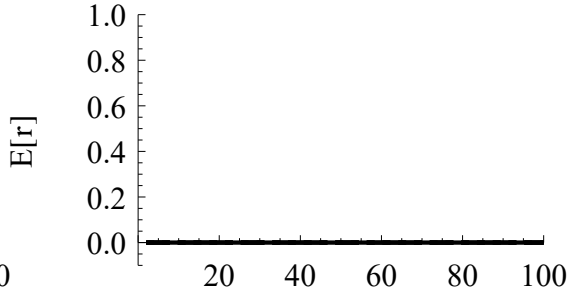

Fickle Customers (y)

The firm level expected return is plotted aginst the number of "fickle" customers, $y$, for different numbers of "loyal" consumers, $x$, in the market. The top row shows the incumbent's expected return for the four different market structures, while the next two rows are for the entrant and spin-off respectively.

relative to the skunkworks approach for its better protection from cannibalization as seen in Figure 4.8. While the skunkworks approach better maximises the value of the growth option, the loss in value for assets-in-place overwhelms this result to an even greater degree than found in the baseline case. If the incumbent internalises the growth option then they can profitably preempt the entrant while the spin-off remains locked in a random Markov-perfect equilibrium with no guarantee of success. 
The "insurance put option" approach has become more valuable as the incumbent can profitably preempt the entrant from a lower number of "fickle" consumers relative to the baseline case. The ability to preemptively invest at a lower $y$ relative to the entrant, whose investment threshold has hardly changed from the baseline case, allows the incumbent to better protect and maximise the value of the assets-in-place. This explains why the difference in the assets-inplace value is significantly larger in Figure 4.9, relative to the second row of Figure 3.5, while the growth option difference is the same as found in the final row of graphs in Figure 3.5 of the baseline case. The preemption thresholds for the spin-off and entrant are nearly the same between the baseline and increased "fickleness" case so there is no real change to the bottom row in Figure 4.9 compared to Figure 3.5.

The top row of Figure 4.10 plots the firm level expected rate of return for the incumbent against the number of "fickle" consumers in the market. The exposure to systematic risk is similar for the incumbent as in the baseline case. As the number of "fickle" consumers rises in the market the incumbent's exposure to $x$ - and $y$-risk falls and the nature of the expected return curve becomes relatively inelastic. By increasing the "fickleness" of "fickle" consumers, the incumbent is able to profitably self-disrupt themselves from a lower number of "fickle" consumers resulting in high cannibalization of their assets-in-place. This means incumbent's firm value is now more sensitive to changes in $y$ than in the baseline case. We see this when comparing Figures 4.10 and 3.6 where the former shows the expected return becoming inelastic for a lower value of $y$.

The middle row of Figure 4.10 shows us that in integration, the expected return for the entrant at $x=50$ becomes nearly perfectly inelastic in nature. With no assets-in-place to fall back on, the entrant is very much at the beck and call of the consumers in the market and their willingness to transition between products. As "fickle" consumers more readily transition the firm value of the entrant becomes relatively sensitive to changes in consumer levels in the market exposing them to greater risk and therefore a higher expected return. The bottom row of graphs in Figure 4.10 displays results for the spin-off's expected return plotted against the number of "fickle" consumers in the market. The spin-off receives an identical expected return to the entrant as seen in the middle row. The spin-off's firm value is now more sensitive to changes in the demand drivers (especially $y$ in this case) hence why the spin-off's expected 
Figure 4.11: Preemption Payoffs and Thresholds with Lower Consumption Intensity

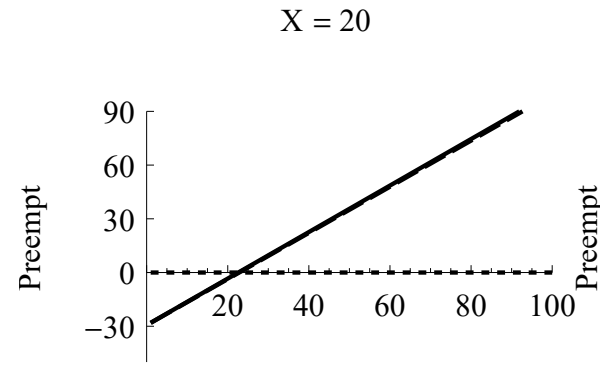

Fickle Customers (y)

$$
X=50
$$

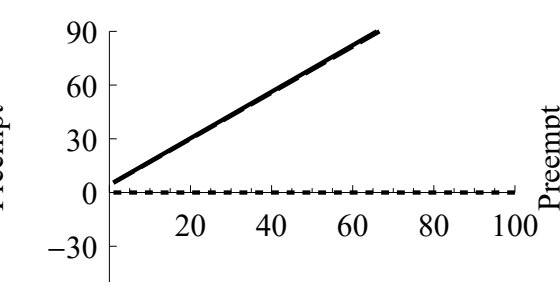

Fickle Customers (y)

$$
X=100
$$

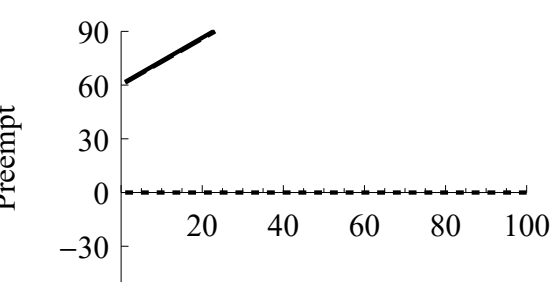

Fickle Customers (y)

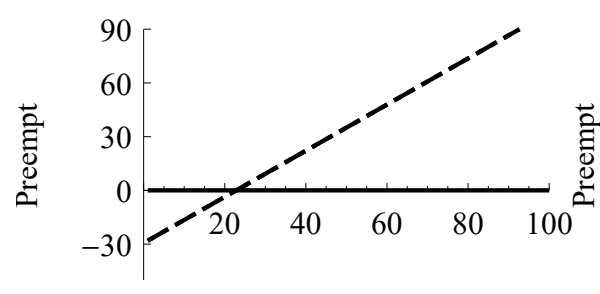

Fickle Customers (y)

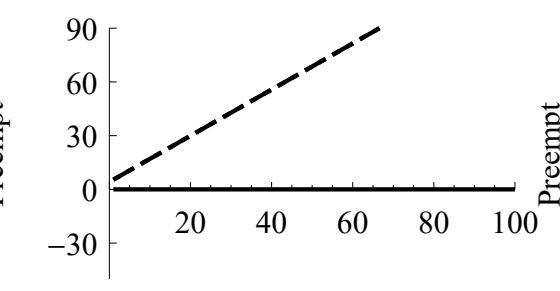

Fickle Customers (y)

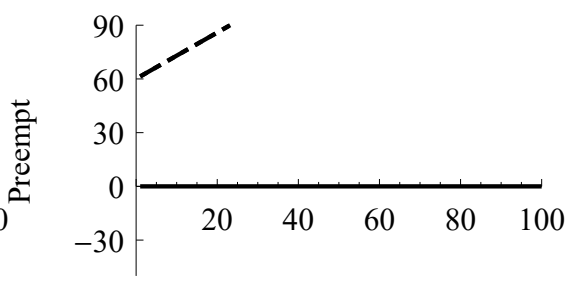

Fickle Customers (y)

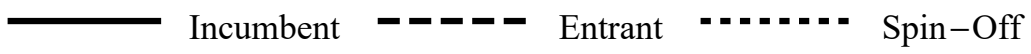

The preemption payoffs for the incumbent, entrant and skunkworks are plotted against the number of "fickle" consumers $(y)$ in the market at any given time. The top row shows the preemption payoffs in the integration structure while the bottom row shows the skunkworks structure. Where the preemption curves cross the horizontal axis is where the firm begins to profit from investing in the growth option.

return becomes more inelastic as $y$ increases. With this change in behaviour, the innovative product becomes more attractive and the spin-off knows they have a $50 \%$ chance of successfully securing the innovation should they attempt to invest simultaneously with the entrant.

\section{Summary of vulnerability}

Looking at the preemption behaviour, we see the incumbent can profitably invest for a smaller number of "fickle" consumers than in the baseline case while both the entrant and spin-off display relatively similar behaviour to that in the baseline case. As a result of this, the incumbent will prefer to internalise rather than exercise the one-off abandonment option at lower number of "fickle" consumers than in the baseline case. Cannibalization rates are higher than in other sections which is to be expected as $y$ units of "fickle" consumers more readily 
Table 4.3: Lower Intensity: Preemption Thresholds and Profitability of Pure Disruption Panel A: Variation

\begin{tabular}{ccccccc}
\hline & \multicolumn{3}{c}{ Preemption } & & \multicolumn{2}{c}{ One-Off Intersection } \\
\cline { 2 - 4 } \cline { 6 - 6 }$x$ & $y_{i}^{*}$ & $y_{e}^{*}$ & $y_{s}^{*}$ & & $y_{\text {int }}$ & $y_{s k}$ \\
\hline 20 & 22.60 & 22.82 & 22.82 & & 28.13 & 30.00 \\
30 & 13.96 & 14.14 & 14.14 & & 19.12 & 21.00 \\
50 & - & - & - & - & - \\
70 & - & - & - & - & - \\
100 & - & - & - & & - & - \\
\hline
\end{tabular}

Panel B: Baseline Case

\begin{tabular}{cccccc}
\hline & \multicolumn{3}{c}{ Preemption } & & \multicolumn{2}{c}{ One-Off Intersection } \\
\cline { 2 - 4 }$x$ & $y_{i}^{*}$ & $y_{e}^{*}$ & $y_{s}^{*}$ & & $y_{\text {int }}$ \\
\hline 20 & 51.73 & 56.70 & 56.70 & 70.39 & $y_{s k}$ \\
30 & 42.73 & 46.97 & 46.97 & 58.04 & 75.00 \\
50 & 24.72 & 27.58 & 27.58 & 37.50 & 62.27 \\
70 & 6.65 & 8.26 & 8.26 & 21.13 & 40.00 \\
100 & - & - & - & - & 25.00 \\
\hline
\end{tabular}

transition from the existing product to the innovative product. By internalising, the incumbent has a lower cannibalization rate than if the incumbent were to spin off the growth option. This lower cannibalization rate means that the incumbent in integration has maximised the value of their assets-in-place better than the skunkworks incumbent. This has only made it more apparent to the incumbent that with increasing "fickleness," they should internalise rather than spin off the growth option. This comes back to the preemption behaviour where in integration the incumbent can profitably preempt the entrant while in skunkworks the incumbent has no preemptive capabilities and the spin-off attempts to invest simultaneously with the entrant. Even though raising the "fickleness' of $y$ units of consumers has made the integration structure more appealing for the incumbent relative to skunkworks, we still find the one-off option to abandon is still more valuable for low numbers of "fickle" consumers.

\subsection{Importance of assets-in-place}

\begin{tabular}{cccccccc}
\hline$\mu_{x}=\mu_{y}$ & $\lambda_{x}=\lambda_{y}$ & $\sigma_{x}=\sigma_{y}$ & $\rho_{x y}$ & $\rho_{x}$ & $\rho_{y}$ & $\delta$ & $c_{2}^{i}=c_{2}^{s}$ \\
\hline 0.02 & 0.05 & 0.2 & -0.5 & 0.7 & 0.8 & $\mathbf{0 . 5} \mathbf{- 0 . 1}$ & 0.8 \\
\hline
\end{tabular}


Figure 4.12: Value of Market Participants with Lower Consumption Intensity
$X=20$
$X=50$
$\mathrm{X}=100$
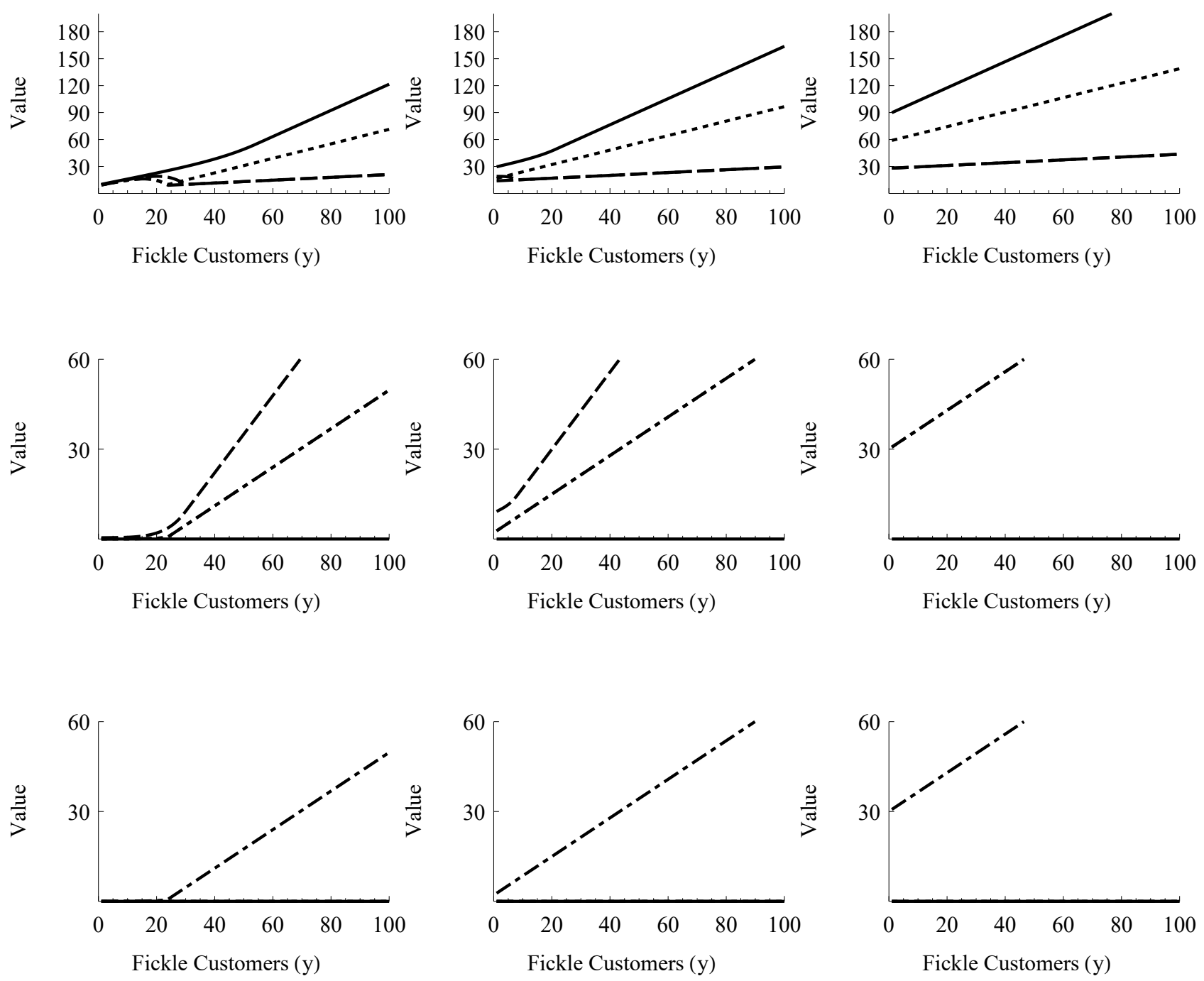

Best case

Pure disruption

Market values for the incumbent, entrant and spin-off are plotted against the number of "fickle" consumers, $y$, for different numbers of "loyal" consumers in the market. The top row shows the values for the incumbent, followed by the entrant and spin-off respectively. The values shown depend on the market structure.

In this section we target the $\delta$ parameter which deals with the relative size of the assets-inplace to the growth option. In the baseline case this was set at 0.5 showing an equal intensity in consumption of existing and new products. We now decrease this value to 0.4 so that the innovative product will receive a noticeable majority of the consumption in the market. The incumbent will have to question the importance of their assets-in-place when the growth option receives a greater present value cash flow. 
Figure 4.11 gives us a visual representation of the behaviour of market participants through their preemption payoffs plotted against the number of "fickle" consumers in the market. The incumbent is still able to preempt the entrant profitably for all values of $x$ as we lower the intensity with which the existing product is consumed. The entrant and spin-off will continue to find it profitable to attempt to invest at the same time so that the winner will always be determined randomly. By decreasing the relative size of the assets-in-place, the incumbent loses its uniqueness and begins to become more like the entrant. We see this in Table 4.3: when $x=20$, the preemption threshold for the incumbent equals $y_{i}^{*}=22.60$ while the entrant and spin-off have the threshold of $y_{e}^{*}=y_{s}^{*}=22.82$. With the majority of the incumbent's firm value now derived from the growth option the preemption threshold is reduced as far as possible before it is not reasonable to go any lower. As we make it impossible for $x$ and $y$ to be negative, when $x=50$ or 100 we state that both the incumbent and entrant will attempt to invest immediately with their decision being independent of the number of "fickle" consumers in the market.

We see the value of firms, depending on the market structure, in Figure 4.12 plotted against the number of "fickle" consumers. Decreasing the relative size of the assets-in-place decreases the overall firm values of the incumbent as shown in the top row of graphs in Figure 4.12. The only scenario where the incumbent receives more value from diminished intensity of existing product consumption is in the best case scenario. As the incumbent in this scenario is a monopolist they control the entire consumption for both the existing product and the innovation. With no competition in the market the incumbent knows they cannot "lose consumers" and so they only reap the rewards for holding both assets-in-place and the growth option. With consumption now favouring the innovative product the incumbent will exercise the growth option earlier and secure higher profits as more "fickle" consumers enter the market. For the other market structures, that have competition or a binding preemption constraint, the incumbent's market value is significantly lower, as we increase the number of "fickle" consumers, relative to the baseline case. With consumption now rising for the innovative product, as more "fickle" consumers enter the market the profits associated with investing in the growth option become more pronounced than in the baseline case. In the pure disruption and skunkworks structures, where the incumbent does not possess the growth option, the incumbent can receive none of 
these profits and instead watches as consumption of the existing product falls.

From the second and third row of graphs in Figure 4.12 we see the value of the entrant and spin-off noticeably increase as a result of consumption in the market favouring the innovative product. This result is to be expected as their firm value is directly tied to the consumption of the innovative product in the market. Both the entrant and spin-off find it so profitable in fact that from $x=50$, they will both immediately attempt to invest in the growth option even if there are no "fickle" consumers in the market.

As seen in Table 4.3, the preemption thresholds occur at lower values of $y$ such that fewer "fickle" consumers are needed in the market before firms can profitably attempt investing in the innovation. The gap between the incumbent and entrant preemption thresholds has become smaller relative to the baseline case. The incumbent can no longer afford to delay for as many "fickle" consumers to enter the market as in the baseline case. This is important to explain why in the integration example, the incumbent now receives less value as they are forced to invest at a lower number of "fickle" consumers to successfully preempt the entrant and perpetually produce the innovation. In the baseline case the incumbent could delay until they were in a more optimal position before investing, but by increasing the consumption intensity of the innovative product, the growth option is now too valuable to delay exercising.

The one-off intersection refers to the highest number of "fickle" consumers where the incumbent in pure disruption receives a greater value than either integration $\left(y_{\text {int }}\right)$ or skunkworks $\left(y_{s k}\right)$. These results are displayed in Table 4.3 which shows that because the growth option is now the dominant asset in the market, the pure disruption scenario provides the incumbent with greater market value than integration and skunkworks for only small values of both "loyal" and "fickle" consumers. In the baseline case, consumption in the market was set up so that the intensity with which consumers purchased the existing product was the same as the innovative product. By setting $\delta=0.4$, the innovative product is more heavily favoured such that consumers purchase the innovative product at a greater intensity compared to the existing product. Even though we have lowered the intensity, the intersection point of $y_{\text {int }}$ occurs at lower values of $y$ than $y_{s k}$ which is consistent with what was found in the baseline case. For example if $x=20$, the incumbent will find it profitable to internalise rather than exercise the one-off option to abandon if $y \geq 28.13$. For the same $x$ value, the incumbent will only spin off 
Figure 4.13: Value in Delaying with Lower Consumption Intensity
$X=20$
$\mathrm{X}=50$
$\mathrm{X}=100$
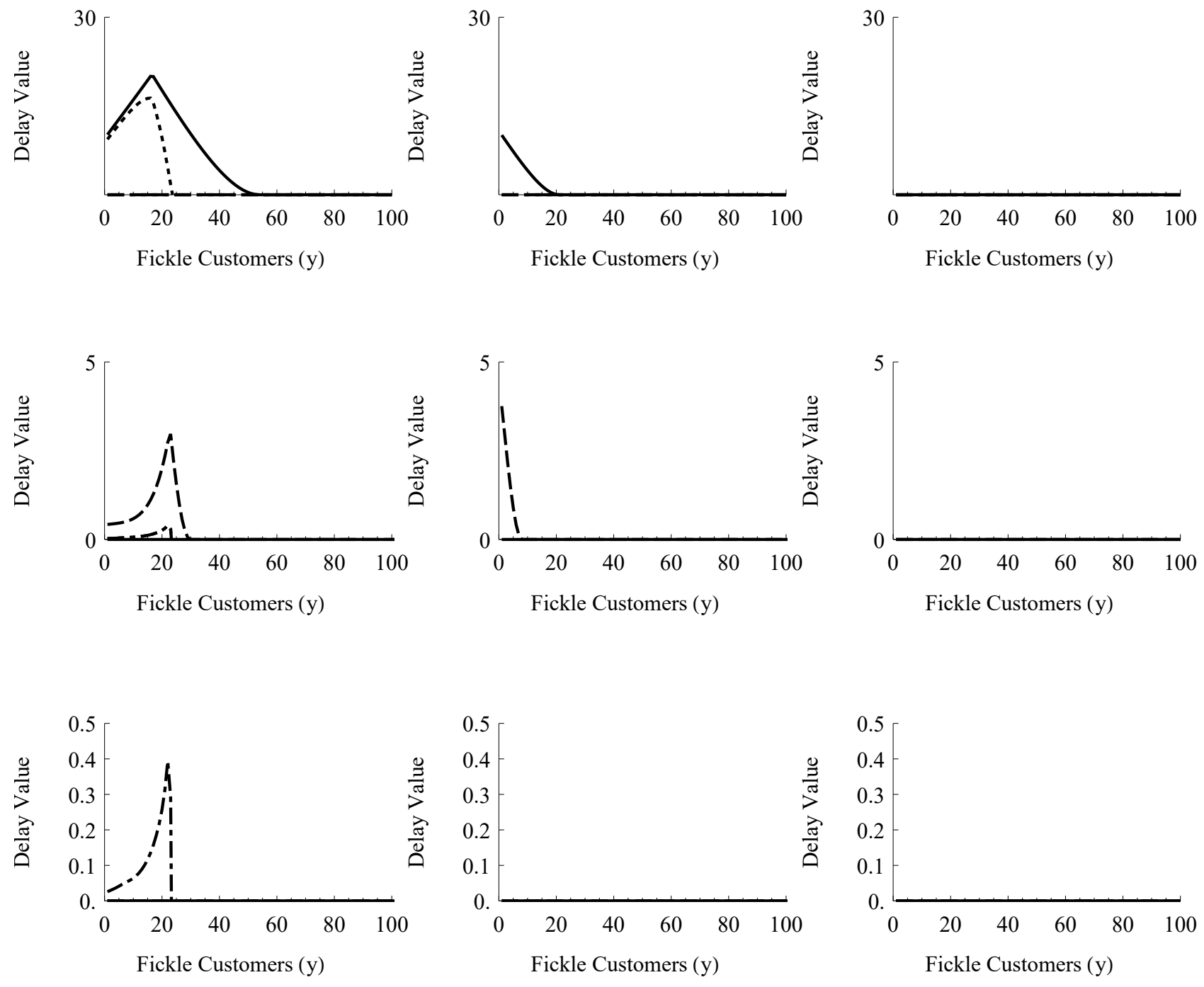

Best case

Pure disruption

Integration

Skunkworks

The value of delaying exercising the growth option is plotted against $y$ for different values of the number of "loyal" consumers, $x$. We can determine the value that would be ignored had we chosen a static discounted cash flow approach rather than a dynamic real options analysis. This value is the difference between our calculation of firm market value minus the value of a now-or-never option to invest.

the growth option, rather than abandoning it, when $y \geq 30$. If we look back at the baseline values for $y_{\text {int }}$ and $y_{s k}$ at $x=20$ the intersection values are 70.39 and 75 respectively. As consumers more readily consume the innovation over the existing product, the incumbent's value function relies more heavily on the growth option to maximise firm value. As the innovative product in the market becomes more popular the incumbent recognises their assets-in-place 
Figure 4.14: Cannibalization Rates with Lower Consumption Intensity
$X=20$
$\mathrm{X}=50$
$X=100$
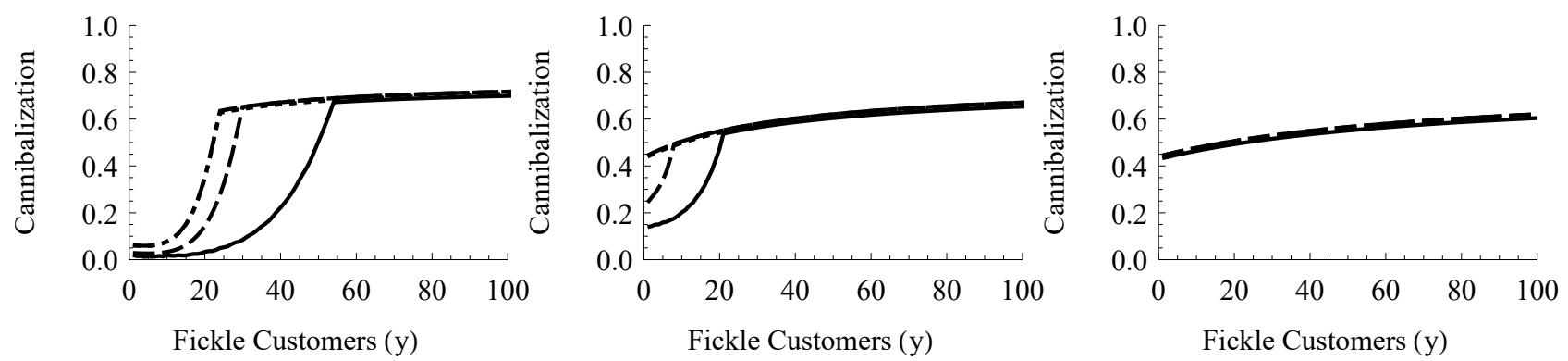

Best case

Pure disruption

Integration

Skunkworks

The rate of cannibalization is plotted against the number of "fickle" consumers in the market, $y$. The cannibalization rate reflects the loss in value of the assets-in-place by choosing to invest in the growth option rather than remaining as a monopoly. Cannibalization occurs in situations where there are binding preemption constraints (best case and pure disruption) and those where there are not (integration and skunkworks).

are facing a natural death. Following a no-competition scenario (best case scenario) the next optimal scenario for the incumbent is to internalise the growth option.

As we have created urgency in the market, by decreasing the importance of of the assetsin-place, there is now less value to be found in delaying investment. This is displayed in Figure 4.13 where the value in delaying is plotted against the number of "fickle" consumers in the market. From the top row in Figure 4.13, we see the incumbent, even in the best case scenario, deciding to immediately invest at a fewer number of "fickle" consumers rather than delay as seen in Figure 3.3. The incumbent can still profitably preempt the entrant which is why at $x=20$ we see there is some value in the integrated incumbent delaying investment. The second row displays results for the entrant where, because the entrant knows the incumbent can invest just before them, their value in delaying is small relative to the incumbent. The entrant only sees value in delaying when there is no binding preemption constraint (pure disruption). The bottom row shows the spin-off's value in delaying is small as competition intensifies over the growth option. With a stronger competition effect the spin-off and entrant can still only attempt to simultaneously invest to secure the growth option.

From Table 4.3 we can see that by lowering the importance of assets-in-place in the market, an internalised incumbent cannot afford to delay for too long as they can in the baseline case. When we increase the number of "loyal" consumers to $x=50$, the only structures that see 
any value in delaying are those where there are no binding preemption constraints on the participating firms. None of the market participants will delay when $x=100$ regardless of the business structure. The decline in the value in delaying can come down to the rise in profitability of the growth option which makes the preemption constraint more tightly binding. As firms find it more profitable to invest in the growth option when there are less "fickle" consumers in the market, the stricter preemption threshold sees participating firms diminish the value in delaying in their haste to invest.

Figure 4.14 plots the rate at which assets-in-place are cannibalized in favour of investing in the growth option and producing the innovative product. In comparison with Figure 3.4, the incumbent finds itself subject to a higher cannibalization ratio as we decrease the intensity of consumption for the existing product. When $x=20$ the integration and skunkworks scenarios have the incumbent cannibalizing their assets-in-place faster than any other stucture. With a binding preemption constraint for integration the incumbent is more willing to cannibalize, the now less important, assets-in-place in order to capitalise on the growth option now being profitable for a lower number of "fickle" consumers relative to the baseline case. In the skunkworks scenario there is a binding preemption contraint between the spin-off and entrant which sees both firms reaching a random Markov-perfect equilibrium where they attempt to invest at the same number of "fickle" consumers. The incumbent receives none of the growth option value and can only increase its value by maximising the value of the assets-in-place. In integration the assets-in-place are cannibalized to capitalise on the improved profitability of the growth option, while in the skunkworks scenario the increased cannibalization arises from increased competition between the spin-off and entrant fighting over the rights to the growth option.

The incumbent can delay the cannibalization of assets-in-place the most if they are in the best case scenario. With no threat of preemption or competition, the incumbent is free to delay as long as necessary until it is optimal for a firm owning both assets-in-place and the growth option that the latter is exercised. Following this is the pure disruption case where the incumbent can only maximise their firm value through the assets-in-place. In terms of cannibalization ratios, as the importance of assets-in-place diminishes, the incumbent becomes indifferent between whether to internalise or spin off the growth option. With the assets-in-place becoming less important, the internalised incumbent is more willing to sacrifice existing assets 
Figure 4.15: Optimal Incumbent Design with Lower Consumption Intensity

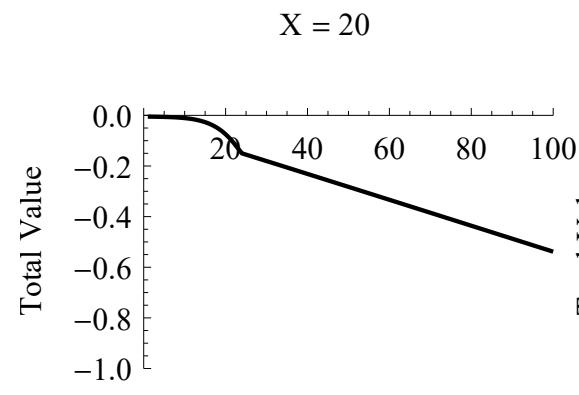

Fickle Customers (y)

$$
X=50
$$

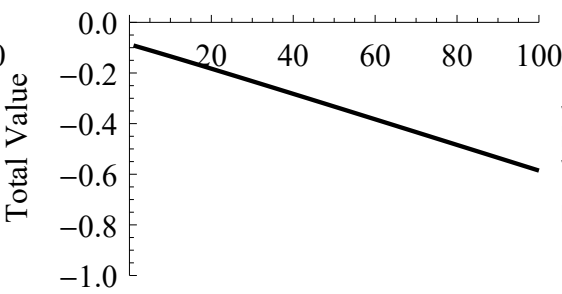

Fickle Customers (y)
$\mathrm{X}=100$

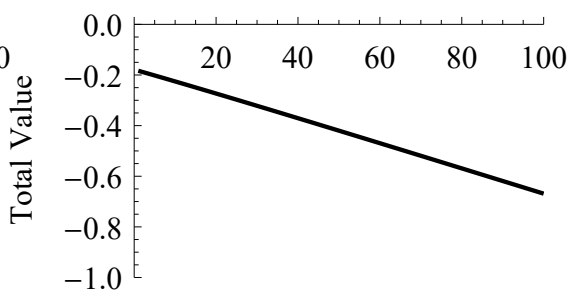

Fickle Customers (y)

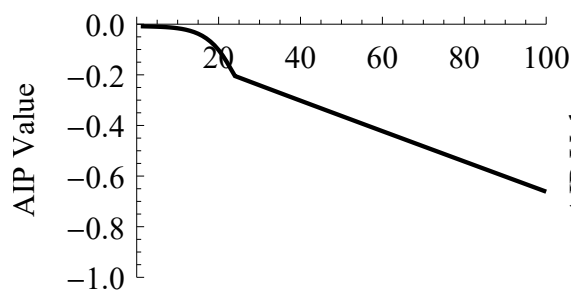

Fickle Customers (y)

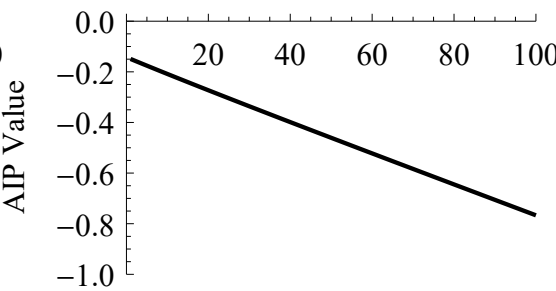

Fickle Customers (y)

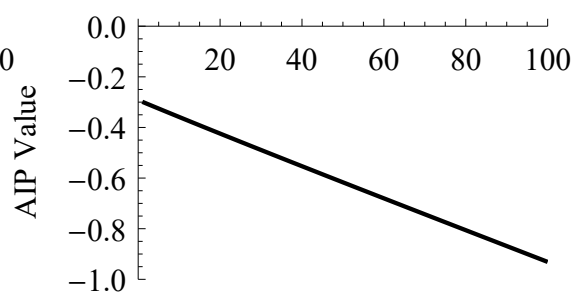

Fickle Customers (y)
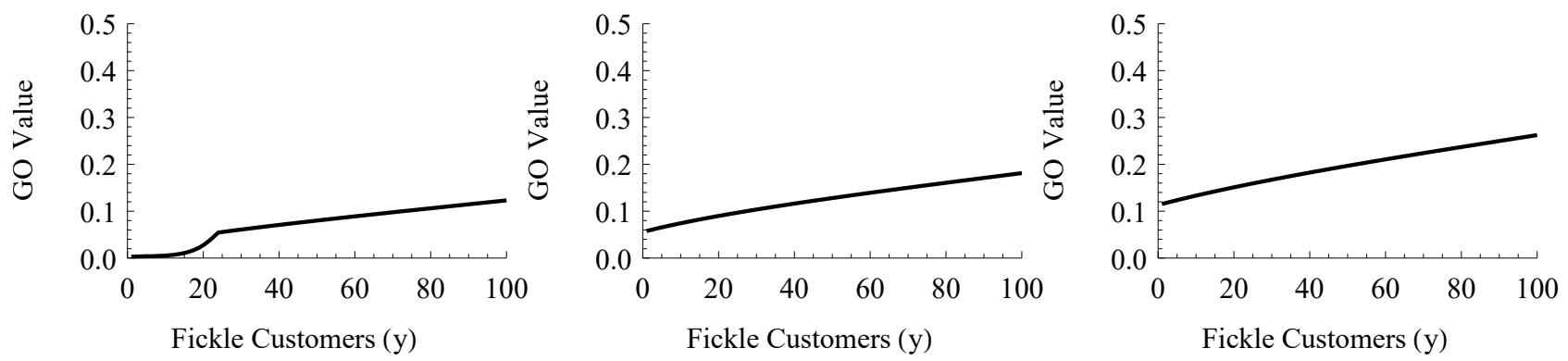

Cost of Spin-Off

The difference in value of the incumbent in integration and skunkworks is plotted against the number of "fickle" consumers in the market, $y$ for different values of $x$. The top row looks at the total value of the internalised incumbent deducted from the combined value of the incumbent and its spin-off. The next row focuses on the difference in value of the assets-in-place depending on whether the incumbent decides to follow the integration or skunkworks structure. The final row looks at the change in value of the growth option value for the two structures.

in favour of the investment growth option, and both the spin-off and entrant are more willing to exercise the growth option for fewer "fickle" consumers. For $x=50$, both the integration and skunkworks structure see no value in delaying, resulting in immediate investment. As more "loyal" consumers exist in the market the assets-in-place are cannibalized at lower rates which 
makes sense as these are the "loyal" customers that less readily transition away from the existing product. As more consumers enter the market, the profitability of both assets-in-place and the growth option rise. When there are 100 "loyal" consumers in the market there is enough of a traditional consumer base that firms will immediately invest in the growth option.

Even though the importance of the assets-in-place has dropped, the best way for the incumbent to protect their assets-in-place, should an entrant exist in the market, is to abandon the growth option. Rather than actively competing against the entrant, by internalising or spinning off, the incumbent should commit to not competing in order to better protect their assets-in-place. The pure disruption scenario shows in Figure 4.14 that as the growth option becomes more profitable to exercise at lower "fickle" consumer numbers, the incumbent should eliminate competition to postpone the effects of cannibalization. This can be done by hiding the innovation behind a patent thereby locking the entrant out before they have a chance, best case, or by making an irreversible commitment with the entrant to avoid competition, pure disruption. This further lends credence to the theory that the best preemptive measure an incumbent firm can take to maximise their firm value is to commit to doing nothing by actively avoiding the innovation.

We now consider Figure 4.15 which determines whether it is best for the incumbent to manage the growth option from an integration or skunkworks approach. The top row in Figure 4.15 shows by decreasing the consumption of the existing product, we reduce the value by which the internalised incumbent exceeds the combined value of the incumbent and its spin-off. Even though we have reduced the intensity of consumption for the existing product, the internalised incumbent still has a marginally higher value than a spin-off structure. By lowering $\delta$, the internalised incumbent is now more similar to the combined incumbent and spin-off, relative to the baseline case. The assets-in-place are still better protected in the internalised approach and the spin-off presents the highest growth option value. The difference between integration and skunkworks has noticeably diminished relative to the baseline values. With the desire to protect assets-in-place diminishing, the objective of the internalised incumbent becomes similar to that of the spin-off, which aims to maximise the value of the growth option. As we decrease the intensity of the existing product consumption, the incumbent becomes indifferent between internalising and spinning off. As markets move towards favouring the innovative products, 
Figure 4.16: Firm-level Expected Rate of Return with Lower Consumption Intensity

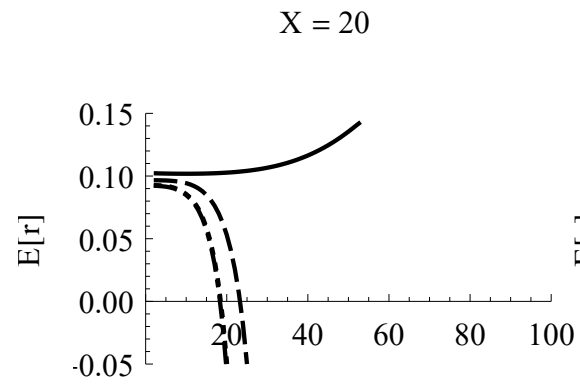

Fickle Customers (y)

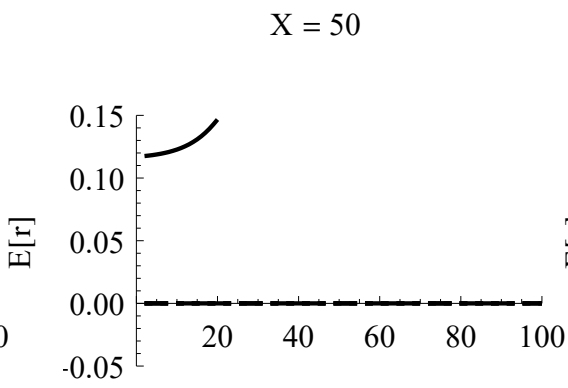

Fickle Customers (y)
$X=100$

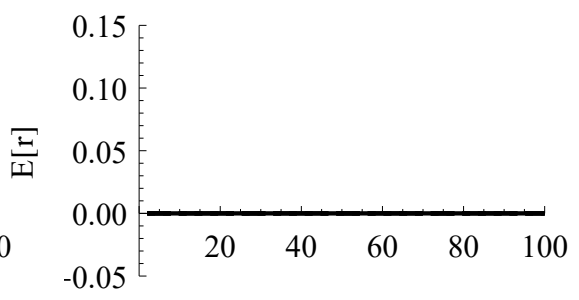

Fickle Customers (y)

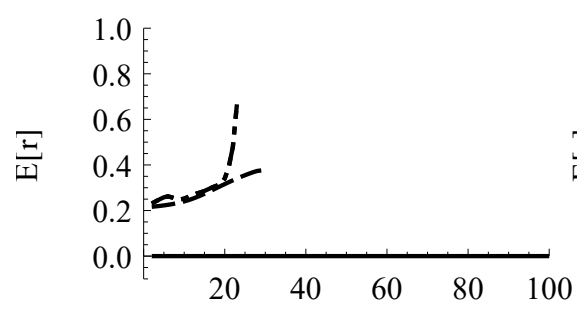

Fickle Customers (y)

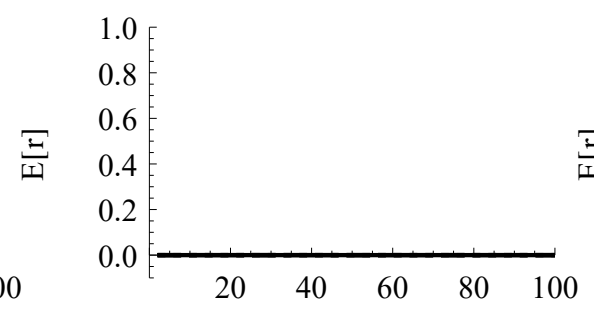

Fickle Customers (y)

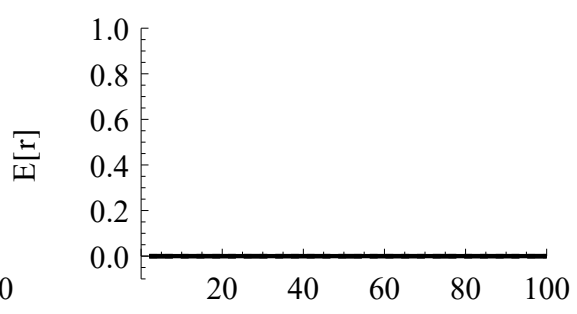

Fickle Customers (y)

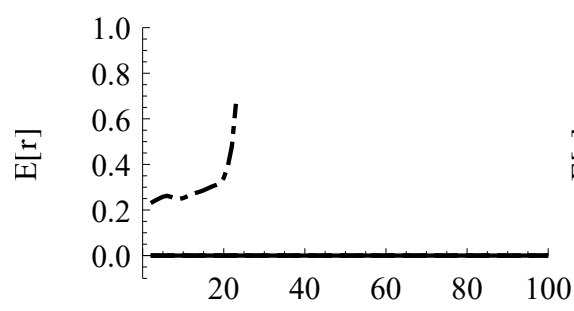

Fickle Customers (y)

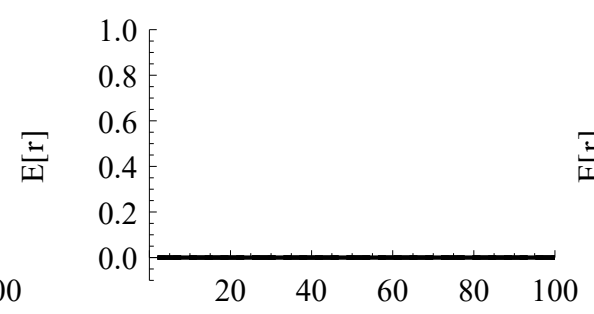

Fickle Customers (y)

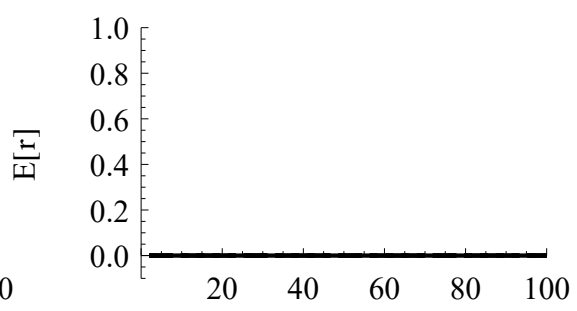

Fickle Customers (y)

Best case

The firm level expected return is plotted aginst the number of "fickle" customers, $y$, for different numbers of "loyal" consumers, $x$, in the market. The top row shows the incumbent's expected return for the four different market structures, while the next two rows are for the entrant and spin-off respectively.

incumbent firms are better off spinning off the growth option as they will only lose value as a result of assets-in-place.

What we find in Figure 4.15 is to be expected as firms in a market cater to the preferences dispayed by the consumers that inhabit the market. Should customers consume less of a product then the market will naturally correct itself and firms will dynamically change to match this as their profits are directly tied to consumption. Even when the innovative product commands 
a dominant consumption position over the existing product, the incumbent would still find it better to internalise rather than spin off. If we kept lowering the intensity at which customers consume the existing product we would see how incumbent firms eventually deteriorate which we expressed in our first chapter as "creative destruction" or the fire ecology story. As existing assets diminish, the innovation brings in new life to the market that would otherwise die out. Innovation does not cause the death of markets, it instead revitalises them and allows them to adapt and change to suit the needs of consumers. The typical consumer does not care whether the incumbent internalises or spins off the growth option to produce the innovative product, and with the importance of assets-in-place falling, the incumbent firm now becomes indifferent between the two methods as well.

If we look at the "insurance put option" approach, we consider the reasons behind why the incumbent wants to preemptively invest. The baseline case made the assumption that customers in the market consumed both existing and innovative products at the same intensity. As we have altered this intensity to favour the innovative product, and hence the growth option, the incumbent is not investing preemptively to protect the value of the assets-in-place, but to receive the value of the growth option. The insurance put approach only works so long as the incumbent seeks to preemptively invest, thereby "self-disrupting" themselves, to mitigate the effects of cannibalization. By reducing the intensity of consumption for the existing product, the incumbent becomes indifferent to the effects investment has on the assets-in-place.

Figure 4.16 plots the expected return for all firms, across the different structures, against the number of "fickle" consumers in the market. The top row shows the incumbent's expected return for different numbers of "loyal" consumers where, consistent with the baseline case, the expected return diminishes before becoming negative. The only case this does not occur for is the best case scenario where it actually increases just before the optimal stopping region. By lowering the consumption intensity of the existing product, the weighted average of firm value favours the growth option. The incumbent's firm value is now more sensitive to changes in the number of "fickle" consumers as these are the consumers that more readily transition from the existing product to the innovation. With no binding preemption constraint the incumbent's firm value, now weighted towards the growth option, is more exposed to systematic risk and hence they receive a higher expected return just before the optimal stopping threshold. 
For all other cases the incumbent either does not hold the growth option or is subject to a binding preemption constraint, and so becomes less exposed to systematic risk. Compared to Figure 3.6 in the baseline case, the sensitivity of the incumbent's firm value to changes in the demand drivers becomes inelastic in nature for a smaller number of "fickle" consumers in the market. As we lower the importance of the assets-in-place, the weighted average of firm value that determines the expected return now favours the growth option. The incumbent's firm value is more sensitive to changes in $y$ as these are the consumers that have a higher propensity to transition and make the growth option more valuable to exercise. The pure disruption (dashed curve) and skunkworks (dash-dotted curve) are scenarios where the incumbent does not hold the growth option which explains why the incumbent's expected return becomes inelastic for low values of $y$ in these cases as their assets-in-place lose importance.

The second row in Figure 4.16 plots the entrant's expected return against the number of "fickle" consumers in the market while the third row does the same for the spin-off. The risk of the entrant and spin-off in the pure disruption and skunkworks structures rises with $y$ as the market participants move closer to the optimal stopping region. The entrant in pure disruption is not subject to a binding preemption constraint and can exercise the growth option with no threat of competition. The entrant's firm value is not as sensitive to changes in the demand drivers $(x$ and $y)$ as it is in the skunkworks where there is a binding preemption constraint as they compete against the spin-off. In the skunkworks structure both the spin-off and entrant have a random Markov-perfect equilibrium where both firms will attempt to invest at the same time where only one will succeed. As the firms move closer to the investment threshold, both the entrant and spin-off see their expected return curves become inelastic as their market values become more sensitive to changes in the demand drivers ( $x$ and $y)$.

\section{Summary of importance}

By lowering the consumption intensity the behaviour of the incumbent becomes similar to that of the entrant (and the spin-off). While the incumbent can still profitably preempt the entrant, should the importance of assets-in-place continue to drop the incumbent and entrant will revert to a random Markov-perfect equilibrium. We see this as the preemption thresholds for the incumbent and entrant occur at nearly the same number of "fickle" consumers as we 
lower the consumption intensity for the existing good. As we lower the importance of the assets-in-place, by shifting consumer preferences to favour the innovative product, the attempt to invest in the growth option occurs at lower number of "fickle" consumers. The incumbent is now more willing to cannibalize a higher proportion of their assets-in-place in favour of exercising the growth option relative to the baseline case. By lowering the consumption of the existing product, the objective function for the incumbent in integration aligns with that of the incumbent and spin-off in skunkworks. With consumption now favouring the innovation, the internalised incumbent begins to act more like the spin-off in skunkworks. In both cases the internalised incumbent and spin-off favour the growth option and will attempt to invest when it maximises the value of the growth option regardless of its effect on the assets-in-place. 


\section{Concluding Remarks}

The ability of an incumbent firm to alter its business structure provides it with greater freedom to compete more efficiently with the entrant. This thesis shows how an incumbent can mould itself to effectively compete against an entrant. The ability to compete is dependent on uncertainty arising from the number of both "loyal" and "fickle" consumers in the market. Should both the incumbent and entrant be efficient producers of the innovation then the incumbent will be able to profitably invest just before the entrant. Despite this position in the market the incumbent will prefer to abandon the innovation permanently provided it can credibly commit to permanent abandonment. The hesitancy the incumbent displays by deciding not to compete over the innovation arises from the majority of the incumbent's firm value being drawn from the assets-in-place, and an unwillingness to see them cannibalized.

In our baseline case, the incumbent finds that permanently abandoning the growth option is the most viable response for the incumbent unless a significant number of "fickle" consumers enter the market to justify competing with the entrant. The incumbent can commit to this decision by making an irreversible decision to convert the asset for use in another project to avoid competition over the same innovative product. An example of this decision could be converting crucial land for a factory into residential properties. Making this decision means the incumbent effectively still preempts the entrant but does so by abandoning rather than investing. By convincing the entrant they are committed to not competing, the incumbent can reduce the cannibalization effect on their assets-in-place and maintain a higher expected return than if they competed by internalising or spinning off the growth option.

Should the incumbent produce the innovation at a sufficiently higher cost than the entrant, then the former loses the ability to profitably preempt the latter. This only increases the value 
of the one-off option to abandon rather than internalising or spinning off the growth option, and competing with the entrant. If the incumbent knows they cannot win, then they choose to lose in such a way they can preserve the value of their assets-in-place over a greater number of "fickle" consumers that enter the market.

Increasing the "fickleness" dyanmic allows the incumbent to profitably preempt the entrant at a lower number of "fickle" consumers relative to the baseline case. To protect the assets-inplace, the incumbent is willing to invest earlier in response to "fickle" consumers more readily transitioning away from the existing product. Although increasing the "fickleness" of $y$ units of consumers should increase the value of the entrant following successful investment, the incumbent's protectiveness of assets-in-place negates this and cancels out the "fickleness" effect. As we increase the "fickleness" we see the one-off abandonment option to be less valuable over the number of "fickle" consumers in the market. The commitment of the incumbent exercising the one-off abandonment option occurs for a lower number of "fickle" consumers as the growth option becomes more valuable to the incumbent.

If consumer preferences shift away from the existing product, then the innovation is more intensely consumed in the market. As consumer preferences move in favour of innovation the incumbent begins to align its objective function with that of the entrant. The one-off option to abandon the development of the innovation now becomes less attractive than internalising or spinning off the growth option. If the incumbent were to abandon the growth option then they would have failed to read the market as the growth option is now more valuable with the increased popularity of the innovative product. The incumbent becomes less concerned about maintaining assets-in-place value and instead looks to capitalise on the success of the innovative growth option.

When we started with the baseline case, the incumbent maximised their objective function by minimising the cannibalization of assets-in-place and optimally investing in the growth option. Gans (2016) would argue that as the incumbent can profitably preempt the entrant, the best course of action would be to internalise the growth option. If the internalised incumbent can produce the innovation as efficiently as the entrant, or spin-off, with no additional costs required to integrate both product systems then we agree with Gans (2016). What we found was the integration structure provided greater value to the incumbent than the skunkworks 
scenario. While the spin-off did increase the growth option's value by more than the internalised incumbent, this did not outweigh the loss in the value of assets-in-place by spinning off rather than internalising.

If there are architectural cost inefficiencies, then the best solution for the incumbent is to spin off the growth option rather than internalise it. The incumbent can avoid inefficient costings by allowing the spin-off to take ownership and control of the growth option. The spinoff is more effective in competing with the entrant relative to the internalised incumbent who can never profitably invest in the growth option befores the entrant. The integration approach still better protects the assets-in-place, but the gain from the growth option by spinning off exceeds the value lost through cannibalization of assets-in-place.

By decreasing the relevance of the assets-in-place, the incumbent attempts to invest earlier than in the baseline case. They are more willing to subject the assets-in-place to a higher degree of cannibalization as the innovative product proves to be more popular than the existing product. The incumbent begins to behave like an entrant by shifting their focus to maximising the growth option value at the expense of the assets-in-place. Consider the integration approach. As the assets-in-place's importance decreases then the incumbent begins to prioritise maximising the value of the growth option more and more until the incumbent is essentially just another entrant. The incumbent's combined value of their existing business plus spin-off begins to solely rely on the spin-off so that the objective function of the incumbent is maximising the value of the spin-off. As both integration and skunkworks reduce to this result the difference between the two also reduces.

This thesis has investigated the optimal strategy for firms to mitigate disruption risk and maximise value when presented with an investment opportunity. We have seen the incumbent identify the importance of assets-in-place and attempt to prolong the natural life of this asset. We have provided significant freedom to the incumbent by allowing them to effectively choose between three different strategies targeted to capitalise on the investment opportunity. If an incumbent wishes to be a proactive market participant, then internalising and spinning off the investment opportunity can provide a greater benefit to their firm value. An inability to convey their commitment to indefinitely forgoing the opportunity will result in an incumbent being better off internalising the investment opportunity rather than spinning it off. The benefit of 
committing to abandonment can be appealing to the incumbent firm and can prove inaction is just as effective as acting. Rather than invest in the new innovation, we have found that it can be in a firm's best interests to indefinitely abandon the innovative opportunity and eventually be disrupted. The incumbent can focus on maximizing stakeholder value by securing existing assets over potentially profitable innovations. When presented with the threat of disruption, it can be in the best interests of a firm to avoid conflict entirely rather than try to throw the first punch. 


\section{Bibliography}

Adner, R. (2002). When are technologies disruptive? A demand-based view of the emergence of competition. Strategic Management Journal, 23:667-688.

Adner, R. and Levinthal, D. A. (2004). What is not a real option: Considering boundaries for the application of real options to business strategy. Academy of Management Review, $29: 74-85$.

Aghion, P. and Tirole, J. (1994). The management of innovation. The Quarterly Journal of Economics, 109:1185-1209.

Aguerrevere, F. (2009). Real options, product market competition, and asset returns. The Journal of Finance, 64:957-983.

Anton, J. and Yao, D. (1995). Start-ups, spin-offs, and internal projects. Journal of Law, Economics, \& Organisation, 11:362-378.

Athey, S. and Schmutzler, A. (2001). Investment and market dominance. The RAND Journal of Economics, 32:1-26.

Babenko, I. and Tserlukevich, Y. (2017). Embracing risk: Hedging policy for firms with real options. Working Paper, Arizona State University.

Beath, J., Katsoulacos, Y., and Ulph, D. (1989). Strategic R\&D policy. The Economic Journal, 99:74-83.

Berk, J., Green, R., and Naik, V. (1999). Optimal investement, growth options, and security returns. The Journal of Finance, 54:1553-1607.

Brennan, M. and Schwartz, E. (1985). Evaluating natural resource investments. The Journal of Business, 58:135-157. 
Carlson, M., Dockner, E., Fisher, A., and Giammarino, R. (2014). Leaders, followers, and risk dynamics in industry equilibrium. The Journal of Financial and Quantitative Analysis, 49:321-349.

Childs, P., Ott, S., and Riddiough, T. (2001). Valuation and information policy for claims written on noisy real assets. Financial Management, 30:45-75.

Christensen, C. (1997). The Innovator's Dilemma. Harvard Business Review Press, Massachusetts.

Cockburn, I. and Henderson, R. (1994). Racing to invest? The dynamics of competition in ethical drug discovery. Journal of Economics \& Management Strategy, 3:481-519.

Cohen, W. and Levinthal, D. (1994). Fortune favors the prepared firm. Management Science, $40: 227-251$.

Connell, J. and Slatyer, R. (1977). Mechanisms of succession in natural communities and their role in community stability and organization. The American Naturalist, 111:1119-1144.

Dasgupta, P., Gilbert, R., and Stiglitz, J. (1980). Invention and innovation under alternative market structures: The case of natural resources. Bell Journal of Economics, 11:1-28.

Dasgupta, P. and Stiglitz, J. (1980). Uncertainty, industrial structure and the speed of R\&D. Bell Journal of Economics, 11:1-28.

DellaSala, D. and Hanson, C. (2015). The ecological importance of mixed-severity fires. Elsevier, Amsterdam, Netherlands.

Dixit, A. (1992). Investment and hysteresis. The Journal of Economic Perspectives, 6:107-132.

Dixit, A. K. and Pindyck, R. S. (1994). Investment under uncertainty. Princeton University Press.

Epstein, L. and Zin, S. (1989). Substitution, risk aversion, and the temporal behaviour of consumption and asset. Econometrica, 57:937-969.

Farmer, R. (1990). RINCE preferences. The Quarterly Journal of Economics, 105:43-60. 
Femminis, G. and Martini, G. (2011). Irreversible investment and R\&D spillovers in a dynamic duopoly. Journal of Economic Dynamics and Control, 35:1061-1090.

Gans, J. (2016). The Disruption Dilemma. The MIT Press, Cambridge.

Gilbert, R. and Newbery, D. (1982). Preemptive patenting and the persistence of monopoly. The Amercian Economic Review, 72:514-526.

Gomes, J., Kogan, L., and Zhang, L. (2003). Equilibrium cross section of returns. Journal of Political Economy, 111:693-732.

Grenadier, S. (2002). Option exercise games: An application to the equilibrium investment strategies of firms. The Review of Financial Studies, 15:691-721.

Grenadier, S. and Malenko, A. (2011). Real options signaling games with applications to corporate finance. The Review of Financial Studies, 24:3993-4036.

Grenadier, S. and Wang, N. (2005). Investment timing, agency, and information. Journal of Financial Economics, 75:493-533.

Guthrie, G. (2011). A note on operating leverage and expected rates of return. Finance Research Letters, 8:88-100.

Guthrie, G. (2017). Investment flexibility as a barrier to entry. Victoria University of Wellington, Working Paper.

Hackbarth, D. and Johnson, T. (2015). Real options and risk dynamics. Review of Economic Studies, 82:1449-1482.

Henderson, R. and Clark, K. (1990). Architectural innovation: The reconfiguration of existing product technologies and the failure of established firms. Administrative Science Quarterly, $35: 9-30$.

Huberts, N., Dawid, H., Huisman, K., and Kort, P. (2019). Entry deterrence by timing rather than overinvestment in a strategic real options framework. European Journal of Operational Research, 274:165-185. 
Huberts, N., Huisman, K., Kort, P., and Lavrutich, M. (2015). Capacity choice in (strategic) real options models: A survey. Dynamic Games Applications, 5:424-439.

Kamien, M. and Schwartz, N. (1982). Market Structure and Innovation. Cambridge University Press, Cambridge.

Kasanen, E. and Trigeorgis, L. (1994). A market utility approach to investment valuation. European Journal of Operational Research, 74:294-309.

Lambrecht, B. and Perraudin, W. (2003). Real options and preemption under incomplete information. Journal of Economic Dynamics \& Control, 27:619-643.

Lavrutich, M., Huisman, K., and Kort, P. (2016). Entry deterrence and hidden competition. Journal of Economic Dynamics \& Control, 69:409-435.

Lerner, J. (2012). The Architecture of Innovation. Oxford University Press, Great Clarendon Street, Oxford.

McDonald, R. and Siegel, D. (1986). The value of waiting to invest. Quarterly Journal of Economics, 101:707-727.

Myers, S. (1977). Determinants of corporate borrowing. Journal of Financial Economics, $5: 147-175$.

Nembhard, H. and Aktan, M. (2010). Real options in engineering design, operations, and management. Ringgold Inc, Portland.

Novy-Marx, R. (2007). An equilibrium model of investment under uncertainty. The Review of Financial Studies, 20:1461-1502.

Pawlina, G. and Kort, P. (2006). Real options in an asymmetric duopoly: who benefits from your competitive disadvantage? Journal of Economics and Management Strategy, 15:1-35.

Reinganum, J. (1983). Uncertain innovation and the persistence of monopoly. The American Economic Review, 73:741-748.

Salant, S. (1976). Exhaustible resources and industrial structure: A Nash-Cournot approach to the world oil market. Journal of Political Economy, 84:1079-1094. 
Schumpeter, J. (1942). Capitalism, Socialism and Democracy. Harper \& Brothers, New York.

Schwartz, K. M. E. (2002). R\&D investments with competitive interactions. Review of Finance, $8: 355-401$.

Slater, S., Reddy, V., and Zwirlein, T. (1998). Evaluating strategic investments: Complementing discounted cash flow analysis with options analysis. Industrial Marketing Management, $27: 447-458$.

Smets, F. (1991). Exporting versus FDI: The effect of uncertainty, irreversibilities, and strategic interactions. Working Paper, Yale University.

Swinney, R., Cachon, G., and Netessine, S. (2011). Capacity investment timing by start-ups and established firms in new markets. Management Science, 57:763-777.

Tourinho, O. (1979). The valuation of reserves of natural resources: an option pricing approach. Ph.D. Dissertation, University of California, Berkeley.

Trigeorgis, L. (1996). Real Options: Management Flexibility and Strategy in Resource Allocation. MIT Press, Cambridge. 


\section{Appendices}

\section{A.1 Optimal Quantities}

In order to find the optimal quantities we start by rearranging the budget constraint so that the demand for the composite good equals

$$
q_{0}=M-p_{1} q_{1}-p_{2} q_{2}
$$

From here we then substitute this into the utility function so that we find

$$
\begin{aligned}
U & =q_{0}+\left(q_{1}^{\rho}+q_{2}^{\rho}\right)^{\frac{\alpha}{\rho}} \\
& =M-p_{1} q_{1}-p_{2} q_{2}+\left(q_{1}^{\rho}+q_{2}^{\rho}\right)^{\frac{\alpha}{\rho}}
\end{aligned}
$$

which we then take first derivatives of with respect to $q_{1}$ and $q_{2}$. These derivatives take the form

$$
\begin{aligned}
& \frac{\partial U}{\partial q_{1}}=-p_{1}+q_{1}^{-1+\rho} \alpha \delta\left(q_{2}^{\rho}(1-\delta)+q_{1}^{\rho} \delta\right)^{-1+\frac{\alpha}{\rho}} \\
& \frac{\partial U}{\partial q_{2}}=-p_{2}+q_{2}^{-1+\rho} \alpha(1-\delta)\left(q_{2}^{\rho}(1-\delta)+q_{1}^{\rho} \delta\right)^{-1+\frac{\alpha}{\rho}}
\end{aligned}
$$

which are set to equal zero. We move $p_{1}$ and $p_{2}$ to the LHS of their respective equations and then solve them simultaneously by dividing through such that

$$
\frac{p_{1}}{p_{2}}=\frac{q_{1}^{-1+\rho} \alpha \delta\left(q_{2}^{\rho}(1-\delta)+q_{1}^{\rho} \delta\right)^{-1+\frac{\alpha}{\rho}}}{q_{2}^{-1+\rho} \alpha(1-\delta)\left(q_{2}^{\rho}(1-\delta)+q_{1}^{\rho} \delta\right)^{-1+\frac{\alpha}{\rho}}} .
$$


By simplifying and rearranging this equation we find that $q_{1}$ will equal

$$
q_{1}=\left(\frac{p_{1} q_{2}^{-1+\rho}(1-\delta)}{p_{2} \delta}\right)^{\frac{1}{\rho-1}}
$$

We cannot stop here as $q_{1}$ is still a function of $q_{2}$ and we only want it subject to output prices $\left(p_{1}\right.$ and $\left.p_{2}\right)$. From equation (IA.1) we know that

$$
p_{2}=q_{2}^{-1+\rho} \alpha(1-\delta)\left(q_{2}^{\rho}(1-\delta)+q_{1}^{\rho} \delta\right)^{-1+\frac{\alpha}{\rho}}
$$

and after substituting in $q_{1}$, from equation (IA.2) we find

$$
p_{2}=q_{2}^{-1+\rho} \alpha(1-\delta)\left(q_{2}^{\rho}(1-\delta)+\left(\frac{p_{1} q_{2}^{-1+\rho}(1-\delta)}{p_{2} \delta}\right)^{\frac{\rho}{\rho-1}} \delta\right)^{-1+\frac{\alpha}{\rho}}
$$

where we can find the optimal $q_{2}$ which will only be conditional on output prices. By moving $q_{2}$ to the LHS we simplify the equation to

$$
\begin{aligned}
q_{2} & =\left(\frac{p_{2}\left(1+\delta\left(-1+\left(\frac{p_{2} \delta}{p_{1}(1-\delta)}\right)^{\frac{\rho}{1-\rho}}\right)\right)^{1-\frac{\alpha}{\rho}}}{\alpha(1-\delta)}\right)^{\frac{1}{\alpha-1}} \\
& =\left(\frac{p_{2}\left(p_{1}^{\frac{\alpha-\rho}{1-\rho}}\right)(1-\delta)^{\frac{\alpha-\rho}{1-\rho}}\left((1-\delta)^{\frac{1}{1-\rho}} p_{1}^{\frac{\rho}{1-\rho}}+\delta^{\frac{1}{1-\rho}} p_{2}^{\frac{\rho}{1-\rho}}\right)^{1-\frac{\alpha}{\rho}}}{\alpha(1-\delta)}\right)^{\frac{1}{\alpha-1}} \\
q_{2}^{*} & =\left(\frac{p_{1}^{\frac{\alpha-\rho}{1-\rho}} p_{2}(1-\delta)^{\frac{\alpha-1}{1-\rho}}\left(p_{1}^{\frac{\rho}{1-\rho}}(1-\delta)^{\frac{1}{1-\rho}}+p_{2}^{\frac{\rho}{1-\rho}} \delta^{\frac{1}{1-\rho}}\right)^{1-\frac{\alpha}{\rho}}}{\alpha}\right)^{\frac{1}{\alpha-1}} .
\end{aligned}
$$

If we then substitute this back into the $q_{1}$ formula above and simplify we find

$$
q_{1}^{*}=\left(\frac{p_{1} p_{2}^{\frac{\alpha-\rho}{1-\rho}} \delta^{\frac{1-\alpha}{\rho-1}}\left(p_{1}^{\frac{\rho}{1-\rho}}(1-\delta)^{\frac{1}{1-\rho}}+p_{2}^{\frac{\rho}{1-\rho}} \delta^{\frac{1}{1-\rho}}\right)^{1-\frac{\alpha}{\rho}}}{\alpha}\right)^{\frac{1}{\alpha-1}}
$$

which gives us the optimal quantities for both the existing and innovative products. Which $\rho$ is used depends on whether the consumer in question is "loyal" or "fickle." 


\section{A.2 Own-Price Elasticity Parameter}

Consider the incumbent before any investment that only sells the existing good (good 1). We would then have a utility function that equals

$$
\begin{aligned}
U & =q_{0}+\left(q_{1}^{\rho}+0\right)^{\frac{\alpha}{\rho}} \\
& =q_{0}+q_{1}^{\alpha}
\end{aligned}
$$

where there is no demand for the innovation as it is not yet produced. From the budget constraint we can set the quantity of the composite good as

$$
q_{0}=M-p_{1} q_{1}
$$

which equals all other consumption in the market excluding that of the existing product. If we take a first order condition of the utility function with respect to $q_{1}$ and set it equal to zero this implies

$$
\begin{aligned}
\frac{\partial U}{\partial q_{1}} & =-p_{1}+q_{1}^{\alpha-1} \alpha=0 \\
q_{1}^{*} & =\left(\frac{p_{1}}{\alpha}\right)^{\frac{1}{\alpha-1}} .
\end{aligned}
$$

We then find that $\alpha$ is a parameter to reflect the own-price elasticity of demand using the following formula:

$$
\begin{aligned}
\epsilon_{D} & =\frac{p_{1}}{q_{1}^{*}} \cdot \frac{\partial q_{1}^{*}}{\partial p_{1}} \\
& =-\frac{1}{1-\alpha}
\end{aligned}
$$

\section{A.3 Homogeneity}

In our model, we have a utility function subject to constant elasticity of substitution which means consumer preferences are homothetic. Because of this, the demand is homogeneous of degree 1 . As previously established, consumers in our model base their demand on the relative output prices $\left(p_{1}\right.$ and $\left.p_{2}\right)$ rather than on income $(M)$ or scale. What this tells us is that 
if income were to increase then consumption would translate to a linear expansion path for the existing and innovative products. We know that the net cash flows for the existing and innovative products can be written as follows:

$$
\begin{aligned}
& \Pi_{1}(x, y)=\left(p_{1}-c_{1}\right)\left(x q_{x 1}+y q_{y 1}\right) \\
& \Pi_{2}(x, y)=\left(p_{2}-c_{2}\right)\left(x q_{x 2}+y q_{y 2}\right) .
\end{aligned}
$$

As these net cash flows are homogeneous to degree 1 in $(x, y)$-space we can state

$$
\Pi_{1}(\lambda x, \lambda y)=\lambda \Pi_{1}(x, y)
$$

where this applies for all positive values of $\lambda$. What this shows is that if the inputs, $x$ and $y$, are multiplied by $\lambda$ then the output, $\Pi$ is also multiplied by $\lambda$. By setting $\lambda=\frac{1}{x+y}$, we are able to determine the demand for each consumer in the market which implies

$$
\begin{aligned}
\Pi_{1}\left(\frac{x}{x+y}, \frac{y}{x+y}\right) & =\frac{1}{x+y} \Pi_{1}(x, y) \\
\Pi_{1}(x, y) & =(x+y) \Pi_{1}\left(\frac{x}{x+y}, \frac{y}{x+y}\right) \\
\rightarrow \Pi_{1}(x, y) & =(x+y) \Pi_{1}\left(\frac{x}{x+y}, 1-\frac{x}{x+y}\right) \\
\rightarrow \Pi_{1}(x, y) & =(x+y) \Pi_{1}(\tau, 1-\tau)
\end{aligned}
$$

which we use in the successive over-relaxation calculation for the non-homogeneous term where $\tau=\frac{x}{x+y}$. The final equation shows the total consumption in the market for the existing product for both "loyal" and "fickle" consumers.

\section{A.4 First Order Conditions Satisfied}

\section{A.4.1 Before Investment}

Before any investment in the growth option the profit formula for the incumbent is

$$
\Pi_{1}=\left(x q_{x 1}+y q_{y 1}\right)\left(p_{1}-c_{1}\right)
$$


which we know from Appendix A.1 can be expanded to

$$
\begin{aligned}
\Pi_{1}= & {\left[x\left(\frac{p_{1} p_{2}^{\frac{\alpha-\rho_{x}}{1-\rho_{x}}} \delta^{\frac{1-\alpha}{\rho_{x}-1}}\left(p_{1}^{\frac{\rho_{x}}{1-\rho_{x}}}(1-\delta)^{\frac{1}{1-\rho_{x}}}+p_{2}^{\frac{\rho_{x}}{11-\rho_{x}}} \delta^{\frac{1}{1-\rho_{x}}}\right)^{1-\frac{\alpha}{\rho_{x}}}}{\alpha}\right)^{\frac{1}{\alpha-1}}+\right.} \\
& \left.y\left(\frac{p_{1} p_{2}^{\frac{\alpha-\rho_{y}}{1-\rho_{y}}} \delta^{\frac{1-\alpha}{\rho_{y}-1}}\left(p_{1}^{\frac{\rho_{y}}{1-\rho_{y}}}(1-\delta)^{\frac{1}{1-\rho_{y}}}+p_{2}^{\frac{\rho_{y}}{1-\rho_{y}}} \delta^{\frac{1}{1-\rho_{y}}}\right)^{1-\frac{\alpha}{\rho_{y}}}}{\alpha}\right)^{\frac{1}{\alpha-1}}\right]\left(p_{1}-c_{1}\right) .
\end{aligned}
$$

Because this is before investment, the price of good 2 is effectively $p_{2}=\infty$ which we substitute into the above formula. We then take a first order condition with respect to $p_{1}$ and set this equal to zero in order to solve for the optimal price of good 1 before any investment. By doing this we find the optimal $p_{1}$ to be $c_{1} / \alpha$.

\section{A.4.2 After Incumbent Invests}

Consider the profit formula for the monopolist after investing in the innovative growth option:

$$
\Pi_{1}^{\prime}+\Pi_{2}=\left(x q_{x 1}+y q_{y 1}\right)\left(p_{1}-c_{1}\right)+\left(x q_{x 2}+y q_{y 2}\right)\left(p_{2}-c_{2}\right) .
$$

By investing in the innovation the incumbent has locked the entrant out of the market and produces both the existing and innovative product. If we substitute the optimal quantity formulas, found in Appendix A.1 for $q_{1}$ and $q_{2}$, into this profit formula and take a first order condition with respect to $p_{1}$ we find that

$$
\frac{\partial \Pi_{1}^{\prime}+\Pi_{2}}{\partial p_{1}}=0 \quad \text { if } \quad p_{1}=\frac{c_{1}}{\alpha} ; p_{2}=\frac{c_{2}}{\alpha} .
$$

As a result of the complexity of the equation, after substituting in the optimal quantities, we do not display the full formula. What this tells us is that by taking the derivative of the incumbent's monopolistic profit function with respect to $p_{1}$ and solving by setting it equal to zero we find that the optimal prices are equal to

$$
p_{g}=\frac{c_{g}}{\alpha}, \quad g \in(1,2) \text {. }
$$


This occurs in both the best case and integration scenarios when the incumbent preempts the entrant and investsin the growth option.

\section{A.5 Finite difference approximation}

From Guthrie (2017) we write the finite difference approximation of the partial differential equation, should both the incumbent and entrant delay, as

$$
\mathcal{L} V_{i}\left(x_{j}, y_{j}\right)=\alpha_{j} V_{i}\left(x_{j-1}, y_{j}\right)+\beta_{j} V_{i}\left(x_{j}, y_{j}\right)+\gamma_{j} V_{i}\left(x_{j+1}, y_{j}\right)+\delta_{j} \leq 0
$$

where the coefficients are known functions of the model's parameters and grid points. If we rearrange this equation we find that

$$
V_{i}\left(x_{j}, y_{j}\right) \geq \frac{-\alpha_{j} V_{i}\left(x_{j-1}, y_{j}\right)-\gamma_{j} V_{i}\left(x_{j+1}, y_{j}\right)-\delta_{j}}{\beta_{j}}
$$

The right-hand side of this inequality can be replaced with the weighted average of this expression and the current estimate of the incumbent's value function. The right hand side of the above equation can now be written as

$$
(1-\omega) V_{i}\left(x_{j}, y_{j}\right)+\omega \cdot \frac{-\alpha_{j} V_{i}\left(x_{j-1}, y_{j}\right)-\gamma_{j} V_{i}\left(x_{j+1}, y_{j}\right)-\delta_{j}}{\beta_{j}}=V_{i}\left(x_{j}, y_{j}\right)-\omega \frac{\epsilon_{j}}{\beta_{j}}
$$

where $\omega$ is constant. The successive over-relaxation method reduces the inequalities of equation (2.12) to

$$
V_{i}(x, y)=\max \left(V_{i}(x, y)-\omega \epsilon_{j} / \beta_{j}, V_{i i}(x, y)\right)
$$

which shows the incumbent's maximising decision is to either delay or immediately exercise the growth option. 